University of Rhode Island

DigitalCommons@URI

Open Access Dissertations

2016

\title{
Technical and Management Aspects and Socio-Cultural Perceptions of Sea Turtle Bycatch in Ecuador
}

Nikita Gaibor

University of Rhode Island, nikita_gaibor@my.uri.edu

Follow this and additional works at: https://digitalcommons.uri.edu/oa_diss

\section{Recommended Citation}

Gaibor, Nikita, "Technical and Management Aspects and Socio-Cultural Perceptions of Sea Turtle Bycatch in Ecuador" (2016). Open Access Dissertations. Paper 443.

https://digitalcommons.uri.edu/oa_diss/443

This Dissertation is brought to you for free and open access by DigitalCommons@URI. It has been accepted for inclusion in Open Access Dissertations by an authorized administrator of DigitalCommons@URI. For more information, please contact digitalcommons-group@uri.edu. 
TECHNICAL AND MANAGEMENT ASPECTS AND SOCIO-CULTURAL PERCEPTIONS OF SEA TURTLE BYCATCH IN ECUADOR

\author{
BY \\ NIKITA GAIBOR
}

\begin{abstract}
A DISSERTATION SUBMITTED IN PARTIAL FULFILLMENT OF THE
REQUIREMENTS FOR THE DEGREE OF

DOCTOR OF PHILOSOPHY
\end{abstract}

IN

MARINE AFFAIRS

UNIVERSITY OF RHODE ISLAND

2016 
DOCTOR OF PHILOSOPHY DISSERTATION

OF

NIKITA GAIBOR

APPROVED:

Thesis Committee:

Major Professor Richard B. Pollnac

Carlos García- Quijano

Kathleen M. Castro

Nasser H. Zawia DEAN OF THE GRADUATE SCHOOL

UNIVERSITY OF RHODE ISLAND

2016 


\begin{abstract}
Due to the technological improvements of the last two decades, it is possible for innovations to follow each other rapidly. However, not all innovations are useful ones, and a lot of producers often do not know how to market their new products. Diffusion theory, started by Gabriel Tarde (1903), first proposed the S-shaped diffusion curve. After this research few investigations followed until 1943. In this year Bryce Ryan and Neal Gross published their study about innovation diffusion. This led to an enormous overflow of publications. Later, Rogers (2003) contributed additional research and many others followed him.

When an individual or a company comes up with a new idea, they want this idea to be adopted by all potential users as soon as possible. This spreading of an innovation is called diffusion. According to Rogers (1995) diffusion is: "The process by which an innovation is communicated through certain channels over time among the members of a social system." Therefore, an innovator should spread this message by multiple channels to inform as many people as possible who could be interested in this new idea. When this is done properly, one is able to follow the adoption process and can determine if the innovation is rejected or adopted. So, diffusion is the adoption process of the population.
\end{abstract}

Fisheries bycatch is considered the most serious global threat to marine species, particularly sea turtles. During the past 20 years, the use of different types of fishing gear, especially pelagic longlines (Carranza et al. 2006, Pradhan \& Leung 2006, Swimmer et al 2005), have reduced the population of sea turtles and other marine fauna (Peckham et al 2007, Bugoni et al 2008, Alfaro Shingueto et al 2010) 
due mainly to bycatch (Broderick et al 2006). As a result these species have become subject to intensive conservation efforts.

One of our research questions when examining circle hooks was: which factors influence an individual to try a new fishing gear device? Considerable research indicates that attitudes towards an adoption of change are influenced by a number of community and individual level variables (Rogers 2003). Adoption research methods attempt to predict behavior regarding innovations as perceived by potential adopters by assessing acceptability of innovations (Tango-Lowy \& Robertson 2002). This technology was introduced to reduce the consequences of fisheries bycatch.

In order to reduce the incidental capture of sea turtles in commercial fisheries, NOAA has been studying the efficacy of Bycatch Reduction Devices (BRD) such as circle hooks $(\mathrm{CH})$. Alongside other international agencies, NOAA has supported training and outreach efforts to spread knowledge of proper baiting and hooking techniques since the mid-90s. The circle hook NOAA advocates is less likely to be swallowed by sea turtles, reducing the risk of drowning.

As a consequence of those findings, the circle hook was introduced in Latin America to replace traditional J-shaped hooks with the purpose of reducing sea turtle bycatch. To see the effects of this BRD on sea turtles in the artisanal long line fisheries of Ecuador, a joint venture project started in 2003 amongst the following agencies: the Inter-American Tropical Tuna Commission (IATTC); the World Wild Fund (WWF); the Western Pacific Fishery Management Council (WPRFMC); NOAA; the Ocean Conservancy; the Western Pacific Regional Fishery Management Council (WPRFMC); and the Overseas Fisheries Cooperation Foundation of Japan (OFCF 
Japan). In addition to the support of these agencies, this program received support from the Ecuadorian government and local organizations, such as: the Undersecretariat of Fishery Resources (SRP); the "Programa Nacional de Observadores Pesqueros de Ecuador" (PROBECUADOR); the "Asociación de Exportadores de Pesca Blanca" (ASOEXPEBLA); the "Federación Nacional de Cooperativas de Pescadores en el Ecuador" (FENACOPEC); the "Escuela de Pesca del Pacífico Oriental" (EPESPO) of Manta; and the Escuela Superior Politécnica del Litoral (ESPOL). All gave their support and participated in different activities, especially training workshops that educated local fishermen concerning circle hooks and trained fishermen in their use. This program grew to become a region-wide bycatch network and the largest regional artisanal fisheries conservation program in Latin America.

In order to understand the factors influencing an individual to try a new fishing gear, this study augments existing literature on adoption and diffusion, providing evidence of the importance of learning from individual perceptions regarding the adoption of new technologies. The goals of this study are to determine whether the initiative to promote circle hooks and turtle exclusion devices as turtle conservation tools is well perceived by fishers, and also to learn from them if they significantly reduce or do not reduce the capture and mortality of sea turtles.

Although this study has focused on potential issues related to adoption and diffusion of two bycatch reduction devices, there is no doubt that these fishing technologies can be successfully applied as a partial solution to the problem of sea turtle bycatch. Nevertheless, it is through the recognition of potential sociocultural 
factors and taking steps toward their solution that we can facilitate successful technology transfer wherever and whenever it is needed.

The first chapter attempts to identify perceptions of fishers in the transfer technology that affect an individual's willingness to accept an innovation. Rogers' theoretical framework forms the basis for adoption research and is used to structure a wide variety of studies such as; organizational culture conflict (Reeves-Ellington 1998), resistance to increase regulations in the shrimp fishery (Johnson et al 1998), and coastal development programs (Aswani \& Weiant 2004; Pollnac \& Pomeroy 2005). Innovation attributes are the perceived properties of an innovation that influence a potential adopters' decision (Rogers 2003). Adoption research assesses perception of innovation attributes by potential adopters to better explain adoption practices or how to better design innovations for project participants. In the context of this study, relationships of the factors of attitudes toward fishing, future perspective and perceptions of recovery activities with willingness to participate, were investigated.

This approach examines individual perceptions and experience with the transfer technology of circle hooks and how fishers affect acceptance of this innovation. Rogers (2003) suggests that adoption of innovations is more likely if a need exists or it is arises among the members of a community. This approach examines individual perceptions and experience with the transfer technology of circle hooks and how fishers affect acceptance of an innovation in general. Rogers (2003) suggests that adoption of innovations is more likely if a need exists or arises. Future perspective is an individual characteristic that can be an indicator of willingness to 
adopt an innovation (Rogers 2003). The study area is six villages in the Ecuadorian coast that have knowledge of the existence of this new BRD.

Although the effort to transfer circle hook technology has occurred in Ecuador since 2004, there is no doubt that its diffusion process has been slow in most of the fishing towns in this study. Survey results indicate that circle hook adoption in Ecuador is low; only 64 out of 272 informants (23 percent) indicated that they used circle hooks on their boats. Adoption is not easy, especially when the Ecuadorian fishers have spent many years fishing with J hooks. They have time yet to learn and/ or develop adequate techniques to operate with circle hooks, so we can hope that with more time we will see improvements in their catch rates with circle hooks in the future.

Chapter two examines the unintended consequences of technology transfer; specifically, circle hooks in fisheries as a conservation initiative that was intended to curb the accidental capture of sea turtles in Ecuadorian longline fisheries. However, results from this study indicate that BRD can have unintended consequences on other species, specifically sharks. The hypothesis of this study is that the presence of an Ecuadorian shark fishery is a consequence of the most recent Government regulation on sharks coupled with a lucrative international shark fin market may create incentives to misuse this technology and target sharks.

The goal of this analysis is to determine to what extent the promotion of circle hooks as a turtle conservation tool has led to the unintended consequence of circle hooks, which are highly effective in capturing large species such as tuna and swordfish, being used to exploit a regulation that allows fishers to keep any shark 
caught as bycatch. Ironically, the very device being promoted to conserve the sea turtles is being exploited to catch shark, a regulated species. This study concludes that fishers purposefully use circle hooks rather than j-hooks as a "work around" to catch regulated shark species as bycatch and within the regulations, keep them.

The lucrative trade in shark fins and the incidental established shark fishery in Ecuador provide an incentive to use the circle hook to target sharks. There is no easy solution to this problem. Ecuador, and those at the Inter American Tropical Tuna Commission (IATTC) and World Wildlife Fund (WWF), are in the unenviable position of trying to decide with uncertain science whether to promote a hook that may save sea turtles but put sharks at risk.

Finally, chapter three evaluates fishermen's perceptions regarding the use of the Turtle Excluder Devices (TED), and if this BRD ensures conservation of sea turtles to assure better fisheries management. Actions and decisions regarding any new regulation must be taken with regards to not only scientific information, but also the welfare of all stakeholders involved in one specific fishery. Decisions should not favor one fishery sector or group. Decisions should attempt to favor all the stakeholders as well as the marine resources.

Bycatch reduction is a result of the use of more selective fishing gears such as trawl nets equipped with TEDs. Although this device was, in some way, imposed by the US to enforce its use by the Ecuadorian shrimp vessels and to avoid any ban on shrimp exportation, results of this study indicate that $82 \%$ of shrimp vessels use this device, $74 \%$ of interviewees obey the use of TEDs because they consider (84\%) that it 
protects sea turtles when they are trapped by the shrimp trawlers, and $72 \%$ responded that bycatch has decreased in the past 24 years.

This study concluded that the use of TEDs in Ecuador, although it was imposed in a top-down management manner driven by the interests of government agencies in export markets, its use over the years may have helped sea turtles survive and may have reduced the bycatch of sea turtles. 


\section{ACKNOWLEDGMENTS}

Here at the end of this long endeavor, I am profoundly grateful for all of the individuals and institutions that guided, assisted, and supported me throughout my very rewarding Ph.D. journey. I apologize for any errors or omissions in my acknowledgments, which are entirely my own.

My work on bycatch reduction devices and their interaction with sea turtles and sharks in Ecuador began when Professors Dr. Patrick Christie and Dr. Leyla Jenkins from the University of Washington invited my major Professor, Dr. Richard Pollnac, to participate in their project studying bycatch reduction devices in 2011. Their project examined a conservation initiative in Ecuador and Costa Rica intending to curb the accidental capture of endangered sea turtles in surface longline fisheries. The initiative focused on exchanging the commonly used j-hooks for circle hooks.

Dr. Pollnac, also known as Dr. P., expressed his interest in working on this project to Drs. Christie and Jenkins. As Dr. P.'s student, I became involved in this work, which was fascinating to me, and it provided an opportunity to do my own research in my home country, Ecuador. Dr. P. taught me a great deal about research methods and statistics and was instrumental in the development of the methodology and survey instruments used by our study. Together, we learned more about bycatch reduction devices, sea turtles and sharks, and in the end, he helped me to craft three interdisciplinary studies. He has been an extraordinary mentor, and I cannot thank him enough for his incredible generosity with both his knowledge and time, and for his steadfast support and cheerfulness. It has truly been an honor to study under the grand professor and mentor, Dr. Pollnac. 
I would also like to thank the research and surveying team headed by Mr. Michael Vina, Mr. Mike Mizrahi, Ms. Nancy Benitez-Vina, Ms. Monica Fabara, Ms. Lorena Monserrate, Ms. Cristina Jines, and Mr. Omar Alvarado for their contributions and support in carrying out the surveys in Ecuador.

My committee members, Dr. Kathy Castro and Dr. Carlos Garcia-Quijano, who have shared their insights and expertise throughout their advices. I thank them not only for their ideas and comments, but also for the opportunity to speak with them in my native language, which made understanding many things so much easier. The same applies to Dr. Brian Crawford who was also an invaluable part of my defense committee.

In 2012, because of an unfortunate bureaucratic snafu in my home country, Ecuador, I found myself in the unfortunate position of being left without enough funding to register for courses during the last three years of my tenure at URI. Not being able to register required that I leave the United States of America immediately, as my visa was no longer valid.

The prospect of having to return to Ecuador without my Ph.D. was not only unpleasant; it would be inevitable if I could not find a grant, a scholarship, or some kind of on-campus employment. The sadness and the disappointment of having to give up just shy of getting my doctorate, for reasons completely outside of my control, was my reality.

With perseverance, I knocked on many doors at the University of Rhode Island and other institutions, and found an abundance of human generosity and good will. To those who "answered the door," I am very thankful: to the World Wildlife Foundation 
(WWF), especially to Mrs. Andrea Santy, Director of Russell E. Train Education for Nature Program/WWF for a grant that paid for two semesters. Also to the CAPACITAR Foundation in Ecuador, and especially to its Director Mr. Xavier Garcia for a two-year grant that allowed me to pay for meals and a place to live.

Similarly, I am also very grateful for the people in the Marine Affairs Department, and the Modern and Classical Languages and Literatures Department. My sincere gratitude goes to Ms. Debbie Messner, the administrative languages assistant, and to Dr. Zoila Castro, the coordinator of the Beginning and Intermediate Spanish Program, for the opportunity to teach my native language to URI undergraduate students, which allowed me additional resources to finance my program. Also, I thank Ms. Kristin Haberek for her assistance in processing the paperwork for my position as adjunct professor. I learned a lot about being docent from the language faculty. Also, I learned a lot about American culture and myself from my fellow students.

I also thank the following people from URI who helped me to overcome my financial difficulties: Dr. Tom Duncan, Vice President of Student Affairs; Ms. Naomi R. Thompson, Associate Vice President for the Office of Community, Equity and Diversity; Dr. Dania Brandford-Calvo from the International Office of Scholars at URI, and to Dean Nazer Zawia from the Graduate School office at URI.

I thank Dr. Don Robadue and Dr. Jim Tobey from the URI-Coastal Resources Center for their ideas and comments to my manuscripts.

Furthermore, many thanks go to the people from the National Fisheries Institute of Ecuador (INP). First of all, my thanks go to Ms. Yahira Piedrahita, 
former Director of the National Fisheries Institute, for not only giving me the incredible opportunity to work in Ecuador, but especially for providing logistical support to my research team and I along the way. Thanks to Mr. Edwin Moncayo, current Director of the INP, for allowing me to continue my studies, by extending my permission to stay at URI. I appreciate the support of INP researchers who shared their knowledge and their data on fisheries in Ecuador: David Chicaiza, Walter Mendívez, Pilar Solis and Marco Herrera. Muchas gracias a todos!

I am tremendously thankful to the many wonderful friends I have found here in the United States of America. They, one way or another, gave me the moral support that I needed to complete my Ph.D. Because of these extraordinary men and women, I have not felt alone or abandoned in the United States, a country which I have found a people of great generosity and spirit.

Ms. Marianne Barker, my landlady, allowed me to live in her beautiful house near campus for next-to-nothing during the last two years of my stay. Living in this cozy place allowed me to be near my classes, my office, the library, the gym, and everywhere else on URI's Main Campus, which made things much easier when things were difficult.

Many thanks also go to Ms. Pam Rubinoff, who welcomed me into her home when I came to this country to start my Ph.D. Pam's support was very important during the first year of my studies, and also at the end.

Dr. Barbara Heavers and her late husband, Richard Heavers, gave me the opportunity to hone my skills as a painter on their farm, painting houses, and learning of "life on the farm." 
I cannot forget Mr. John Samuel Peterson, “Sam,” a social communicator, photographer, publicist and inventor, but especially, a great human being and my best friend here in Rhode Island. He always gave me his hand and always gave me his words of support without any reward. I enjoyed sharing breakfast, lunch and dinner with him to exchange opinions and comments about our lives and about the world. Also thanks to Mr. James Garrick and Mr. Dillan Weinert from the URIWriting Center for their invaluable help with some of my manuscripts. They have taught me how to be a better communicator in English, something I continue to work on.

I'm also very grateful with the people from St Augustine's Episcopal Church at URI, especially to Rev. David Dobbins, the Venerable Janice Grinnell, and Dr. Dwight Giles for their amazing spiritual guidance and support.

Thanks to my following peers and friends: Miss Elizabeth McLean, Ms. Kristine Beran, Mr. Chris Rotinsolou, Mr. Mat Rosa, Mr. Abdul Halik, Ms. Sue Rubinoff, Mr. Preston Steele, Mr. Wilson Villamar, Mr. Jorge Rivera, and Mr. Alex Rodríguez, for their encouraging words and for pushing me ahead with my studies despite financial difficulties. To all of you, "Thanks so much."

Finally, I thank all the members in my family for their tremendous support, especially my sister Tania, my sister-in law Gina D'Castagneto, and my cousin Jorge Guerrero, for giving their financial support when I needed it. I cannot forget my spiritual parents, Nelly and Walter Gonzalez De la Rosa for their emotional support and love. Deepest thanks to my son Christian and my father Bolivar Gaibor, who gave me their emotional support during these years. My dad always taught me to 
strive for my goals in life; his inspiration is one reason why I did not give up my studies despite the problems I encountered on this Journey. To each of you, I love you with all of my heart!

"Life has so many challenges and obstacles that we must overcome. We cannot stop difficulties; the only thing left is to fight and overcome all these obstacles so that we feel fulfilled. The light is always at the end of the road for those who persist and have faith!"

—Nikita Gaibor 


\section{PREFACE}

This dissertation has been written in manuscript form with a general

Introduction and Conclusion providing an overview and discussing the significance of the complete body of work. Each chapter is written as a separate manuscript and will be (or has been) published separately in different scientific journals; as such, they are formatted as required for submission to each journal.

Manuscript 1 is formatted for Bulletin of Marine Science

Manuscript 2 is formatted for Ocean and Coastal Management

Manuscript 3 is formatted for Marine Policy 


\section{TABLE OF CONTENTS}

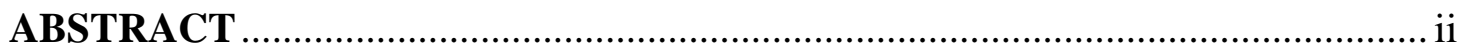

ACKNOWLEDGMENTS .............................................................................. ix

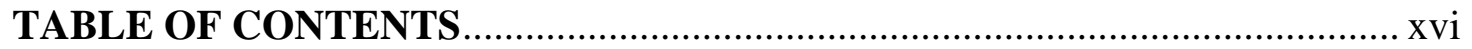

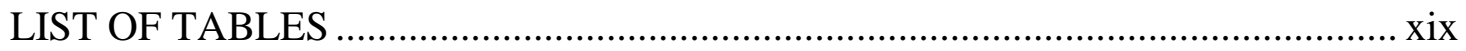

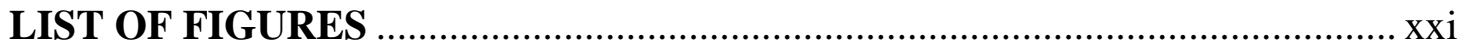

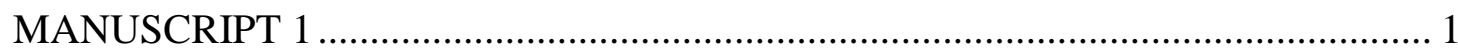

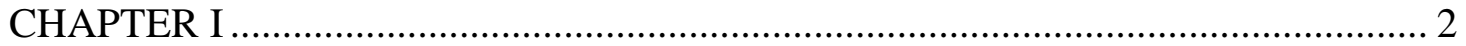

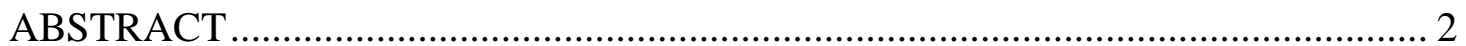

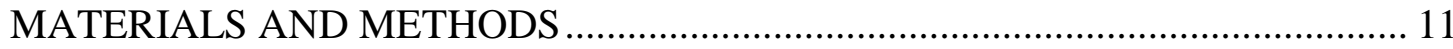

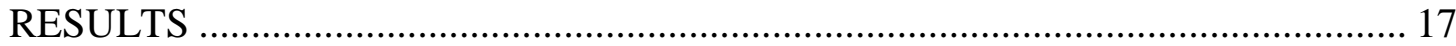

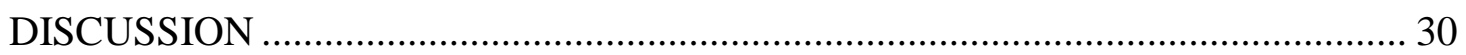

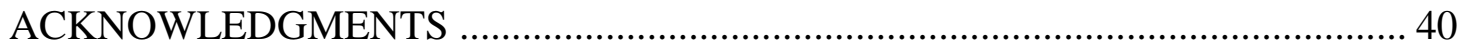

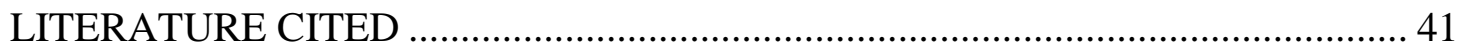

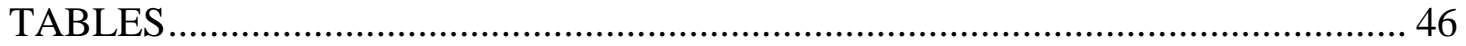

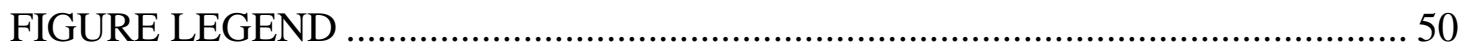

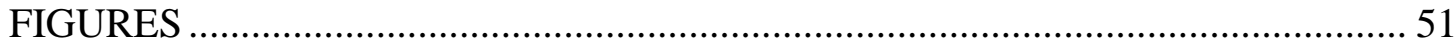

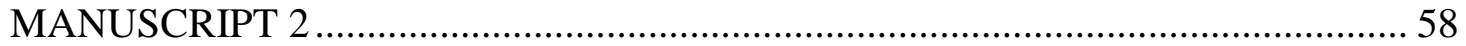

Conservation Initiatives and Unintended Consequences in Technology Transfer:

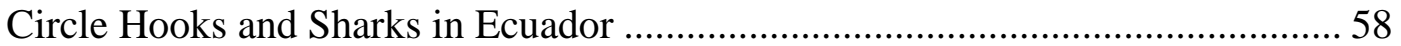

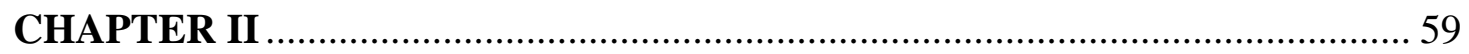

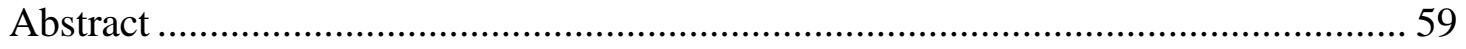

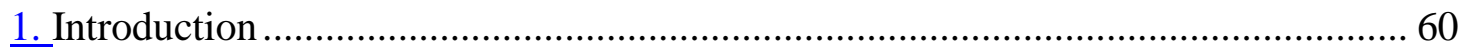




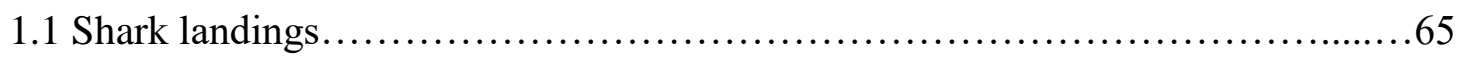

1.2 Shark regulations and fin market..........................................68

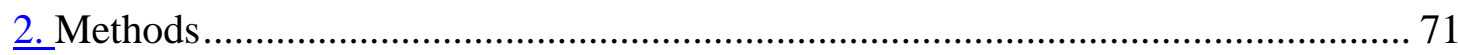

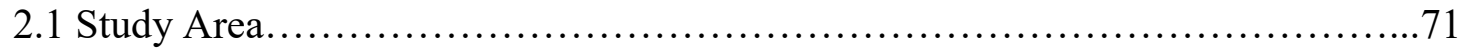

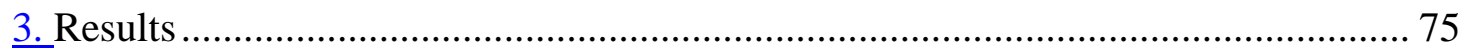

3.1 Characteristics of users of circle hooks..................................... 75

3.2 Characteristics of circle hooks regarding sharks..............................76

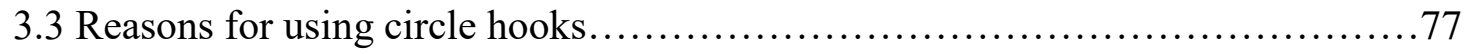

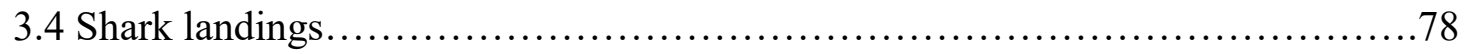

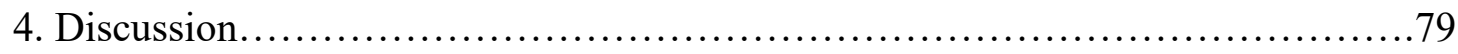

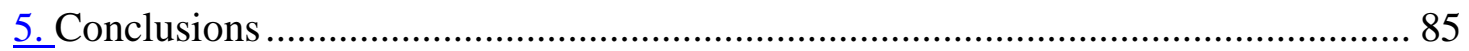

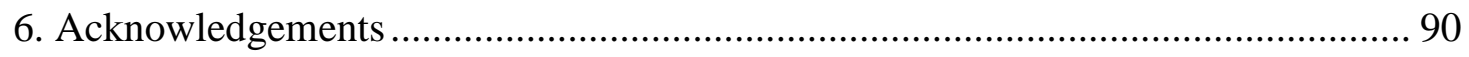

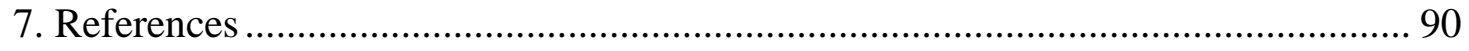

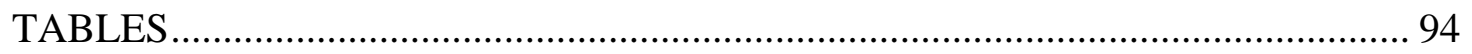

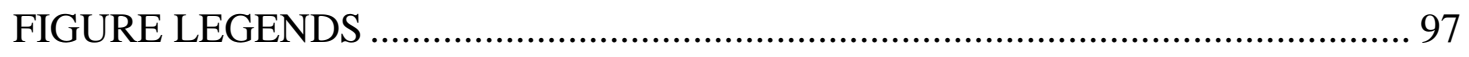

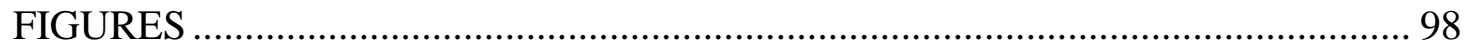

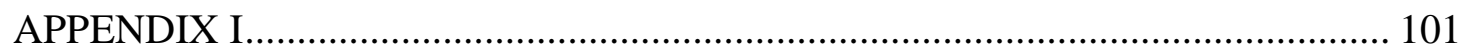

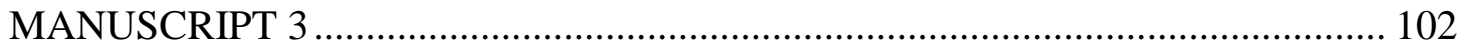

A Case Study of the Effects of Turtle Excluder Devices on Conservation and the

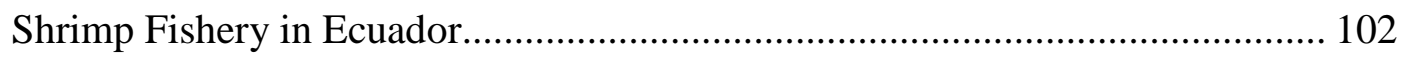

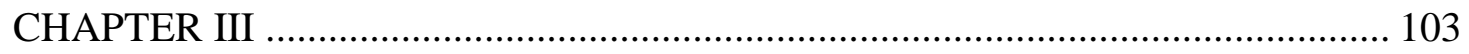

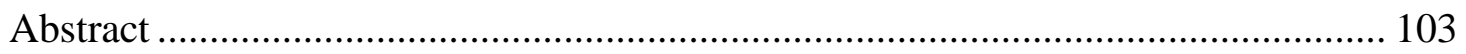

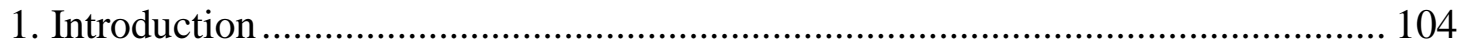


1.1. Features of the Shrimp Fisheries......................................... 109

1.1.1 The Shrimp "Pomada" Fishery.......................................... 109

1.1.2. The Shrimp "Langostino" Trawl Fishery..................................110

1.2. Regulations......................................................111

2. Materials \& Methods.................................................113

3. Results......................................................... 114

3.1. Socioeconomic Characteristics........................................ 114

3.2. Dependent Variable.................................................. 115

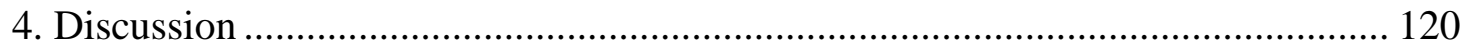

5. Conclusions....................................................... 123

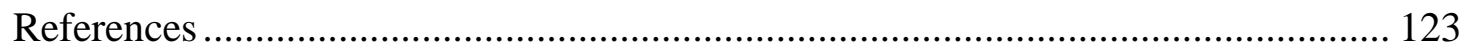

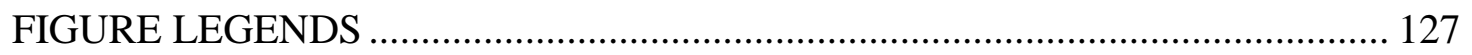

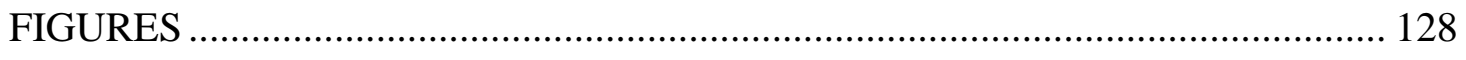

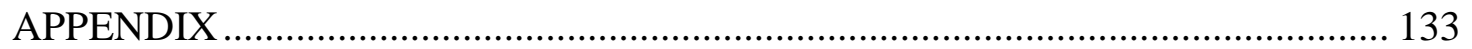

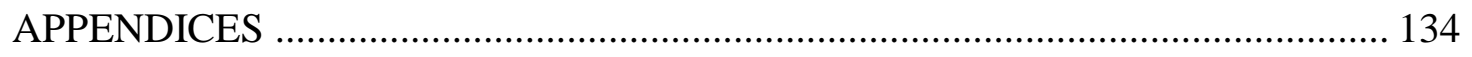

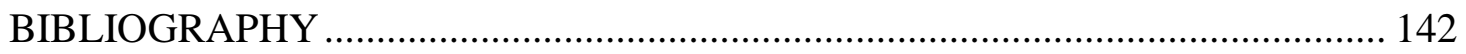




\section{LIST OF TABLES}

TABLE

PAGE

Tabla 1.1.Percentage of fishers who use circle hooks (Santa Marianita vs. "Other

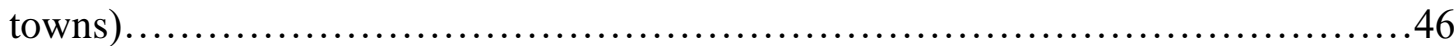

Table 1.2 Principal component analysis of technology transfer techniques............. 47

Table 1.3 Principal component analysis of impacts of technology transfer $\ldots . . . . . . . . .48$

Table 1.4 Correlations between technology transfer components and selected. ........ 49

Table 2.1 Percent distribution of fishers' response regarding user of circle hooks for

sharks.

Table 2.2. Pooled variance among variables (e.g. age, years fishing, boat length, line length, and number of hooks) and capture of sharks.

Table 2.3. Annual disembark ( $\mathrm{t}$ ) of sharks per fishing port, per fishing target specie, per type of boat and fishing gear during 2011 


\section{PREFACE}

This dissertation is written in manuscript format with three main chapters corresponding to the format of journal articles.

The following research questions are addressed in my dissertation:

\section{Chapter I:}

1. How does the circle hook's use spread among fishers?

2. Do fishers perceive circle hooks to be an effective Bycatch Reduction Device (BRD) to protect sea turtles?

3. Does the decrease of fish bycatch and cost of hooks affect the use of circle hooks? Chapter II:

4. Will the fishers have a range of attitudes about specific aspects of the promotion and adoption processes?

5. What are the unintended consequences of using circle hooks?

6. What other factors may affect the unintended consequences for using circle hooks?

\section{Chapter III:}

7. Is compliance with regulations requiring TEDs a significant factor in accounting for bycatch reduction? 


\section{LIST OF FIGURES}

Chapter I

Page

Figure 1:1-I X-ray of a sea turtle that has swallowed a bait with a "J" hook. When this happens it is likely the sea turtle is either gut-hooked, damaged internally, or dies....40

Figure 2: 2-I Schematic of two circle hook designs (A, B) and a conventional "J" hook $(\mathrm{C})$. 52

Figure 3: 3-I Map of the Study Area and the Workshops Places and Agencies for

Circle Hooks 53

Figure 4: 4-I Fishing Site Areas in the coast of Ecuador. 54

Figure 5: 5-I Interviewees' age Figure 6. 6-I Interviewees’ Education Level 55

Figure 7: 7-I Principal Component scores for the Technology Transfer Method Component and the Usage of Circle Hooks Impact Component.. 56

Figure 8: 8-I Level of Diffusion \& Adoption of Innovation of Circle Hook .57

\section{Chapter II}

Figure 9: 1-II Shark fishing's areas by the target fishing resource of the artisanal fishing fleet. Figure 1a shows the distribution area of the fishery fleet that capture tuna-weevil, and swordfish species, while figure $1 \mathrm{~b}$ shows the distribution area of the fishery fleet that capture dolphinfish..................................... 98

Figure 10: 2-II. Total annual landings (t) of pelagic fishes and shark species.........99 Figure 11. 3-II. Fishing Site Areas where this study was conducted: Esmeraldas is economically important for the northern part of Ecuador;Manta is the main fishing port along the coastal Ecuador; San Mateo is a fishing village located on a cliff overlooking the sea 7.5 miles from Manta; Santa Marianita, a small artisanal fishing village about $20 \mathrm{~km}$ south of Manta, and; Santa Rosa, located in the Peninsula Santa Elena (Province of Santa Elena) is one of the most important artisanal fishing ports of Ecuador............................................................ 100 


\section{Chapter III}

Figure

Figure 12: 1-III. Turtle Excluder Devices (TEDs) are Shrimp Trawler net

modifications, consisting of grates that are sewn into nets adjacent to open flaps

that function as escape hatches.................................... 128

Figure 13: 2-III. Fishing areas (Gulf of Guayaquil) of the Pomada Shrimp Fleet that captures the specie Protrachypene. Precipua, which is best known as shrimp

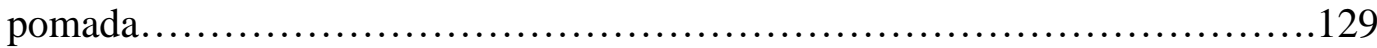

Figure 14: 3-III. Site Areas (Posorja and Esmeraldas) where this research was conducted. Both sites are the fishing area activities for the shrimp trawler fleet, while the Gulf of Guayaquil is the main fishing area for the pomada fleet......130 Figure 15: 4-III. Distribution of Interviewed Fishers' Ages by Fishing Town...131 Figure 16: 5-III. Distribution of Interviewed Fishers' Education Levels by Fishing

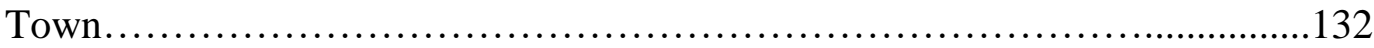




\section{MANUSCRIPT 1}

\section{Fisher's Perceptions Concerning the Adoption and Promotion of Circle Hooks as a Bycatch Reduction Device to Protect Sea Turtles}

Nikita Gaibor ${ }^{1}$, Richard Pollnac ${ }^{2}$, Michael Vina ${ }^{3} \&$ Kathleen Castro ${ }^{4}$

To be submitted to the Journal of Bulletin of Marine Science 2016

${ }^{1} \mathrm{PhD}$ Candidate. Department of Marine Affairs, University of Rhode Island, Kingston, RI, 02881, USA, Email: nikita_gaibor@my.uri.edu

${ }^{2}$ Professor. Department of Marine Affairs, University of Rhode Island, 1 Greenhouse Rd., Kingston, RI 02881, US.A, Email: pollnacrb@uri.edu

${ }^{3} \mathrm{Ph} . D$. Candidate. Department of Social Anthropology, University of Bergen, Fosswinckelsgate 6, N-5020 Bergen, Norway. Email: Michael.Vina @uib.no

${ }^{4}$ Professor. Department of Fisheries, Animal and Veterinary Science, University of Rhode Island, 9 East Alumni Avenue, Kingston, RI 02881, US.A, Email:

kcastro@uri.edu 


\title{
CHAPTER I
}

\begin{abstract}
The goal of this study is to determine whether promotion of circle hooks as a turtle conservation tool has been adopted by Ecuadorian fishers. Survey results indicate that circle hook adoption in Ecuador is low; only 64 out of 272 informants (23\%) indicate that they used circle hooks on their boats. Adoption is not easy, especially when Ecuadorian fishers have spent many years fishing with J hooks. However, according to the quantitative data, $59 \%$ of Santa Marianita fishers believe that their first experience with circle hook was positive or very positive together. Thirty percent of fishers believe that circle hook will not affect bycatch, while $14 \%$ believe it would increase the bycatch. Indeed, when the key informants were asked about the impact of circle hooks on bycatch, six of the nine indicated that circle hooks were good for catching sharks. Although, the effort to transfer circle hook technology has occurred in Ecuador since 2004, there is no doubt that its diffusion process has been slow in most of the fishing towns of this study. There is no doubt that this fishing technology can be successfully applied as a partial solution to the problem of bycatch of sea turtles. It is through the recognition of potential sociocultural factors and taking steps toward their solution that we can facilitate the successful of the technology transfer wherever and whenever it is needed.
\end{abstract}


Most social scientists agree that an effective program of technology transfer consists of several essential and interrelated ingredients (Lionberger et al. 1991, Rogers 2003, Stöckelová 2012, IETC 2003), and an understanding of the social organization of communities can aid in developing realistic programs which will enhance the probability of sustainable development (Pollnac 1978a,b; Rhoades 1975).

Among these issues, the development of a technology compatible with the target environment and economy is the first element. Second, the idea of the new technology must be communicated to the target population. Third, the target population must perceive or recognize that the new technology will fulfill a need and will be, or can be, made consonant with existing beliefs, values, attitudes, and status and role relationships. These preliminary stages are either followed by a trial period or outright rejection. After a trial, the innovation may be rejected, revised, or adopted. The adoption stage, therefore, is reached when substantial numbers of the target population begin to use the innovation. For example, in Costa Rica, the conservation technology known as Turtle Excluder Device (TED) was modified to the point where a new device - the Tico TED — emerged. This new TED proves without doubt that sea turtles are not jeopardized by the modifications done by Costa Rican fishers.

Following adoption, incompatibilities may become more salient, and the new technology may be rejected, revised or adopted. If not, it finally reaches the institutionalization stage where its "innovation" status is removed and it becomes part of the sociocultural system (cf. Rogers \& Aganwada-Rogers 1976).

Even where the new technology is compatible with the sociocultural and physical environment, there will be individual differences in adoption due to variances 
in individual socioeconomic and personality attributes. Rogers \& Shoemaker (1971) have identified over 30 of these variables which have appeared in empirical studies in the literature. Included are variables like education, social status, attitudes toward credit, level of aspirations, changes and contact, mass media exposure, etc. These variables are further related to characteristics of the local society such as the social stratification system; educational opportunity structure, degree of sociocultural stability, extent of communication and transportation networks, and degree of market versus subsistence orientation (cf. Pollnac 1976). These variables must be considered as important sociocultural variables intervening between and otherwise appropriate fishing technology and its adoption.

Rogers' theoretical framework forms the basis for adoption research and is used to structure a wide variety of studies such as: organizational culture conflict (Reeves-Ellington 1998), resistance to increase regulations in the shrimp fishery (Johnson et al 1998), and coastal development programs (Aswani \& Weiant 2004; Pollnac \& Pomeroy 2005). Innovation attributes are the perceived properties of an innovation that influence a potential adopters' decision (Rogers 2003). Adoption research assess perception of innovation attributes by potential adopters to better explain adoption practices or better design innovations for project participants.

Adoption and diffusion of technology are two concepts that are connected to one another. The decision to use or not use of a given technology will depend on many factors (i.e. economic units, regions and attributes of the technology itself) over a period of time. Therefore, adequate understanding of the process of technology adoption and its diffusion is necessary for designing effective agricultural research and 
extension programs (Rogers 2003). Rogers (2003) suggests that adoption of innovations is more likely if a need exists or if it arises among the members of a community. Future perspective is an individual characteristic that can be an indicator of willingness to adopt an innovation (Rogers 2003).

In fisheries information regarding the importance of bycatch reduction devices (BRD), their extent of adoption, impact on profit and risk — which are key factors in influencing fishers' adoption decisions over time — are not available in Ecuador or elsewhere in Latin America. Fisheries bycatch is one of the most serious worldwide threats to marine species such as sea turtles, sea birds, and marine mammals. The United Nations Food and Agriculture Organization (FAO) estimates that every year the world's fisheries discard 7.3 million tons of bycatch (Kelleher 2005). During the past 20 years, the use of different types of fishing gear, especially pelagic longlines (Carranza et al. 2006, Pradhan \& Leung 2006, Swimmer et al 2005) have reduced the population of sea turtles and other marine fauna (Peckham et al 2007, Bugoni et al 2008, Alfaro Shingueto et al 2010) due, mainly, to bycatch (Broderick et al 2006). Pelagic longline is a fishing method that is used worldwide and ranges from small-scale artisanal fisheries to modern mechanized, industrialized fleets. Pelagic fishing vessels employ miles of lines (up to 100-km long) and baited hooks (up to 3500), which are set near the surface with buoys (Brothers et al. 1999). This fishing method catches the majority of the world's swordfish (Xiphiaus gladius), marlin (Makaira spp.), and other billfishes (Istiorphoridae spp.). Pelagic longline also catches large tuna species (Thunnus spp.), mahi mahi or dolphinfish species (Coryphaena hypurus), as well as shark species (Lewison et al. 2004). Among Southeast Pacific 
nations, Ecuador has the largest artisanal fishing fleet (CPPS 2003), which is composed of 59,616 fishers and about 16,000 boats (MAGAP 2014). These figures represent around 6 percent of the active economic population inhabiting the Ecuadorian coast.

In Ecuador, the preferred target species for the artisanal longline fishery are the large pelagic fishes, such as bigeye tuna (Tunnus obesus), swordfish (Xiphias gladius), and dolphinfish or mahi mahi (Coryphaena hyppurus), wahoo (Acanthocybium solandri), and 14 species of sharks, such as blue, thresher, and hammerhead (Largacha et al. 2005). Dolphinfish is mainly captured from November to April each year; while tuna and billfish species are caught from May to October (Largacha et al. 2005, Mug et al. 2008). When the target species' abundances are low, the fishers catch a mixture of species, which are much less valuable than the main targets.

Two types of hooks - the Japanese tuna hooks and "J" hooks- have been traditionally used for years in pelagic longline fisheries in Ecuador and around the world, though they both are especially common among tuna longliners. When fishing with bait, dead or alive, traditional methods entail using either the Japanese hook or the "J" hook. This allows both the target fish and other marine species, such as sea turtles, to swallow the bait with a "J" hook (Figure 1). When this happens it is likely for, the fish or sea turtle, to be gut-hooked or damaged internally as the angler applies pressure with the rod or reel (OFCF 1993).

As the number of hooks deployed every year in the Ecuadorian ocean is very large, and the long migrations of many turtle species bring them into fishing grounds, interactions are unavoidable. Interactions occur not only when sea turtles get hooked 
while trying to take the bait on lines, but also when the turtle becomes entangled in the fishing lines. Therefore, even when hooks are intended to fish at depth, sea turtles pass through the near surface waters - less than 40 meters-(Polovina et al. 2003, 2004) and are accidentally entangled or hooked through a flipper or other part of their body.

When sea turtles become hooked, there are several possible outcomes: 1) The turtle is found dead when the line is retrieved (quite rare in shallow sets). 2) The turtle is found alive, the line is cut, and the turtle escapes with the hook still attached. 3) The turtle is found alive, the hook is removed, and the turtle is released. 4) The turtle is found alive, but the removal of the hook results in the turtle's injury or mortality. This last scenario is especially ubiquitous when the hook is lodged deep inside the animal. Hence, a fraction of released turtles will experience post-hooking mortality at a rate that depends on the location of the hook, the injury, and the turtle's characteristics and condition. When the hook is left in the turtle, mortality rates are higher. Rates are also higher for individuals deeply hooked, and for those hooked in the upper jaw rather than in the lower jaw (Largacha et al 2005).

As a result of this interaction, sea turtles have become subject to intensive conservation efforts. In order to reduce the incidental capture of sea turtles in commercial fisheries, NOAA's National Marine Fisheries Service (NOAA Fisheries) has enacted regulations to reduce bycatch from certain U.S. commercial fishing gear (gillnets, longlines, pound nets, and trawls) that have caused, significant bycatch of sea turtles. NOAA has also been studying the efficacy of Bycatch Reduction Devices (BRD) such as the Circle Hook (CH) (Figure 2) and has supported training and outreach efforts in proper baiting and hooking techniques since the mid-90s. 
According to the NOAA Fisheries, a circle hook is defined as a hook with the "point turned perpendicularly back to the shank to form a generally circular or oval shape." Research conducted by NOAA Fisheries with captive sea turtles has shown that the wider the hook, the less likely it is that loggerhead sea turtles will attempt to swallow them (Watson et al. 2003). If the hook is not swallowed, then it should either not hook or hook only in the mouth, which is more benign than deep hooking" (Largacha 2005). According to Jenkins (2010), the circle hook is not only an innovation, but is a revolutionary device because it not only reduces bycatch, but also increases the survival rate and health of sea turtle. It also benefits fishers who depend on fishing resources for profit.

Although circle hooks have recently begun to be used in some of the inshore fisheries, these fishing devices are being used in the longline fishery industry since the 1970s (Taylor 2002). The use of circle hooks is currently being touted as a more conservative gear because they are believed to be less injurious for some species and more effective in hooking and catching the targeted quarry. Conservation groups believe that replacing "J" hooks with "circle" hooks significantly reduces the mortality of some endangered species such as sea turtles (Largarcha et al. 2005), but it has also been suggested that they improve the survival of incidental catch and bycatch (Falterman and Graves 2002).

A literature search documented a limited number of research reports that addressed the comparative effects of "circle" and "J" hooks. More than half of the studies found significant positive advantages to using circle hooks (Falterman and Graves 2002, Prince et al. 2002, Skomal et al. 2002, Lukacovic and Uphoff 2002) 
while the rest found no significant differences between the two hook types (Orsi et al. 1993, Halliday 2002, Malchoff et al. 2002). Four of these studies dealt with flat fishes, summer flounder, and halibut. The remaining studies looked only at using circle hooks of different sizes (Zimmerman and Bochenek. 2002). If we consider the effects and advantages of using circle hooks in the fisheries that target fishes of the Order Perciformes, (the typical torpedo shaped, dorso-ventrally oriented fishes) then all of the pertinent studies found positive significant improvements when using circle hooks.

Studies that compared the effects of the two hook types in the commercial longline and recreational fisheries for tunas found higher rates of "hook and hold," higher frequency of hooking locations in the jaw, less physical damage and consequential lower release mortality, and an overall significant increase in Catch Per Unit Effort (CPUE) (Taylor 2002). Similar studies conducted in the billfish fisheries reported that circle hooks achieved advantages over "J" hooks, such as: there were about twice as many hook ups, $85 \%$ of the hook ups occurred in the jaw, fish caught on "J" hooks were 21 times more likely to bleed, and that circle hooks minimized deep hooking, foul hooking and injury (Taylor 2002).

As a consequence of those findings, the circle hook was introduced in Latin America to replace traditional J-shaped hooks with the purpose of reducing sea turtle bycatch. To see the effects of this BRD on sea turtles in the artisanal longline fisheries of Ecuador, a joint venture project among government and inter-governmental bodies, fishers' unions and cooperatives, and industrial and environmental groups started in 2004 (Figure 3). All these organizations gave their support and participated in 
different activities, especially workshops that educated local fishers about circle hooks and trained fishers in their use.

This program implemented a volunteer exchange hook program, in which more than 15,000 circle hooks were exchanged for 'J' Hooks in 115 vessels (Largacha et al 2005). In addition, an observer program was conducted to monitor the effectiveness of the circle hooks in reducing sea turtle hooking rates as well as the catch rates of the target species.

Although this study has shown preliminary results, such as circle hooks cut hooking rates of sea turtles between $44 \%$ and $89 \%$, depending the size of the hook used (Largacha et al. 2005); there are no studies in Ecuador regarding fishermen perception concerning the technology transfer of any bycatch reduction device, such as circle hook. Therefore, this study is the first one to contribute to social science and attempts to fill some of these gaps by providing evidence of the importance of learning from fisher's perceptions as it relates to the dynamic adoption of improved technologies.

This study will use Roger's theoretical framework to identify perceptions of fishers in the transfer of technology that affect an individual's willingness to accept an innovation. The goals of this study are to examine fisher's perceptions and experience regarding the adoption, diffusion and technology transfer of circle hooks as a turtle conservation tool. Additionally, this study hypothesizes that the Santa Marianita fishing village in particular is where the WWF, IATTC and SRP have had the most success using circle hooks due to the substantial efforts those agencies have made promoting this BRD in this small fishing village. 


\section{MATERIALS AND METHODS}

The fishing grounds of the Ecuadorian artisanal fishery targeting large pelagic species (Tuna, Swordfish, Marlin \& Dolphinfish) are located between $05^{\circ} 00^{\prime} \mathrm{N}$ and $15^{\circ} 00^{\prime} \mathrm{S}$, and as far west as the meridian of $100^{\circ} 00^{\prime} \mathrm{W}$ off the Galapagos Islands. According to the Undersecretary of Fishing Resources (Subsecretaria de Recursos Pesqueros), there is a total of 266 artisanal fishing communities located along the coastline of mainland Ecuador (SRP 2014). The landing sites used by these artisanal fishing communities vary from highly developed ports such as Manta to protected coastal embayments or coves (called "caletas"), and even fishing settlements which can change in location on a yearly or seasonal basis (Herrera et al. 2013).

Among all these landing sites, six fishing communities along the Ecuadorian coast were identified for this study because they have knowledge of, have to some extent used, or have received a workshop on circle hooks from local and international agencies. Listed from northernmost to southernmost with their respective provinces

are: Esmeraldas (Esmeraldas), Manta, San Mateo and Santa Marianita (Manabí), Santa Rosa (Santa Elena), and Puerto Bolivar (El Oro) (Figure 4).

Santa Marianita, a small artisanal fishing village about $20 \mathrm{~km}$ south of Manta, has 99 fishing boats and 551 fishers within an estimated population of 3,600 (Herrera et al. 2013). The area is a dry tropical forest with little rainfall, and its beach is a sandy 300 meters wide and $4 \mathrm{~km}$ long. Manta and Esmeraldas are two fishing communities that have industrial fisheries. Catch statistics per port indicate that 
Manta, in Manabí Province, with 4,994 fishers and 356 fishing boats (Herrera et al 2013), is the most important fishing port for tuna landings and exports of fishery products such as canned tuna (Cámara Nacional de Pesquerías 2003).

The fishing port of Esmeraldas is economically important for the northern part of Ecuador, where there are landings of diverse fish and shrimp species and 3,000 fishers and 1,042 boats (Herrera et al 2013). San Mateo is a fishing village located on a cliff overlooking the sea 7.5 miles from Manta. With 0.75 mile of beach, with 697 fishers and 628 fishing boats (Herrera et al. 2013), San Mateo is also known among surfers for the longest waves in Ecuador. A new harbor was constructed in 2011 to serve as a fishing port. About one third of the beach is covered with fishing boats leaving the remainder of the beach for sunbathing, swimming, boarding and surfing for beginners. Santa Rosa, located in the Peninsula Santa Elena (Province of Santa Elena) is one of the most important artisanal fishing ports of Ecuador. It has 3,500 fishers and 1,410 fiber glass boats (Herrera et al 2013). Finally, Puerto Bolívar, located some $7 \mathrm{~km}$ from Machala, the provincial capital, is surrounded by islands and mangroves and is an international sea port exporting over 2 million metric tons of bananas every year. It is home to 1,825 fishers and 1545 fishing boats (Herrera et al. 2013).

The fishing fleet in Santa Rosa and Puerto Bolívar is composed of artisanal fiberglass boats (approximately 25 feet in length), large wooden-hulled ships (approximately 45 feet in length), and large steel-hulled factory ships (Castro 2011). The large wooden-hulled boats are most commonly known in Ecuador as mother ships. Mother ships tow up to 7 fiberglass boats into open water, providing storage, 
supplies, and support to the smaller boats. This allows for a longer fishing trip. Trips with the mother ship generally last from 15 to 30 days (Key informant, Ecuadorian government employee with working knowledge of fisheries, January 2011). In general, artisanal fiberglass boats powered by outboard motors constitute the majority of operational boats at all other sites.

In each study area, the artisanal fishers were introduced to circle hooks through the promotional efforts of WWF, IATTC, and the Subsecretaria de Recursos Pesqueros (SRP). Promotional efforts were directed towards these towns due to the pervasive use of surface longlines. However, Santa Marianita was the area where the WWF, IATTC and SRP most concentrated their efforts to promote the use of circle hooks. The primary catch for these sites is common dolphinfish from December to April; and tuna, billfish, and shark from June to October (Key informant, Ecuadorian government official knowledgeable on fisheries, January 2011).

A planning meeting among the collaborators was held before the survey was conducted to discuss the design of the survey instrument, key areas to conduct the interviews and roles of various organizations. The group identified two criteria to guide the selection of study areas; namely, wherever long line fishing gear was frequently used, and wherever the circle hook workshops took place.

The team received support from the National Fisheries Institute of Ecuador which was critical in the implementation of the surveys. The project also gained valuable insights from consultation with key informants related to fisheries or working in the fishery industry. Fishers who operated small-scale and traditional boats were sampled at their respective fishing villages. 
A set of questions focused on understanding the diffusion of and adoption of this bycatch reduction device (circle hook) was developed and administered to a sample of longline fishers in Ecuador. The total population $(\mathrm{N})$ of this study is 272 longline fishers, which is composed primarily by deckhands (116) captains (103), and a small concentration of owners (53). The sample is sufficient to represent interviewees' views regarding circle hooks as a reflection of relative proportions of the fishing villages as a whole. A survey form (see appendix I), with several categories regarding circle hooks was used.

In this analysis, sample sizes vary from question to question. This is due to the fact that, while some questions were asked of all respondents, some were asked of only captains or owners or both. Sample sizes for some questions were also influenced by a preceding question; e.g., questions about aspects of workshops could only be asked of those who attended a workshop.

In addition, in each location, key informants were interviewed, since some questions required in-depth knowledge of the fishing activity. Key informant interviews are qualitative in-depth interviews with people who know what is going on in the fishing community. The purpose of key informant interviews was to collect information from a wide range of people_-including community leaders, fishing leaders, fishing authorities, and gear suppliers - who have firsthand knowledge about the fishing community. These community experts, with their particular knowledge and understanding, can provide insight on the nature of problems and give recommendations for solutions. The nine interviewees that directly mention the Ecuadorian circle hook program were considered for analysis. Six interviews analyzed 
were conducted in Ecuador; the remaining three were conducted in the United States. All interviews that were analyzed were conducted face to face, with eight out of the nine agreeing to use digital recorders.

Surveys were deployed after field tests confirmed their viability. A team of 7 native Spanish speakers, including the main author of this research, conducted the surveys. Every other boat was sampled to introduce an element of randomization. This method was used at every location except for Puerto Bolivar where it is believed that every boat was surveyed.

The questionnaire was composed of three main sections that included socioeconomic profiles, fisheries background and turtle interactions, and perceptions and knowledge of turtle issues. The questionnaires were translated into Spanish, the Ecuadorian national language. Fishers' participation involved their responses to several general questions and statements about diffusion and perception regarding BRD and fisheries management.

The survey took 20 to 30 minutes minimum and up to about 45 minutes depending on fisher's response. The respondents were recruited in public places where people usually gather, such as fish landing sites and markets. Data was entered into SYSTAT software for analysis and tabulation.

\section{$\underline{\text { Measurement of Dependent Variables }}$}

The dependent variable in this study is the extent of $\mathrm{CH}$ adoption. We proposed four measures to determine the extent of adoption: first, the number of CHs obtained by 
fishers; second, fishers' perceptions of the proportion of fishermen using the $\mathrm{CH}$; third, fishers' self-reporting of their use of $\mathrm{CH}$, and fourth, the fishers' opinion about the conservation technology.

Measurement of Independent Variables

There are many types of incentives and disincentives for adoption. These include: the degree of stakeholder involvement in management, size, distribution of the fishery, informant characteristics (e.g. level of education, income), and characteristics of the promotion programs.

In general, appropriate multivariate and bivariate statistical analysis techniques were used to determine relationships between the independent variables (e.g., management methods, fishers' socio-cultural characteristics, perceptions of conservation technologies and management effectiveness, etc.) and the dependent variable-level of adoption of CHs.

This study also gained valuable insights from consultations with the key informants working with fisheries and sea turtles in Ecuador. The study also draws from qualitative interviews with NGO reps, fisheries biologists, and fishing leaders (association presidents, boat captains). 


\section{RESULTS}

\section{$\underline{\text { Socio-economic characteristics }}$}

In this study, the mean age is 40 years (with a standard deviation of 14 years and $\mathrm{P}$-Value $=.035)$, which suggests there is a wide range of working age individuals in the sample (Figure 5).

Education characteristics in which individual differences among fishers emerge vary greatly; most of fishers (59\%) that were interviewed have responded to attend primary or elementary school; $31 \%$ mentioned attending high school; and 6\% of them said they had a higher education (university). The difference in education is significant assuming chi-square distribution with $1 \mathrm{df}(\mathrm{p}$-value $=.000)$.

Looking for the characteristics of each town regarding education, we found out that Puerto Bolivar has the highest percent (14\%) of fishers who have achieved university studies, while fishers from Esmeraldas (54\%) and Manta (38\%) have attended high school (Figure 6). However, the higher percentages of fishers who have attended elementary school are fishers from Santa Marianita with $80 \%$.

\section{Adoption of Circle Hook and Workshop Attendance}

Survey results indicate that circle hook adoption in Ecuador is low; only 64 out of 272 informants $(23 \%)$ indicated that they use circle hooks on their boats. Regarding the use of circle hooks in our study areas, the highest percentage of fishers who are using this device are from Santa Marianita (67\%) followed by fishers from Manta (35\%), San Mateo (25\%), and Santa Rosa (22\%). The lowest adoption of circle hooks corresponds to fishers from Puerto Bolivar (8\%) (Table 1). 
Of the interviewed fishers $(\mathrm{N}=166), 18 \%$ pointed out that they have attended a workshop giving by the agencies that promoted the circle hook in Ecuador, while $82 \%$ said "no."

\section{$\underline{\text { Multivariate Indicators }}$}

In these analysis will be examined multivariate relationships between the variables. First, principal component analysis will be used to discover patterns of relationships between variables and then determine if any of these patterned relationships can be used to understand the diffusion of circle hook technology and knowledge.

First, six techniques were used to transfer circle hook technology to the fishermen: provision of free circle hooks, exchanging circle hooks for J-hooks, fishermen engaging in informal conversation about circle hooks with change agents, attending circle hook workshops, reading printed material describing circle hook use and impact, and viewing videos concerning circle hook use and impact.

As a means of determining whether these technology transfer techniques could be formed into a multivariate indicator scale, a principal component analysis using varimax rotation of components was conducted for the six techniques. The screen test (Cattell 1966) was used to determine the number of components, resulting in 2 components which account for a total of $50 \%$ of the variance in the data set. The results of this analysis are found in table 2. Items loading highest on the first component indicate include four methods: Provision of free circle hooks, not informal conversation (negative loading) attendance at a circle hook workshop, and exchange 
of J-hooks for circle hooks. Items loading highest on component two reflect Information transfer using written material or a video.

Component scores representing the position of each fisherman on each component were created for each fisherman. The component scores are the sum of the component coefficients times the sample standardized variables. These coefficients are proportional to the component loadings. Hence, items with high positive loadings contribute more strongly to a positive component score than those with low or negative loadings Nevertheless, all items contribute (or subtract) from the score; hence, items with moderately high loadings on more than one component (e.g., attend workshop in the analysis presented here) will contribute at a moderate level, although differently, to the component scores associated with each of the components. This type of component score provides the best representation of the data. In this paper, for this data we will refer to these scores as Technology Transfer Method Component Scores. They are standardized scores with a mean of zero and a standard deviation of one.

Turning to technology transfer impacts, six survey questions involved aspects of impacts: respondent's use of circle hooks, perceived percentage of boats using circle hooks, perceived changes in circle hook usage, perception that the use of circle hooks is mandatory, perception that the use should be voluntary, and belief that the use of circle hooks avoids turtle mortality.

As a means of determining whether these impacts could be formed into a multivariate impact indicator scale, a principal component analysis, as described above, using Varimax rotation of components was conducted for the six types of impact. The screen test (Cattell 1966) was used to determine the number of 
components, resulting in two components which account for a total of $51 \%$ of the variance in the data set. The results of this analysis are found in table 3. Items loading highest on the first component refer to aspects of usage of circle hooks, while those loading highest on the second component reflect of the impacts of the circle hook technology transfer program (e.g., avoidance of turtle mortality, perceptions that the use of circle hooks should be voluntary and perception that the use is mandatory).

As described for the technology transfer principal component analysis, component scores representing the position of each fisherman on each component were created for each fisherman. Note that respondent's beliefs that use of circle hooks should be voluntary loads moderately on both components; thus, it contributes to the score for each component, but highest for the impact component. In this paper, for this data we will refer to these scores as Impacts of Technology Transfer Component Scores. They are standardized scores with a mean of zero and a standard deviation of one.

\section{Predictors of the Impacts of Technology Transfer}

Zero-order correlations between selected independent variables and the two Impacts of Technology Transfer components are in table 4. Three of the independent variables manifest statistically significant relationships with Usage of Circle Hooks and only one with Circle Hook Impact. Boat length is positively related to the Usage of Circle Hook component along with two of the technology transfer techniques (Attend Workshop and use of Video) and the Technology Transfer Method 2 component. Only one of the independent variables, age, is statistically significant as 
related to the Circle Hook Impact component—as age increases, so does the score on this component.

Inter-community Differences in Technology Change Methods and Impacts

Analysis of Variance was conducted to determine if there are significant differences in the two Technology Change Method Component and the two Technology Transfer Component scores across the six towns in the sample. Results of the analysis are in figure 7. All principal component scores, except for the Technology Transfer Method Component 2 are statistically significantly different across the six towns.

Santa Marianita manifests the highest scores on Technology Transfer Method Component 2 and the Usage of Circle Hooks Impact Component. Finally, Santa Rosa manifests the highest score on the Circle Hook Impact Component.

\section{The Santa Marianita Case Study}

Because the hooks exchange program implemented by the environmental and regulatory agencies in different fishing communities in Ecuador, we decided to compare success of circle hooks between Santa Marianita and the other fishing villages. We predict that it would be easier to make $\mathrm{CH}$ mandatory in SM. Therefore we use a one-tailed test ( $\mathrm{p}$ is one half that for a 2-tail test).

Fishers from Santa Marianita were the group that attended more workshops $(40 \%)$, while the "Others" were $12 \%(\mathrm{p}$-Value $=.000)$. Regarding the use of circle 
hooks, $67 \%$ of respondents from Santa Marianita report using circle hooks in comparison to only $26 \%$ in "other towns" (p-Value $=.000)$.

In Santa Marianita, $50 \%$ of fishers reported to have a positive first experience with circle hooks, and $22 \%$ of them mentioned that it was negative. In fact, nobody in Santa Marianita reported a "very negative" first experience. The distribution of percentage regarding first experience for the "Others" is $43 \%$ positive and $28 \%$ negative. The $\mathrm{p}$-value is .236 assuming chi-square distribution is with $1 \mathrm{df}$.

When fishers were asked if the circle hook affects bycatch, an important percentage (63\%) of Santa Marianita's fishers responded that it does not affect the bycatch (increase or decrease of catch), while fishers from "Other towns" believe that the use of circle hook will keep the same bycatch(43\%), but will increase in $46 \%$ (pValue $=.268)$

Further, fishers from our study population were asked to respond if circle hook exerts an influence on the size of the target species. Seventy one percent of fishers from Santa Marianita and 47\% of fishers from "Other towns" responded that circle hook captures bigger species. On the contrary, 29\% of fishers from Santa Marianita and 53\% of fishers from "Other towns" mentioned that the circle hook does not have any influence on the size of the target species $(p-$ Value $=.107)$. 
Regarding whether the circle hooks could be mandatory; fishers from Santa Marianita (38\%) as well as from "Other towns" (31\%) believe that it would be possible. However, 29\% of fishers from Santa Marianita and 12\% of fishers from "Other towns" said it will not be possible. The p-Value (.082) shows there is not statistical significance.

Fishers' perceptions regarding the impacts of circle hooks on sea turtles

First of all, fishers were asked if there are less or more sea turtles now than when they started to fish (10-15 years as average). Forty six percent responded that there are more sea turtles now and $27 \%$ believe there are less sea turtles species surrounding the Ecuadorian waters. The $\mathrm{p}$-Value is .236 assuming chi-square distribution with $1 \mathrm{df}$.

Later on, our survey population was asked about the impacts of circle hooks on sea turtles. Sixty seven percent of fishers believe that the circle hook prevents sea turtles from dying, but at the same time $33 \%$ of them said the opposite $(\mathrm{p}-$ Value $=$ $.019)$.

Regarding the importance of sea turtles for fishers, results of this question point out that $67 \%$ of fishers cares about these species, while $12 \%$ of fishers have a neutral opinion. In fact, many of fishers told us that they do not eat turtles anymore and they help to protect sea turtles much more than before. In this regard, $74 \%$ of fishers said they do not eat or consume sea turtle's product (i.e. eggs, meat) and 26\% respond that they do. For a low percentage of fishers (5\%), sea turtles conservation is not important. 
Making a comparison between circle hook and the "J" hook, one of our interviewers mentioned that "J" hooks are very bad for sea turtles. If a turtle gets caught with a "J" hook it is as good as dead because it will swallow the hook. On the contrary, the circle hook gets caught on its jaw and the sea turtle cannot swallow it. There is a greater chance that it will survive.

Turning to the importance of sea turtles for fishers, the survey instrument asked if they_fishers_-remove the circle hook from the turtle's mouth once these species are onboard. Sixty eight percent of fishers responded they do and $32 \%$ of them do not. In addition, all the interviewees said to have returned sea turtles to sea after they were captured with their hooks.

Key informants' perceptions-Qualitative data.

Questions related to the promotion of circle hook as a bycatch reduction device such as: promotion and dissemination of circle hook and its program, first experience, impact on the conservation of sea turtles and other species, and costs, were made to key informants.

One of our key informants, a well known researcher from IATTC pointed out regarding his experience in the exchange hook program:

"At the very beginning, for instance, every boat that you change the hooks is one experiment in itself and you know that some are going to succeed and some are going to fail. Therefore, you need to start very early on saying-Wait a minute, this is not going to be perfect the first time you do it - and you show them-Well you are learning how to use the hook, you are learning how to bait, you are learning how to 
do all of these things, so it is not going to be the first trip. He added: Well, you know, fifteen boats did great and six boats did badly, and so what happened here? We will just wait. So we did a few more boats and so on. So to do that, you need to be, you cannot jump in here and then jump in there and skip this, you cannot."

Regarding this point, a key informant from the office of WWF in Ecuador said:

"A lot of fishers base their opinion on their first experience, but if they use them enough times, they will realize that circle hooks are better. They also change their opinion when they catch a lot of tuna. So, yes, I have seen some increase in circle hook use, but it is not something that will change from one day to the other. This is a long process and we have to make them to understand it. Therefore, it is important that every fisher receives this message."

Furthermore, a biologist from the Under Secretary of Fishing Resources of Ecuador pointed out:

"The fishers that do not use circle hooks most likely had a bad experience when they tried out the circle hook for dolphinfish. One boat uses all circle hooks and another uses j hooks. At the end, the boat with $j$ hooks caught more fish and the boat that has used circle hooks nothing or too little. Therefore, fishers rejected the circle hooks and do not want anything to do with them."

On his part, a longliner captain communicated us his first experience using circle hooks:

"At first circle hooks were hard to use. I had difficulties baiting the hooks and so did my crew members. We have to bait the hooks quickly and at first it would take a lot more time than with j hooks. I remember once that first time we were trying out 
circle hooks that a friend of mine in another fibra (fiberglass boat) finished baiting the same amount of $j$ hooks in half time. Our fibras were next to each other and he started joking with me, telling me that I was stupid for using different hooks, but it was all joking. After some time, we became used to baiting circle hooks and now it is done faster."

Another point of view of our key informants regarding circle hooks is:

"Some fishers use circle hooks for the perverse incentive of fishing shark." In this sense, circle hooks are not perceived equally within all fisheries in Ecuador. The shark and billfish fishery prefer circle hooks, while the dolphinfish fishery has a much lower acceptance rate. Indeed, six of the nine key informants interviewed indicated that circle hooks were good for catching sharks. Indeed, one IATTC biologist key informant described the appeal of circle hooks in Santa Marianita:

"Circle hooks do not affect fishing and that is why they are well accepted for shark and marlin (January 2011). However, fishers from San Mateo, a fishing town close to Santa Marianita, although they target sharks yet they are not so receptive to circle hooks."

This is in sharp contrast with Santa Marianita fishers to how interviewees viewed fishers' reception of circle hooks. For the common dolphinfish fishery, six of nine interviewees indicated that circle hooks were rejected because they were perceived to lead to lower catch. A key non-government informant who is an expert on Ecuadorian fisheries explained the difference such as: 
"I have heard that circle hooks are successful for sharks and marlin and to reduce turtle hooking, but for Dorado (common dolphinfish) circle hooks are a disaster" (February 2011).

In explaining why fishers would prefer circle hooks for larger fish, and in particular sharks, a government informant with knowledge of the shark fishery and fishery regulations said:

"They change the materials in general (between common dolphinfish season and TBS season); the hooks, the line, the wire, the type of monofilament. Everything changes. The mother line is thicker for grueso. The hooks are bigger and thicker for shark than for dorado" (Dolphinfish) (January 2011).

Turning to conservation issues, our key informants were asked about the difficulties in making this technology available, especially in remote fishing towns. One of the key informants from WWF expressed:

"We have learned a lot, and we are still learning while we carry out this program. It is part of how a program can advance, we are looking at various issues like availability, regulations, costs, and we know there is still a lot to do."

Later on, a specialist from NMFS added:

"I think there were a significant amount of fishers that saw the benefit of circle hooks. I have seen fishers using them and like them once they tried them, but the problem they run into is supply. When we started in Ecuador, the supply of circle hooks was a major issue. We brought the hooks down here, so the fishers were able to have them. Traditional speaking the Ecuadorian fishers use the J hooks. Indeed, everyone uses a J hook, and there are supply outlets of J hooks here." 
In addition, this key informant pointed out:

"One of the things that we found while we were there the first year, the little $J$ hook that they used in the dolphin fishery, they were paying $\$ 1.10$ or $\$ 1.20$ per hook. In the States, they are $\$ .20, \$ .30$, or maybe $\$ .40$. But the little circle hooks were a lot cheaper. Regarding this situation, an extension agent from WWF and SRP, expressed: When we ran out of hooks, fishers would go back to using J hooks. Some hooks would rust and others would bend and so they need more, but we had none to give them. There was no continuity in our work and they made adoption a lot harder. Moreover he said: I really do not know if the price has gone down. I do not know about the market, but I know that many stores still do not have circle hooks and I am unsure if they are interested in importing circle hooks."

The words were supported by another Key informant, a fish longliner captain from Santa Marianita. He expressed:

Circle hooks are hard to find and the stores do not have them".

When key informants were asked if fishers are interested in conservation efforts of sea turtles, our key informant from IATTC pointed out that:

"Fishers now care about turtles than ever before." He added that "fishers are the real conservationists. They have been fishers their whole lives and most of them believe that their children will be fishers also. They want to make money, certainly, but they do not want to see the marine resources finished."

Finally, our key informants - non-organizers - were asked about the results of the circle hook program. Four of our key informants responded that the program did 
not succeed well. Indeed they all said that the small amount of success, such as the Santa Marianita case, is due to circle hooks donation.

"The problem is carrying out the project establishing a system of distribution of circle hooks to certain fishing communities. It would need to be a more open campaign."

Indeed, one of the key informants was more drastic pointing out that "after seven years of work, a low percentage (2-3\%) of artisanal fleets are using circle hooks."

In his opinion, artisanal fishers will never accept circle hooks because of the fish species they want to catch, the lack of circle hooks and lack of enforcement.

However, when our key informant from IATTC was asked about the same question, he indicated that:

"The programs succeeded in several aspects, pointing out that the major success was to create a very large network of people which have worked together for the first time in their lives. In addition he said that the NGOs have not betrayed the trust of the fishers. They observed what they were supposed to do, and there were no scandals in the media."

The representative of the WWF argues that it is necessary to remember that the agencies are not dealing with only a few fishers. "There are so many fishers and it is hard to reach out all of them." He added that the importance of diffusion of this technology transfer-circle hook-is:

"To communicate with other fishers to let them know about this device and what they have learned." 


\section{DISCUSSION}

The circle hook was promoted as a conservation technology, helping to protect turtles. This bycatch reduction device had no significant history of prior use in Ecuador. The promotional efforts by the international agencies have promoted the benefit of a circle hook as a conservation tool. Therefore, it was expected that a significant number of fisher respondents would have indicated that circle hook use is important for the conservation of turtles.

Although the effort to transfer circle hook technology has occurred in Ecuador since 2004, there is no doubt that its diffusion process has been slow in most of the fishing towns in this study. Although some of the Santa Marianita fishers have been using circle hooks since 2004 due to the efforts that the environmental and regulatory agencies made in this small fishing village, an important number of fishers and boats have set up with J hooks. The results from this study reflect the work of these agencies in Santa Marianita because the majority of the positive responses to the questions from the surveys come from this town, and also confirm the hypothesis that this town had a more positive experience in using circle hooks due to workshops that the agencies implemented in this fishing community.

Also, the results of this study indicate that early adopters of the technology (i.e. Santa Marianita's fishers) were both more likely than later adopters to implement the technology, which follows from Roger's theory (Figure 8). Adoption of innovation theory describes the normal-shaped distribution of adopters, where early adopters such as the fishers in Santa Marianita, are more adventurous than later adopters (Rogers 
2003, Tango-Lowy and Robertson 2002). This could be a result that the agencies that promoted circle hooks focused their initial efforts in Santa Marianita, and selected this fishing town to test circle hooks. In fact, nobody in Santa Marianita reported a 'very negative' first experience.

"Attend Workshops" and "Use of Video" were the only two of the independent variables that manifest statistically significant relationships with the technology transfer techniques. It is important to consider two of the weaknesses in technology transfer through workshops. One is that workshops often use a top-down approach where fishers are thought of being empty vessels that need to be filled with information, and the second one is the importance of knowing the social organization of fishing communities. One of our key informants, an officer from the WWF office in Ecuador, had clearly stated that they had no clue about neither the socio cultural dynamics of these communities nor the social organizations of fishers. This key informant recognizes that there is a huge disconnect between NGOs, institutions and the grounded reality of fishing communities.

In addition, we have noticed that the agencies focused their work more on boat owners and captains. It is completely understandable, but they should also have included deckhands in the mix. Class differences, pervasive stereotypes and power relations are issues to be considered, and a more participatory approach would only help extension efforts.

It is important to remark that even though these technologies have already been developed and tested, empirical technology diffusion literature has demonstrated that the adoption of new technologies can be slow (Bass 1969, Mahajan et al. 1990, 
Hannan \& McDowell 1984, Mulligan 2003, Baker 2001, Engers, Hartmann \& Stern 2009). As Bollinger (2011) says, there are a variety of potential explanations for slow adoption. Among them: 1) fishers do not realize the societal benefits of using this technology and it is not superior in terms of the fishers' goals, 2) fishers may have long equipment replacement cycles which slow the migration to a socially and privately better technology, or 3) fishers may not have sufficient information to evaluate whether or not a switch to a green technology is in their interest.

Technology transfer is best achieved by a combination of forces. Direct interaction (workshops and visits) with the fishers and leaders has shown to be effective. In addition broadcast methods via video and or printed materials showed much promise, and create a multiplier effect of creating "ambassadors" at sea and in the villages.

Although the agencies that were involved in the technology transfer of circle hooks in Ecuador worked with local fishing authorities and fishing associations, it appears that the fishers from most of the survey sites were not convinced to use this BRD. In other words, they were not persuaded at all. Fishers who do not use this device believe it was promoted poorly in their fishing towns. This seems to highlight the hooks promotion in fishing towns as possibly being a large contributor to whether or not fishermen use it.

It must be understood that the requirements imposed for the information and persuasion functions in technology transfer are different. While the media often works well for performing the information function, direct interaction works well for persuasion (Lionberger et al 1991). Rapid increases in adoption rates occur mostly as a 
result of fishers talking to and influencing each other, and while engaging with different aspects of the seascape environment, fishing materials, fish, and sea turtle behavior.

However, according to the quantitative data, 50\% of Santa Marianita fishers believe that their first experience with circle hooks was positive. An important percentage (26\%) of fishers who reported to catch more large pelagic fishes with the circle hook was from Santa Marianita. This result could be related to the experience of fishers in catching large pelagic fishes. They have noticed that large pelagic fishes such as tuna are better caught with circle hooks. The explanation for this positive answer regarding the circle hook could be related to the strength of this hook and the difficulties that large pelagic fishes have to escape. On the contrary, if these species are caught with $\mathrm{J}$ hooks, the probability of a fish to escape is high because the tuna species are very fast fishes and tend to move their jaw a lot once they are hooked. Because of this, tuna will start making a hole in their jaw and these species will break loose and escape.

In addition, $11 \%$ of fishers believe that circle hook will not affect the bycatch species (decrease or increase), but $46 \%$ believe it would increase the bycatch species. When the key informants were asked about the impact of circle hooks on bycatch, six of the nine indicated that circle hooks were good for catching sharks. One IATTC biologist key informant described the appeal of circle hooks: "Circle hooks do not affect fishing and that is why they are well accepted for sharks and for marlins" (personal communication 2011). However, from those negative answers regarding circle hooks from fishers, and also from an observation of a key informant from the 
Undersecretary of Fisheries, there are negative consequences to other fish species such as dolphin fish. He points out that those fishers that do not use circle hooks most likely had a bad experience when they tried out the circle hook for dolphinfish (Dorado). They conducted an experiment with two fishing boats. One boat used all circle hooks and another used "J" hooks only. At the end, the boat with "J" hooks caught more fish and the other boat fished nothing too little. Therefore, this is a good reason for fishers who catch dolphinfish to reject the circle hook. The message is to reinforce the technology can be further refined to reduce turtle bycatch while providing a hook design that will yield similar results to the "J" hooks, if not better.

There remains an opportunity in hook design, through additional design and experimentation that may lead to greater adaptation of the circle hook, especially if the circle hook can catch an equal amount of dolphin fish. Fishers can play a role in suggesting designs for a circle hook that is effective for catching Dolphinfish based on an understanding of Dolphinfish-CH interactions, jaw morphology, and behavior of the animal once it is caught. Dolphinfish are dexterous swimmers and can breach the water's surface at high speeds.

Adoption of innovation theory describes the normal-shaped distribution of adopters, and that early adopters are more adventurous than later adopters (Rogers 2003, Tango-Lowy \& Robertson 2002). Fishers that adopt an innovation and view it positively are more likely to continue using it or to try a different one. That could be the case in Santa Marianita, where fishers have found the technology transfer useful regarding circle hooks. Our conclusion is that the high adoption rate of circle hooks in Santa Marianita could be for two reasons: 1) the first one is due to the efforts that the 
agencies — international and local—put in this fishing village due to its size in fishers number, 2) due to, partly, the specialized shark fishery, and 3) The average age of fishers from Santa Marianita is younger in comparison to fishers from "Other towns" (Figure 5). This result might also indicate the reasons that the Santa Marianita's fishers are the earlier adopters. The younger fishers are more willing to learn and to adopt a new technology than older fishers. They also are more curious to find more efficient ways to fish. Therefore, they will try to use any technology in order to improve their catch.

Because of the fishing experiments that fishers from Santa Marianita participated in the Hook Exchange Program, as well as the workshops these fishers attended, we may say that some fishers from this fishing town have developed high management abilities regarding circle hooks, and those from "other towns" have not. Santa Marianita's fishers seem to be more achievement oriented than fishers from other towns, and they are more willing to take major risks regarding the new technology. These attributes placed the Santa Marianita fishers as the early adopters of circle hooks in relation to the diffusion of innovations model proposed by Rogers

This could lead us to the examination of other issues such as community dynamics and the role of fishing leaders in each community, and how diverse the Ecuadorian coastline is in terms of fishing practices from site to site. Therefore, adequate understanding of these variables in the process of adoption of the technology and its diffusion is necessary for designing effective fisheries research and extension programs in the future. 
In addition, it is important to remember that adoption and diffusion of technology are two interrelated concepts describing the decision to use or not use technology that has been invented. The time required for technology to be adopted varies depending upon attributes of the technology, economic units, regions, stakeholders, community characteristics and goals, as well as education level. However, in this case, the adoption of circle hooks seems to be independent from education, which means there must be other reasons for Ecuadorian fishers in adopting circle hooks.

However, many things must happen for final adoption to take place. For example, there must be: 1) good communication and deeper and long-term work with the real leaders of fishing communities; 2) a reduction in the cost of circle hooks, and 3) a supply of circle hooks in fishing stores or hardware. Fishers using " $\mathrm{j}$ " hooks for a long time need more time to adjust and adopt the circle hooks. Among the things that might help this is to work with fisheries' leaders, who may in turn be messengers of the technology transfer messages through good communication. Good communication is a necessary condition for bringing about change; however, it is not sufficient alone. Good communication is not only the contact with fishers in the moment to transfer the new technology, but also after the workshops and the implementation of the fishing device. Good communication is necessary to ensure the adoption, and to resolve any questions that fishers may have regarding the new technology. Information concerning new technology can be transmitted in different ways; not only though workshops, the media and bulletins; but also through school, fisher to fisher exchanges, and demo those not using circle hooks. 
Regarding cost of the hooks, this was an interesting and unexpected result because when the data was collected we got the opposite impression; that cost was a main factor in whether or not the circle hook was used. In addition, the key informants (e.g. people from the WWF and IATTC) mentioned that the high price of circle hooks compared to "J" hooks, which were used most often by artisanal fishers when we did the study, was one of the main obstacles to the widespread adoption of circle hooks by longline Ecuadorian artisanal fishers. Any solution to improve the use of circle hook use must consider how it will be enforced and at what cost, and whether it is feasible or subsidized. Lastly, a policy's effectiveness can depend on who bears the cost. In the case of the circle hook initiative in Ecuador, key informants indicated that the higher cost of the circle hooks was a reason for low adoption rates. After this study, the Ecuadorian government has removed the tariff of $30 \%$ on imports of circle hooks. The decision was made after reviewing a report prepared by the WWF, which found that circle hooks are more environmentally responsible because they reduce the bycatch of sea turtles by 70\% (http://www.thefishsite.com/fishnews/18617/ecuador-removestariff-on-circle-hooks-to-help-protect-turtles/\#sthash.zChR9mJv.dpuf). Obviously follow-up work is crucial but this involves observing techniques at sea, knowledge in action (conditions in the wild), and how fishers negotiate marine conditions while using the conservation technology and handling sea turtles. It is quite challenging, especially when there is pressure to work fast at night and when the marine conditions are rough. This is one salient issue that fishers kept pointing out. NGOs personnel and biologists usually talk a lot on land, but it would be better for them to head out to sea and understand the conditions under which fishers work and how the technology 
works in nature. Besides, it is important to create a fishers network, so they can interact regularly in order to exchange knowledge.

This study suggests that more research on the human and institutional aspects of fishery technology transfer is necessary in Ecuador. A review of the Ecuadorian fishery literature shows the majority of studies are focused on technical design as well as on the biological aspects of fish species. While these studies may not replace those on technical design and performance, even the best technology can fail when introduced into a poor institutional or human context. Poorly designed technology, however, will not succeed regardless of how positive the overall context.

Such research may be vital to realizing the potential of BRD to resolve bycatch problems in the future, and this is particularly true in the case of those species that lack economic value for fishers such as sea turtles and where values attached to such animals often vary greatly among stakeholders.

Although this study has focused on potential issues related to adoption of circle hooks, there is no doubt that this fishing technology can be successfully applied as a partial solution to the problem of sea turtle bycatch. Through better implementation practices and articulation of critical social cultural factors and political economic contexts, it is possible to facilitate effective technology transfer wherever and whenever it is needed. It is through the recognition of potential sociocultural factors and taking steps toward their solution that we can facilitate the successful transfer of technology wherever and whenever it is needed.

The perceived urgency of environmental problems tends to make immediate behavior change the major focus. But of equal importance is the stability of behavior 
once changed. Therefore, one goal of conservation behavior research might be to discover techniques that change individual behavior while minimizing or eliminating the need for repeated intervention.

For many reasons the techniques commonly used to promote conservation behavior are more reliable at modulating short-term behavior than achieving durable change. Changing fishers' behavior should entail for managers and scientists an interrelated work with fishers, not only in the adoption of the new technology by providing clear and firm guidance, but also in the development of bycatch reduction fishing devices to enhance the fishers' knowledge process to enhance their confidence in new technologies

However, if the environmental community handled the circle hooks issue in a personal and respectful way, but also in a participatory way, there would probably be less resistance from fishers. Less resistance from fishers would mean, among many other things, conservation groups would have much more time, money, and resources to spend on other issues. Environmentalists also would have made important allies in the fight to save the sea turtles instead of enemies.

In conclusion, the technology transfer of the use of circle hooks for reducing turtle bycatch in Ecuador has had mixed success. While the exchange hook program by the agencies point out that circle hooks reduce the hooking rates of sea turtles from $88 \%$ to $44 \%$ in the tuna fishery (a statistically significant difference), and from $37 \%$ to $16 \%$ in the dolphinfish fishery (not tested), our results show up a low adoption (23\%) of circle hooks by fishers interviewed in this study. The Ecuadorian fishers could be 
less interested in the conservation of sea turtles, although they are interested in learning of improvements in their respective captures.

An additional impediment to adoption of the circle hook is that fishers perceive the circle hook as being less effective in the capture of dolphinfish, which represents an important part of their incomes during six months each year. The circle hooks, however, were effective in capturing large pelagic species such as tuna and swordfish.

More fishers have to participate and be involved in any technology transfer, so they become more interested in these activities. The government and NGOs must consult with fisher leaders before presenting a new technology. Working with fishers from the beginning can be a very good strategy to obtain better results.

Adoption is not easy, especially when the Ecuadorian fishers have spent many years fishing with $\mathrm{J}$ hooks. They have yet to have time to adopt and/ or develop adequate techniques to operate with circle hooks. Therefore, what we hope to see in the near future is a better work with fisher leaders, deckhands, and the members of the fishing communities where interaction and exchanging of ideas is a part of the action for better results. With these ideas in mind, we may see improvements not only in the fishers' catch rates with better circle hooks implemented, but also to have a behavior change in them regarding the conservation of sea turtles.

\section{ACKNOWLEDGMENTS}

Financial support for this study was provided by the Intact project. Thanks are due to the National Fisheries Institute of Ecuador who provided technical and 
logistical support for the study, and to all surveyors (Nancy Benitez-Vina, Monica

Fabara, Lorena Monserrate, Omar Alvarado and Christina Jines) for field assistance.

\section{LITERATURE CITED}

Alava, J.J. 2008. Loggerhead sea turtles (Caretta caretta) in marine waters off Ecuador: occurrence, distribution and by catch from the Eastern Pacific Ocean. Marine Turtle Newsletter 119:8-11.

Alfaro-Shigueto J, Mangel JC, Pajuelo M, Dutton PH, Seminoff JA, Godley BJ. 2010. Where small can have a large impact: Structure and characterization of small-scale fisheries in Peru. Fisheries Research 106, 8-17.

Aswani, S. and P. Weiant. 2004. Scientific Evaluation in Women's Participatory Management: Monitoring Marine Invertebrate Refugia in Solomon Islands. Human Organization 63 (3): 301-

319.

Baker, L. C. 2001. 'Managed care and technology adoption in health care: evidence from magnetic resonance imaging', Journal of Health Economics 20(3), 395-421.

Bass, F. M. 1969. A New Product Growth Model for Consumer Durables. Management Science 15, 215-227.

Bentley, J. 1994. "Facts, Fantasies, and Failures of Farmer Participatory Research." Agriculture and Human Values, 11(2\&3):140-150.

Beverly, S., L. Chapman, and W. Sokimi. 2003. Horizontal longline fishing methods and techniques: a manual for fishermen. Secretariat of the Pacific Community, New Caledonia.

Broderick AC, Frauenstein R, Glen F et al. 2006. Are green turtles globally endangered? Global Ecology and Biogeography 15, 21-6.

Bugoni L, Neves TS, Leite NO et al. 2008. Potential bycatch of seabirds and turtles in hook-and-line fisheries of the Itaipava Fleet, Brazil. Fisheries Research 90, 217-24.

Carranza A, Domingo A, Estrades A. 2006. Pelagic longlines: A threat to sea turtles in the Equatorial Eastern Atlantic. Biological Conservation 131, 52-7.

Cattell R.B. 1966. The scree test for the number of factors. Multivariate Beha. Res 1: 245-76. University of Illinois. 
Comisión Permanente del Pacífico Sur- CPPS. 2003. Estudio sobre el impacto socioeconómico de la pesca artesanal en los estados miembros de la Comisión Permanente del Pacífico Sur. Guayaquil, Ecuador. 37 pp.

Falterman, B. and J. Graves. 2002. A Preliminary Comparison of the Relative Mortality and Hooking Efficiency of Circle and Straight Shank ("J") Hooks Used in the Pelagic Longline Industry. Pages $80 \tilde{n} 87$ in: Jon A. Lucy, Editor. Catch and Release in Marine Recreational Fisheries. American Fisheries Society Symposium 30.

National Symposium on Catch and Release in Marine Recreational Fisheries. Virginia Beach, VA. 5ñ8 December 1999.

Farrington, J. and A. Martin, "Farmer Participatory Research: A Review of Concepts and Practice." London: Overseas Development Institute (1987).

Green,D. \& F. Ortiz-Crespo. 1981. Status of sea turtle populations in the Central Eastern Pacific. Páginas 221-233 In: K.A. Bjorndal, editor. Biology and Conservation of Sea Turtles. Smithsonian Institution Press, Washington y Londres.

Halliday, R. G. 2002. A comparison of size selection of Atlantic cod (Gadus morhua) and haddock (Melanogrammus aeglefinus) by bottom longlines and otter trawls. Fisheries Research 57 ( 1 ): p 63ñ73. Amsterdam July, 2002.

Hannan, T. H. \& McDowell, J. M. 1984. 'Market concentration and the diffusion of new technology in the banking industry', The Review of Economics and Statistics 66, 686-691.

Jenkins, L. 2010. Profile and Influence of the Successful Fisher-Inventor of Marine Conservation Technology. Conservation Society 8 (1): 44-54.

IETC. 2003. Technology Transfer: The seven "C" for the successful transfer and uptake of environmentally sound technologies. International environmental Technology Centre. United Nation Environment Programme. Osaka, Japan 2003.49pp.

IUCN. 2012. The IUCN Red List of Threatened Species: Version 2012.1

Johnson, G.G., C. Formichella, J.S. Thomas, D. Bhaumik, F.V. Degruy, III and C.A. Riordan. 1998. Stress and Sistress among Gulf of Mexico Shrimp Fishermen. Human Organization 57(4): 404-413.

Largacha, E., M. Parrales, L. Rendon, V. Velasquez, M. Orozco, and M. Hall. 2005. Working with the Ecuadorian Fishing Community to Reduce the Mortality of Sea Turtles in Longline Fisheries: Year One, March 2004 to March 2005.Rep. Western Pacific Regional Fishery Management Council. Print.

Lewison RL, Crowder LB, Read AJ, Freeman SA (2004). Understanding impacts of fisheries bycatch on marine megafauna. Trends Ecol Evol. 19: 598-604. 
Lionberger, H.F. and P.H.Gwin. 1991. Technology transfer. University of Missouri. Library of Congress Catalog Card Number 91-74102. ISBN 0-933842-24-4.

Lukacovic, Rudolph and James H. Uphoff, Jr. 2002. Hook Location, Fish Size, and Season as Factors Influencing Catch-and-Release Mortality of Striped Bass Caught with Bait in Chesapeake Bay. Pages 97ñ100 in: Jon A. Lucy, Editor. Catch and Release in Marine Recreational Fisheries. American Fisheries Society Symposium 30. National Symposium on Catch and Release in Marine Recreational Fisheries. Virginia Beach, VA. 5ñ8 December 1999.

Mahajan, V., Muller, E. \& Srivastava, R.K. (1990). 'Determination of adopter categories by using innovation diffusion models.' Journal of Marketing Research, 27, $37-50$.

Mug, Moises, Martin Hall and Nick Vogel. 2008. Bycatch Initiative: Eastern Pacific Programme - A vehicle towards sustainable fisheries. Progress report of fishing experiments with modified gear (2004-2007). Rep. World Wildlife Fund, InterAmerican Tropical Tuna Commission, 2008. Print.

Mulligan, J. G. 2003. Market segmentation and the diffusion of quality enhancing innovations: The case of downhill skiing. Review of Economics and Statistics 85(3), 493-501.

Orsi, Joseph A., Alex C. Wertheimer, and Herbert W. Jaenicke. 1993. Influence of selected hook and lure type on catch, size, and mortality of commercially troll-caught chinook salmon. North American Journal of Fisheries Management 13 (4): 709-722

Overseas Fishery Cooperation Foundation (OFCF). 1993. Tuna longline fishing. Overseas fishery cooperation foundation fisheries training Cooperative Project in Federated States of Micronesia

Pollnac, R.B. 1976. Continuity and Change in Marine Fishing Communities. A Stateof-Art. Paper prepared for U.S.A.D.

Pollnac, R.B. 1978a. Sociocultural Aspects of Technological and Institutional Change among Small-Scale Fishermen. Anthropology Working Paper No.22. Paper presented at the International Symposium on Modernization in Fishing Industries and Communities. Institute for Coastal and Marine Resources. East Carolina University.30pp.

Pollnac, R.B. 1978b.. Technological Change and Small-Scale Fishermen. Anthropology Working Paper No.21. Paper presented at the International Symposium on Modernization in Fishing Industries and Communities. Institute for Coastal and Marine Resources. East Carolina University.30pp. 
Pollnac, R.B. and R.S. Pomeroy. 2005. Factors Influencing the Sustainability of Integrated Coastal Management Projects in the Philippines and Indonesia. Ocean \& Coastal Management 48 (5): 233-251.

Ponce, J. 2004. Etnicidad y educación en el Ecuador [Ethnicity and education in Ecuador]. Paper given at the 8th Ecuadorian Congress of Sociology and Latin American Meeting of Social Sciences, Quito, July 2004, FLACSO-Ecuador, Quito, July 2004. Fronesis Institute website.

Prince, Eric D., M. Ortiz, and A. Venizelos. 2002. A Comparison of Circle Hook and "J" Hook Performance in Recreational Catch-and-Release Fisheries for Billfish. Pages 66ñ79 in: Jon A. Lucy, Editor. Catch and Release in Marine Recreational Fisheries. American Fisheries Society Symposium 30. National Symposium on Catch and Release in Marine Recreational Fisheries. Virginia Beach, VA. 5ñ8 December 1999.

Reeves-Ellington, R.H. 1998. A mix of Cultures, Values, and People: An Organizational Case Study. Human Organization 57 (1): 94-107.

Rhoades, R. 1975. "Farmers and Experimentation." London: Overseas Development Institute (1987), H. Brammer, "Some Innovations Don't Wait for Experts: A Report on Applied Research by Bangladeshi Peasants." Ceres 13:24-28 (1980), and A. Dommen, "The Bamboo Tubewell: A Note on an Example of Indigenous Technology." Economic Development and Cultural Change, 23(3):183-187.

Rogers, E.M. and F. Shoemaker. 1971. Communication of Innovations ( $2^{\text {nd }}$ ed.). New York: The Free Press.

Rogers, E.M. and R. Agarwala-Rogers. 1976. Communication in Organizations. New York: The Free Press.

Rogers, E.M. (1995). Diffusion of innovations (4th edition). New York: The Free Press.

Rogers, E.M. 2003. The Diffusion of Innovations. 5th ed. New York: Free Press. 550 pp.

Skomal, Gregory B., Bradford C. Chase, and Eric D. Prince. 2002. A Comparison of Circle Hook and Straight Hook Performance in Recreational Fisheries for Juvenile Atlantic Bluefin Tuna. Pages 66ñ79 in: Jon A. Lucy, Editor. Catch and Release in Marine Recreational Fisheries. American Fisheries Society Symposium 30. National Symposium on Catch and Release in Marine Recreational Fisheries. Virginia Beach, VA. 5-8 December 1999.

Stöckelová, T. 2012. Social technology transfer? Movement of social science knowledge beyond the academy. Theory \& Psychology. SAGE. DOI: 
10.1177/0959354311433235. Downloaded from tap.sagepub.com at University of Rhode Island Library on March 3, 2016http://tap.sagepub.com/

Swimmer Y., Arauz R, Higgins B et al. 2005. Food color and marine turtle feeding behavior: Can blue bait reduce turtle bycatch in commercial fisheries? Marine Ecology Progress Series 295, 273-8.

Swimmer Y, Arauz R, Wang J, Suter J, Musyl M, Bolaños A, López A. 2010. Comparing the effects of offset and non-offset circle hooks on catch rates of fish and sea turtles in a shallow longline fishery. Aquatic Conserv: Mar Freshwat Ecosyst. 20:445-451. http://dx.doi. org/10.1002/aqc. 1108

Tango-Lowy, T. and R.A. Robertson. 2002. Predisposition toward adoption of open ocean aquaculture by Northern New England's inshore, commercial fishermen. Human Organization 61 (3): 240-251.

Taylor R.G. 2002. Results of a Bibliographic Search Comparing the Effects of Circle and J Hooks. 24 September 2002

Trumble, Robert J., Stephen M. Kaimmer, and Gregg H. Williams. 2000. Estimation of discard mortality rates for Pacific halibut bycatch in groundfish longline fisheries. North American Journal of Fisheries Management 20 (4): 931-939.

Trumble, Robert J., Stephen M. Kaimmer and Gregg H. Williams. 2002. A Review of the Methods Used to Estimate, Reduce, and Manage Bycatch Mortality of Pacific Halibut in the Commercial Longline Groundfish Fisheries of the Northeast Pacific. Pages 88ñ96 in: Jon A. Lucy, Editor. Catch and Release in Marine Recreational Fisheries. American Fisheries Society.

Woll, Astrid K., J. Boje, R. Holst, and A. C. Gundersen. 2001. Catch rates and hook and bait selectivity in longline fishery for Greenland halibut (Reinhardtius hippoglossoides, Walbaum) at East Greenland. Fisheries Research 51 (2ก̃): p 237ñ246 (Amsterdam).

Zimmerman, Steven R. and Eleanor A. Bochenek. 2002. Evaluation of the Effectiveness of Circle Hooks in New Jerseyís Recreational Summer Flounder Fishery. Pages $106 \tilde{1} 109$ in: Jon A. Lucy, Editor. Catch and Release in Marine Recreational Fisheries. American Fisheries Society 10 Symposium 30. National Symposium on Catch and Release in Marine Recreational Fisheries. Virginia Beach, VA. 5-8 December 1999. 


\section{TABLES}

Table 1.

Percentage of fishers who use circle hooks (Santa Marianita vs. Other Fishing Towns).

$\begin{array}{llll}\text { Other Towns } & \text { Santa Marianita } & \text { Total N }\end{array}$

\begin{tabular}{llcrr}
\hline & & & & \\
NO & 73.649 & 33.333 & 65.761 & 121 \\
YES & 26.351 & 66.667 & 34.239 & 63 \\
Total & 100.000 & 100.000 & 100.000 & \\
N & 148 & 36 & & 184 \\
p-Value $=.000$ & & & \\
\end{tabular}


Table 2.

Principal component analysis of technology transfer techniques.

\begin{tabular}{lcc}
\hline & Method 1 & Method 2 \\
\hline & & \\
Free Circle Hooks & 0.725 & -0.234 \\
Informal Conversation & -0.582 & -0.058 \\
Attend Workshop & 0.564 & 0.342 \\
Hook Exchange & 0.545 & 0.331 \\
Written Material & -0.133 & 0.805 \\
Video & 0.342 & 0.676 \\
Percent Total Variance & 26.913 & 23.165 \\
& & \\
\hline
\end{tabular}


Table 3.

Principal component analysis of impacts of technology transfer

Usage of $\mathrm{CH} \quad$ Impact of $\mathrm{CH}$

Boats using Circle Hooks (CH) $\quad 0.807 \quad 0.000$

Respondent Use Circle Hooks $\quad 0.794 \quad-0.161$

Community Change in Circle Hook Usage $0.530 \quad 0.163$

Use of Circle Hook is Mandatory $\quad 0.051 \quad 0.728$

$\begin{array}{lll}\text { Circle Hooks avoid Turtle Mortality } & -0.105 & 0.649\end{array}$

Use of Circle Hook Should be Voluntary $\quad 0.435$

$\begin{array}{lll}\text { Percent Total Variance } & 29.427 & 21.103\end{array}$ 
Table 4.

Correlations between technology transfer components and selected independent variables

\begin{tabular}{lcc}
\hline & Uses of Circle Hook & Impact of Circle Hook \\
\hline & & \\
Age & -0.092 & $0.168^{*}$ \\
Education & -0.083 & -0.160 \\
Boat Length & $0.404^{*}$ & 0.171 \\
Line Length & -0.099 & 0.190 \\
Number of Hooks & -0.036 & -0.039 \\
Written Material & 0.164 & 0.137 \\
Attend Workshop & $0.175^{*}$ & -0.035 \\
Video & $0.191^{*}$ & -0.025 \\
Conversation & -0.053 & -0.017 \\
Free Circle Hooks & -0.027 & -0.129 \\
Hook Exchange & 0.113 & -0.155 \\
Technology Transfer Method 1 & 0.076 & -0.160 \\
Technology Transfer Method 2 & $0.241^{*}$ & 0.085 \\
& & \\
\hline
\end{tabular}




\section{FIGURE LEGEND}

Figure 1. X-ray of a sea turtle that has swallowed a bait with a "J" hook. When this happens it is likely the sea turtle is either gut-hooked, damaged internally, or dies.

Figure 2. Schematic of four circle hook designs.

Figure 3. Map of the Study Area and the Workshops Places and Agencies for Circle Hooks.

Figure 4.Fishing Site Areas in the coast of Ecuador.

Figure 5. Interviewees' age.

Figure 6. Interviewees' Education.

Figure 7. Principal Component scores for the Technology Transfer Method Component and the Usage of Circle Hooks Impact Component.

Figure 8. Level of Diffusion \& Adoption of Innovation of Circle Hook. 


\section{FIGURES}

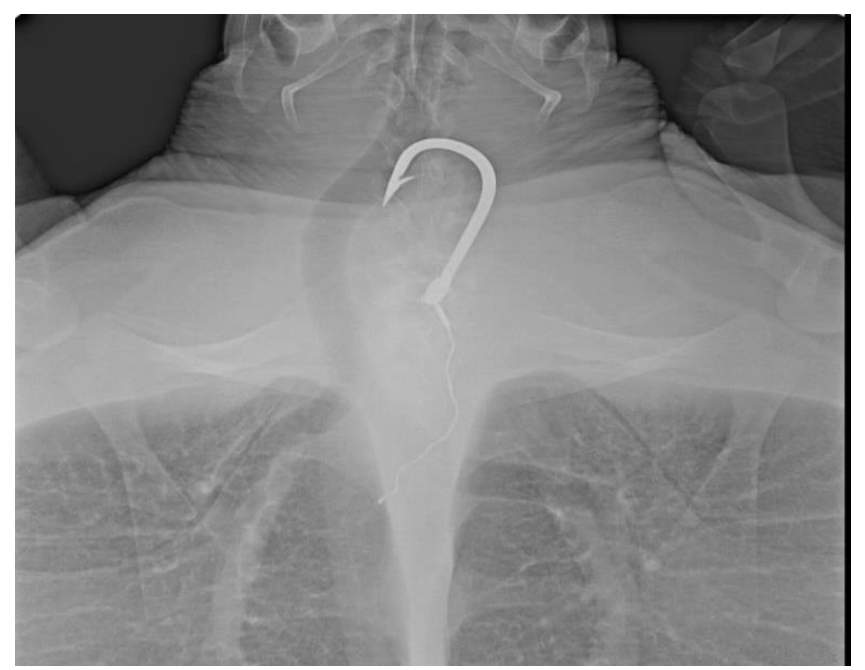

Figure 1: 1-I X-ray of a sea turtle that has swallowed a bait with a "J" hook. When this happens it is likely the sea turtle is either gut-hooked, damaged internally, or dies. An estimated 20,000 leatherbacks and 30,000 loggerheads are accidentally caught by pelagic longlines using J-shaped hooks in the Pacific each year (Lewison et al. 2004). 


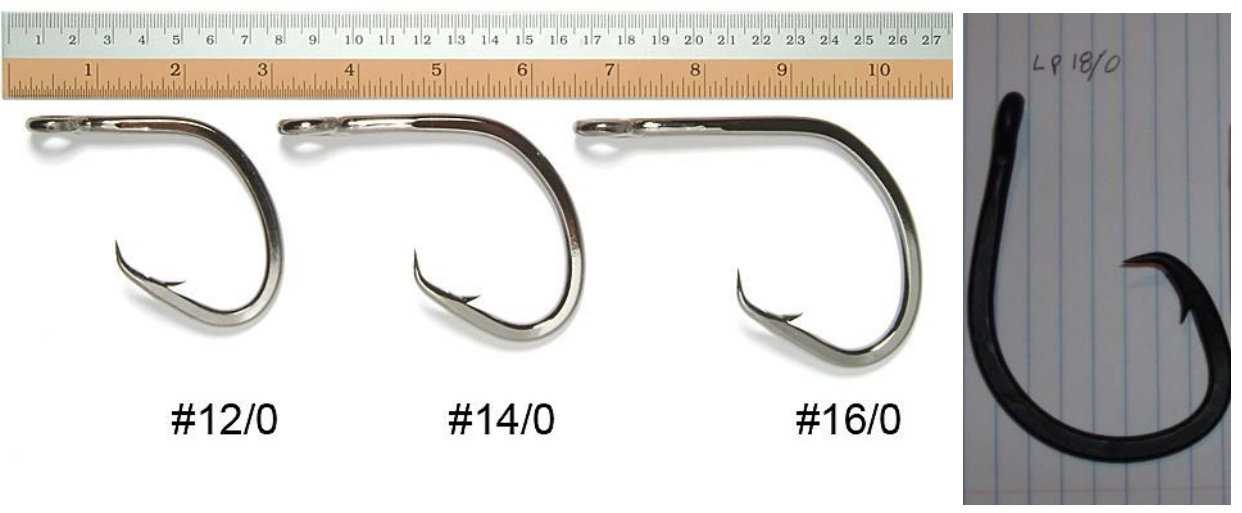

Source: www.ebay.com Longline fishing hooks

Figure 2: 2-I Schematic of four circle hook designs. The two hooks used in the exchange hook program were: 1) $\# 16 / 0=51 \mathrm{~mm}$ (width); $73 \mathrm{~mm}$ (length), and 2) $\# 18 / 0=57 \mathrm{~mm}$ (width); 86 mm (length) 


\section{Background: Promotion of Circle Hook in Ecuador}
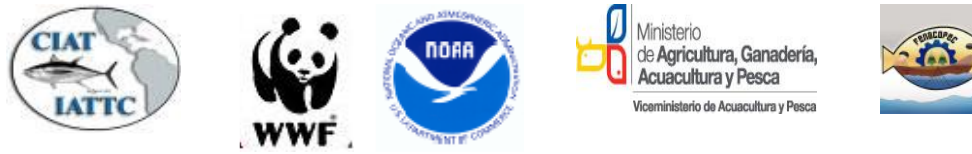

IATTC ,WWF

\section{Others:}

-Asociación Exportadores de Pesca Blanca (ASOEXPEBLA).

-PROBECUADOR

-Escuela de Pesca del Pacifico

Oriental (EPESPO).

-Escuela Politécnica del Litoral Santa Elena (ESPOL).

-Fundación Jatun Sacha

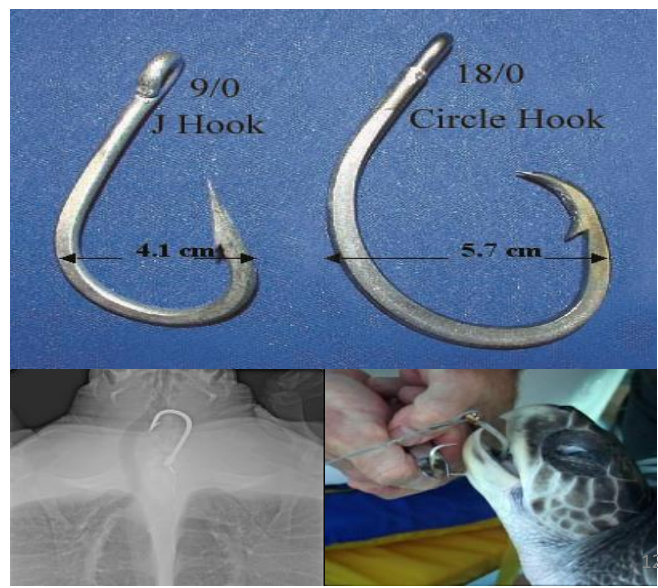

Figure 3: 3-I Exchange Hook Program of J Hooks (left) for Circle Hooks (right) by the International and Local Agencies that Participated in this Program. 


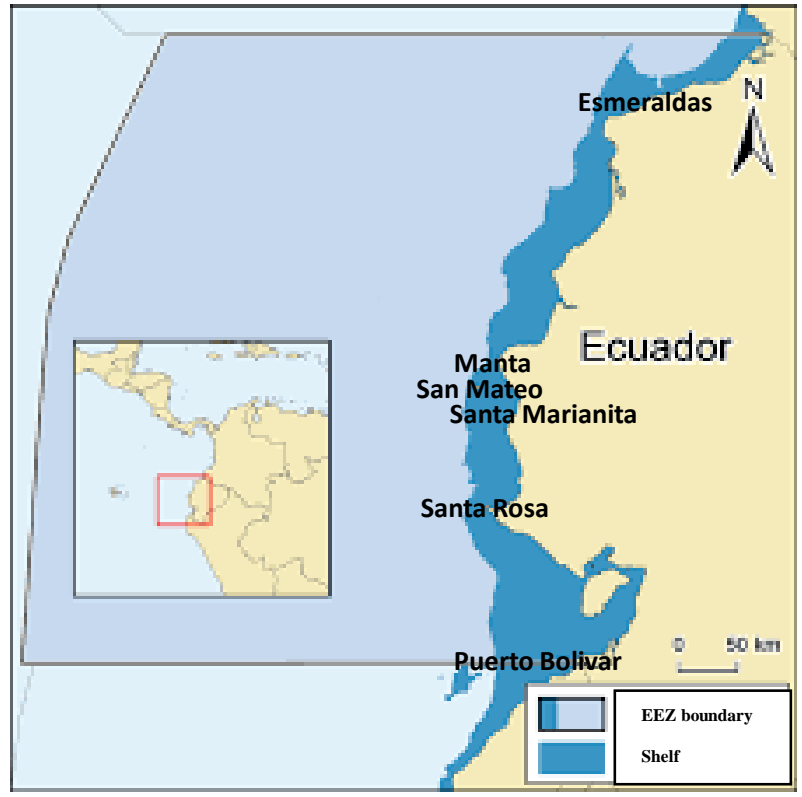

\begin{tabular}{|l|}
\multicolumn{1}{|c|}{ CIRCLE HOOK } \\
WORKSHOPS \\
\multicolumn{1}{|c|}{ IN ECUADOR: } \\
Esmeraldas - EI Matal - \\
Muisne - Crucita - \\
Jaramijó - Manta - San \\
Mateo - Santa \\
Marianita - Puerto \\
López - Santa Rosa - \\
Anconcito-Puerto \\
Bolívar.
\end{tabular}

Source: INP 2007. Adapted by Gaibor 2015

Figure 4: 4-I Site areas sampling in the coast of Ecuador. In the green box, there are the sites where the exchange hook program did the promotion through workshops. 


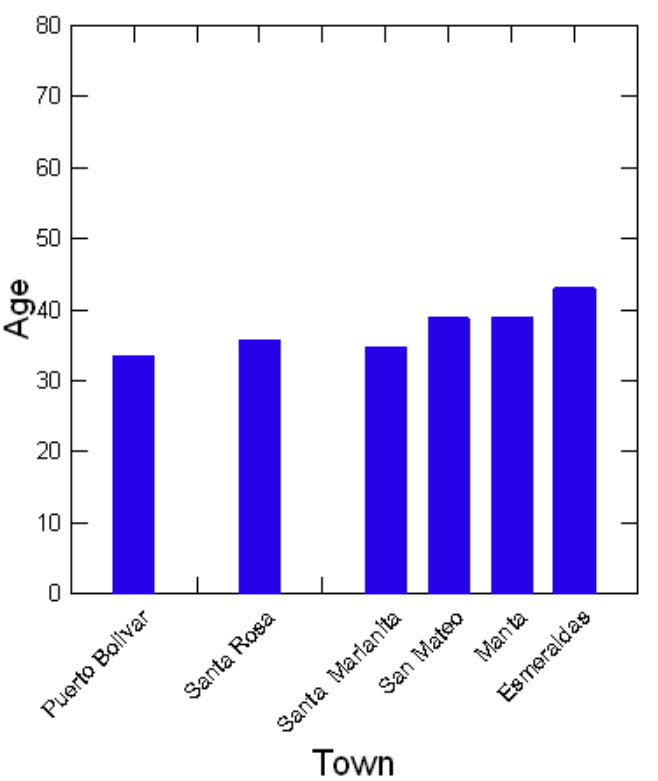

N: 272

Means: 40.3

SD: 13.7

Figure 5: 5-I Fishers' age in the six sampled sites

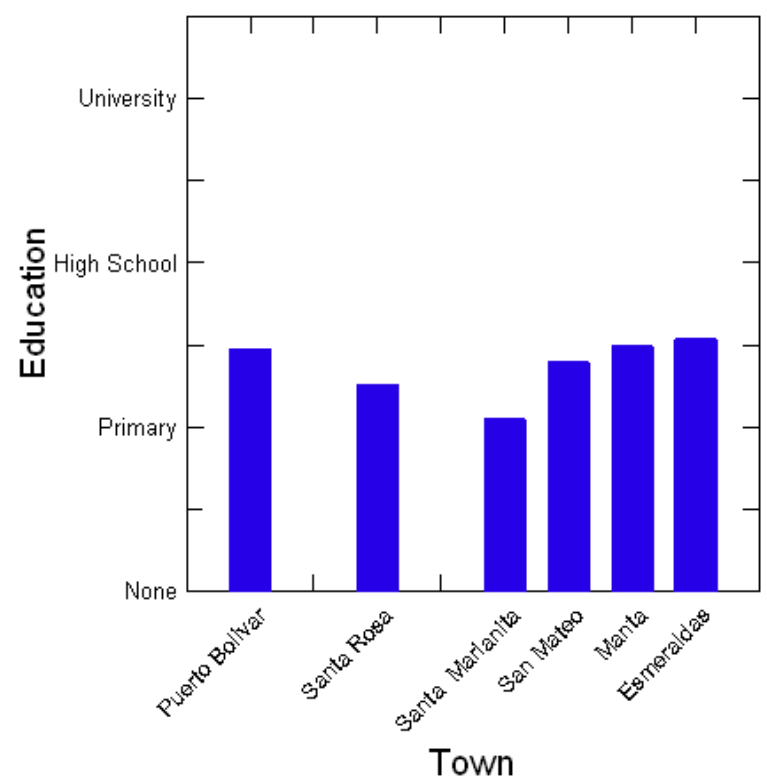

$\mathrm{N}: 272$

Means: 6.2

SD: 3.6

Figure 6: 6-I Fishers' education level 


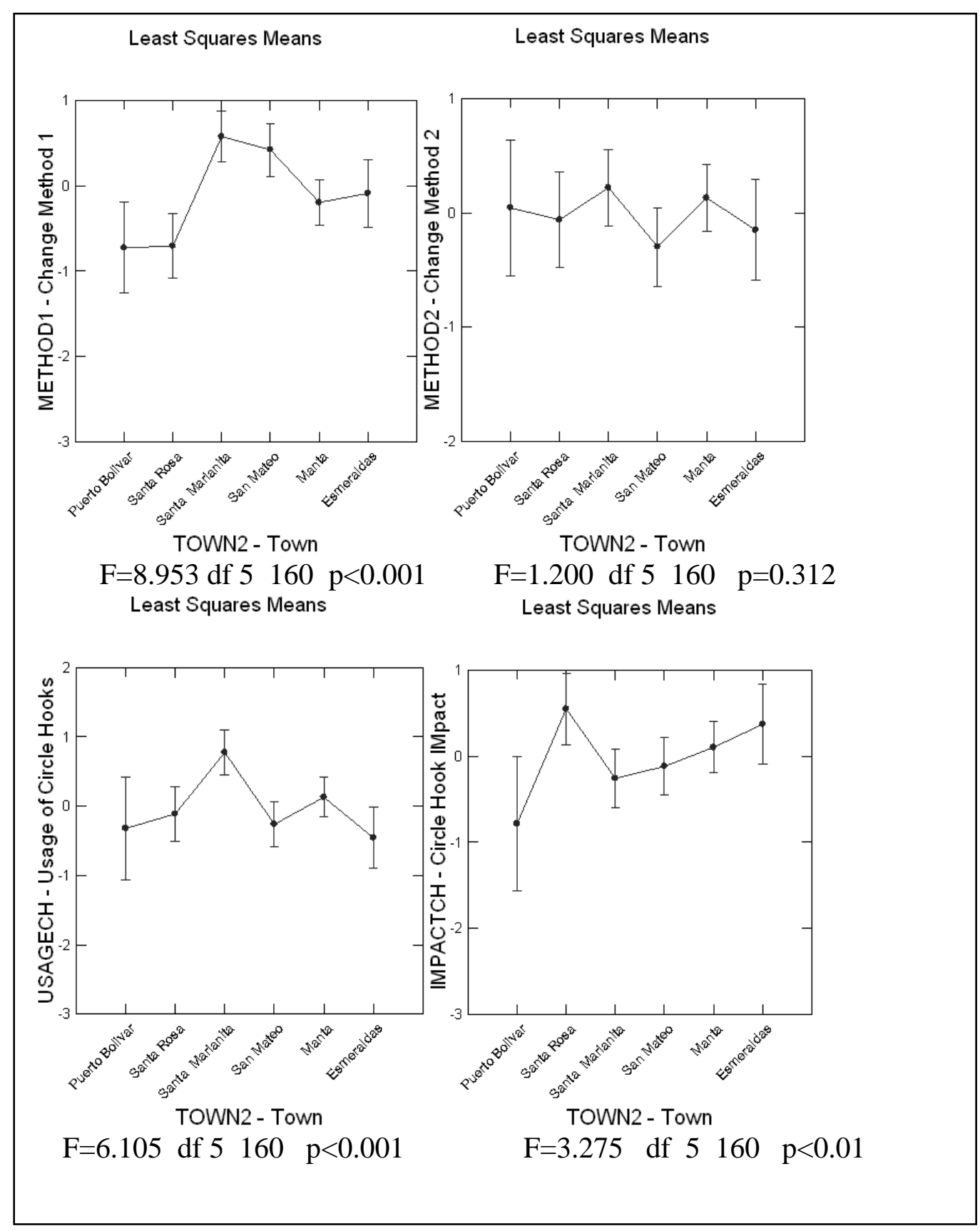

Figure 7: 7-I Principal component scores for the technology transfer method component and the usage of circle hooks impact component. 


\section{Level of diffusion $\&$ adoption of innovation}

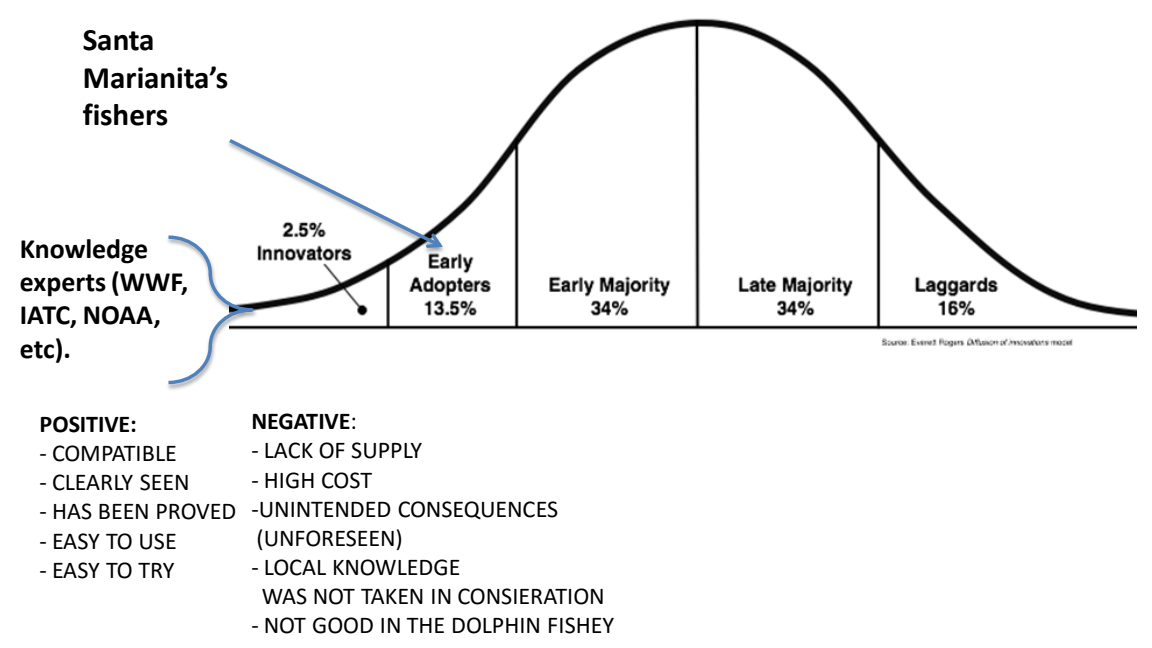

Model based on Rogers (1995)

Figure 8: 8-I Rogers' curve showing groups of consumers adopting the new technology in Ecuador (shown in blue arrow -Santa Marianita's fishers). The curve in this case has only two sections: 1) The Innovators, which are the international (NOAA, WWF, IATC, etc.), and 2) The Early Adopters, which are the fishers from Santa Marianita. The exchange hook program started in 2004 and has not passed yet to the early majority adopters. The tipping point, where a series of small changes or incidents becomes significant enough to cause a larger, more important change, has not happened yet. The elimination of tariff by the Ecuadorian government could contribute to the tipping point happens. However, other incentives are needed for the diffusion of circle hook take place in Ecuador. 


\section{MANUSCRIPT 2}

\section{Conservation Initiatives and Unintended Consequences in Technology Transfer: Circle Hooks and Sharks in Ecuador Nikita Gaibor ${ }^{1}$, Mark Mizrahi², Richard Pollnac ${ }^{3}$ \& Marco Herrera ${ }^{4}$}

Nikita Gaibor ${ }^{1}$, Mark Mizrahi $^{2}$, Richard Pollnac $^{3}, \&$ Marco Herrera $^{4}$

To be submitted to the Journal of Ocean and Coastal Management 2016

${ }^{1} \mathrm{PhD}$ Candidate, Department of Marine Affairs, University of Rhode Island, Kingston, RI, 02881, USA, Email: nikita_gaibor@my.uri.edu

${ }^{2}$ Master Student. Department of Marine and Environmental Affairs, University of Washington, 3707 Brooklyn Ave. NE. Seattle, Washington 98105-6715, USA.

${ }^{3}$ Professor. Department of Marine Affairs, University of Rhode Island, 1 Greenhouse Rd., Kingston, RI 02881, US.A, Email: pollnacrb@uri.edu

${ }^{4}$ Fishery Researcher. Instituto Nacional de Pesca, Ecuador. Letamendi 102 y La Ria. Guayaquil, Ecuador. 


\section{CHAPTER II}

\section{Abstract}

This paper examines the unintended consequences of technology transfer; specifically, circle hooks in fisheries, as a conservation initiative that was intended to curb the accidental capture of sea turtles in Ecuadorian longline fisheries. This initiative focused on exchanging the commonly used j-hooks for circle hooks. The presence of an Ecuadorian shark fishery coupled with a lucrative international shark fin market, as well as regulations allowing incidental shark catch, may create incentives to misuse this technology and target sharks. The goal of this analysis is also to determine to what extent the initiative to promote circle hooks as a turtle conservation tool could lead to unintended consequences if the circle hooks are used instead to target sharks. Additionally, this study examines other variables that may affect the increasing shark captures in Ecuador. One variable is the shark fishing landings in the principal fishing ports of Ecuador and the second variable looks at regulations of shark capture. This study concludes that fishermen are motivated to use circle hooks rather than $\mathrm{j}$-hooks in the tuna fishery, purposefully, to catch more sharks. The lucrative trade in shark fins and the incidental established shark fishery in Ecuador provide an incentive to use the circle hook to target sharks. There is no easy solution to this problem. Ecuador, and those at IATTC and WWF, are in the unenviable position of trying to decide with uncertain science whether to promote a hook that may save sea turtles but put sharks at risk.

Key words: bycatch, circle hooks, Ecuador, sea turtles, sharks. 


\section{Introduction}

Sharks are one of the most primitive taxa, having adapted to life in a wide range of aquatic habitats at various temperatures. While some species inhabit shallow coastal regions, others live in deep waters, on the ocean floor, and in the open ocean (Grove and Lavenberg, 1997). Some species, like the bull shark, are known to swim not only in fresh water, but also in salty or brackish waters.

These cartilaginous fish are apex predators at or near the top of their marine food chains; they regulate the populations of species below them and exert significant influence on the distribution and abundance of prey species including invertebrates, fish, cephalopods, and marine mammals (Stevens et al. 2000).

Sharks are distributed throughout the water column at different depths; the hammerhead (Sphyrna spp.) swims in coastal waters while the big mouth shark (Megamouth shark) can swim as deep as 2000 meters. Sharks also inhabit soft bottoms (mud-sand) where they remain buried at depths between 80 and $150 \mathrm{~m}$, as in the case of the angelfish shark (Pacific Angel-shark). Only 5\% of sharks are really oceanic species (Bonfil, 1994).

Most shark species are highly migratory and straddling stocks, and they often are endemic in border regions. For example, the blue shark (Prionace glauca) and the white tip shark (Carcharhinus longimanus) are migratory and travel great distances. However, there are species of shark with limited distributions. The migration of many 
shark species hinders delineation of natural populations (Cortés, 1995; Holden, 1973, 1974, 1977); therefore, it limits our understanding of their population structure and dynamics.

The scientific literature suggests the existence of more than 465 known species of sharks living in our oceans today. According to Herrera et al. (2011), 39 shark species of the 500 reported by Compagno et al. (2005) have been registered in Ecuador. The most common shark families reported in fisheries landings in Ecuador are: Alopiidae ("Thresher Shark" in English), Carcharhinidae ("Requiem Shark" in English), Lamnidae ("Mackerel" or "White Shark" in English), Sphyrnidae ("Sharks Hammers" or "Hammerhead Sharks") and Triakidae ("Houndshark" in English) (Diaz, 2008; Herrera, 2011; Peralta, 2009). These shark species are frequently caught by pelagic long line fisheries, ranging from small-scale artisanal fisheries to modern industrialized fleets that direct their efforts toward tuna and other species.

These vessels employ miles of lines (up to $100 \mathrm{~km}$ ) and baited hooks (up to 2500 per line) which float near the surface with buoys (key informant, personal communication 2011). There are differences in the number and type of hooks that are used on longlines to capture dolphinfish (\# 3 and 4) and tuna (Chinese or Japanese \# 7/0, 8/0, square hook \# 7/0, 8/0 and hook \# 38 and 40) (Herrera, 2008), but most importantly the "dolphinfish hook" is much smaller than the "tuna-billfish-shark hook" (Martinez et al. 2015). 
These incidental catches affect shark populations in Ecuador as well as in other parts of the world's oceans. Estimates state that about $50 \%$ of the volume of worldwide catch (more than 20 million metric tons per year) is bycatch (Alverson, 1994; Bonfil, 1994, 2000). In some countries, fishermen purposefully catch shark for their fins, which have a high commercial value in Asian markets. Therefore, there is growing apprehension worldwide concerning the targeting of sharks and the direct and indirect impacts on prey populations and the functioning of the marine ecosystem (Hazin et al. 1994).

The preferred target species for the artisanal longline fishery in Ecuador are the big pelagic fishes, such as bigeye tuna (Tunnus obesus), swordfish (Xiphias gladius), wahoo (Acanthocybium solandri), and dolphinfish or mahi mahi (Coryphaena hyppurus). Historical fishing data in Ecuador show that these species are present during different seasons. The first season, December through March, peaking in January and February, targets the common dolphinfish (Coryphaena hippurus), while the second season, from May to October, targets mostly tuna (Thunnus spp.) and billfish (Istiophoridae spp.) Largacha et al. 2005; Mug et al. 2008). November and April are considered months of transition for the fisheries When the target species are tuna, weevil and swordfish, the artisanal fishing fleet operates near the continental margin to international waters off northern Ecuador, to beyond two hundred miles off the central area of Ecuador and outside of the 40 miles of the Galapagos Marine Reserve (Figure 1a); whereas when it is dedicated to capture dolphinfish, the fishing is carried out near the continental margin to international waters off southern Ecuador 
(Figure 1b) (Herrera et al. 2011). At the same time, when the target species' abundances are low, the fishers catch a mixture of species, which are much less valuable than the main targets.

In the past, sharks were considered a fish of little commercial value so they did not receive high priority in the collection of fisheries data and only limited research was conducted (FAO, 1995). This situation has changed in the last two decades due to increased demand for products from sharks such as fins, cartilage and meat. The shark fin is one of the most expensive fish products in the world, fetching upwards of US\$400 per kilogram (Clarke, 2004; Vannuccini, 2002). Shark fin production more than doubled between 1984 and 2004, from 40,000 metric tons to 100,000 metric tons. A downturn in the domestic Asian markets in the fourth quarter of 1997 and the first quarter of 1998 did not bring a decrease in metric ton importation of shark fins to Hong Kong, providing evidence of the strength and continuity of the market (Wang, 1999). As the FAO (1995) has pointed out, this growing demand for shark products coupled with their high profitability creates an incentive for capture. This increased demand has not only led to an increase in the levels of commercial captures, but also has generated pressure from environmental organizations to produce research regarding the health of shark populations and aroused international attention for their conservation.

In order to reduce the accidental capture of marine species such as sea turtles in commercial fisheries, NOAA’s National Marine Fisheries Service (NOAA Fisheries) 
has been studying the efficacy of the Circle Hook $(\mathrm{CH})$ as a Bycatch Reduction Device (BRD), and has supported training and outreach efforts in proper baiting and hooking techniques since the mid-1990s. According to the NOAA Fisheries, a circle hook is defined as a hook with the "point turned perpendicularly back to the shank to form a generally circular or oval shape." Conservation-based technologies are particularly attractive and useful to those interested in reducing bycatch.

However, conservation technologies may have unforeseen consequences. For example, the successful cloning of a lamb called Dolly was announced in February by Scottish researchers. It set off a spate of anxious questions. Many of them concerned the ethics of cloning, but another set asked about the unanticipated consequences. If we go down the cloning road, where will it lead? The answer is that we don't know. All of our technological roads twist and turn and we can never see around the bend or through the fog. In the case of fisheries, hooks that were intended to help conservation efforts have led to marine environment degradation (Hannah et al. 1994; Williams, 2002; Zimmerer, 2006; Zimmerer and Young, 1998). New hooks could lead to increase in bycatch of other species. It is therefore important to understand whether hook exchanges will achieve only their intended goals, or generate negative consequences, before promoting their adoption.

This study examines the unintended consequences of technology transfer; specifically, circle hooks in fisheries as a conservation initiative that was intended to curb the accidental capture of sea turtles in Ecuadorian longline fisheries. This initiative 
focused on exchanging the commonly used $\mathrm{j}$-hooks for circle hooks. The circle hooks, according to previous studies, mitigate sea turtle bycatch, although there is debate as to whether this leads to higher catch rates for sharks than $\mathrm{j}$-hooks. For example, Godin et al. (2012) conducted a meta-analysis on shark catch rates using circle hooks, extracting effect sizes and weighted effect sizes against study power, and found that circle hooks did not influence shark catches significantly. However, Serafy et al. (2012) with a literature review on circle hooks concluded that results were mixed and it is possible that circle hooks increased shark bycatch.

This study hypothesizes that the presence of an Ecuadorian shark fishery coupled with a lucrative international shark fin market and with fishing regulations that permit incidental shark catch may create incentives to misuse this technology and target sharks. Therefore, the goal of this analysis is to determine, from the fisher's perspective, to what extent the initiative to promote circle hooks as a turtle conservation tool could lead to unintended consequences if circle hooks are used instead to target sharks. Additionally, this study examines shark landings in the principal fishing ports of Ecuador. By examining shark landings, we might come to understand how shark landings have changed over time, and how this change might be related to different types of hooks and regulations.

\subsection{Shark Landings}

Landing statistics regarding Ecuadorian shark catch are limited. For the years that these statistics are available, sharks are a significant part of the pelagic longline 
fishery. For the years 1991 to 2011, the National Fisheries Institute of Ecuador (INP) reports indicate an irregular trend in the volume of total landings of artisanal fisheries. Similar behavior is recorded for shark landings (Fig. 2).

Shark volumes recorded in the years 1991 to 1998 and 2003 accounted for most values less than $10 \%$ of the total artisanal landings; while from 1999 to 2002, they fluctuated between $11 \%$ and $20 \%$, reaching a peak in 2001 , mainly due to a considerable landing of Prionace glauca (blue shark, also known as "aguado" shark in Ecuador) registered in Manta. However, there was an increase starting in 2005, up until 2012. The greatest number of shark landings occurred between 2008 (6480 t) and 2012 (9386 t). It is notable that in 1999, 2009, and 2010, the data collection of fishing landings is irregular due to poor data collection. The information for these years corresponds only to 7,6 , and 5 months of data collection, respectively, as opposed to the standard collection of data of 12-month period.

By 2007, the Ecuadorian government reported that the shark fishery accounted for 21 percent of landings of large pelagic fish, specifically 4,301 tons (Diaz, 2008). By 2008, shark catch accounted for 29 percent of all pelagic catch by weight. The reported shark catch in 2008 was 6,480 tons, a 150 percent increase from 2007 (Peralta, 2009). The government estimates of shark yields for 2007 and 2008 are 3.1 times higher than those reported by Food and Agriculture Organization (FAO) (FAOSTAT, 2002) (Diaz, 2008; Peralta, 2009). However, by 2010, INP reported the highest percentage of shark landings with 34 percent of the total artisanal pelagic 
fishes from Ecuador. After this year, there was a slight decrease in shark landings: 27 percent in 2011 and 25 percent in 2012 (INP, 2012).

Shark species most commonly landed at the artisanal level at major ports of mainland Ecuador are: Alopias pelagicus, Prionace glauca, Carcharinus spp, Sphyrna spp and Isurus oxyrrinchus. Biological sampling conducted by INP indicates that for several of these species, such as Sphyrna spp, I. oxyrrinchus and P. glauca, female sharks were captured at an immature size as defined by Compagno et al. (2005).

A large percentage of these sharks are landed in the port of Manta. Catch statistics per port indicate that Manta—overall, the largest Ecuadorian port for landings and exports of fishery products-is clearly the most important port in Ecuador for shark landings. Indeed, the fishing boat fleets from San Mateo and Santa Marianita usually land their catches in Manta because of the facilities at this fishing port. Additionally, the fiberglass boats of both towns, San Mateo and Santa Marianita, land their fishing catches in the area known as Tarqui in the city of Manta, which is near to the main fishing port. INP reports indicate that 1,745 metric tons of sharks were landed in Manta in 2006.

Esmeraldas on the northern coast of Ecuador had the next highest volume of shark catch at 166 metric tons (Diaz, 2008). In 2008, Manta reported 5,751 metric tons of pelagic shark catch, with Esmeraldas again recording the second highest reported catch of pelagic sharks at 239 metric tons. Shark catch accounted for 31 percent of all 
large pelagic catch in Manta in 2008 (Peralta, 2009). Part of Manta's high catch rate may be due to the existence of mother ships at port. One key informant explained that in Manta, mother ships go out for 15 to 30 days at a time, returning from every trip with up to 700 sharks (government official key informant with knowledge of Manta's ports, personal communication, January 2011). No clear information is available on the size of the mother ship fleet; however, at least 41 such boats in Manta reported capture of sharks in 2007 (Diaz, 2008). Of this number, 20 to 25 boats are from San Mateo and their fishing targets are sharks (government official key informant, personal communication, December 2015).

Shark catches in other ports, such as Esmeraldas and Santa Rosa, accounted for 12 percent of large pelagic catch in 2008 (Peralta, 2009). The Esmeraldas boats usually fish in southern Colombia or off the coast of the province of Esmeraldas. This fishing area is smaller in comparison to the area used by the fishing boat fleet from Manta that normally goes out to capture sharks in both northern Peruvian $\left(10-12^{\circ} \mathrm{S}\right)$ and international waters next to Ecuador.

\subsection{Shark regulations and fin market}

Historically, sharks were not considered important species to fisheries managers in Ecuador because they were not economically important and very little was known about these species. As data became available, and there were concerns raised about shark species by conservation groups, it became clear that shark populations were declining and conservation measures were needed for many species. Currently, 
Ecuador is a member of several conservation and management initiatives and plans that operate on many levels from international conventions to local laws.

Ecuador is party to or a member of international and regional agreements or arrangements that are of relevance to its shark conservation and management activities. These include the United Nations General Assembly (UNGA), the United Nations Convention on the Law of the Sea (UNCLOS, 1982), the Inter-American Tropical Tuna Commission (IATTC), the Food and Agriculture Organization (FAO) and its Code of Conduct for Responsible Fisheries, the Convention on International Trade in Endangered Species of Wild Fauna and Flora (CITES), among others. All of these organizations have raised the issue of shark conservation and management.

An important step for the conservation and management of this resource was the admittance of Ecuador into the United Nations for Food and Agriculture (FAO) in 1998. In the same year, Ecuador signed "The International Plan of Action for the Conservation and Management of Sharks" and in 2006 Ecuador produced the "National Plan of Action for the Conservation and Management of Sharks" (PAT-Ec). In addition, Ecuador has actively participated in the development and implementation of the "Plan of Action for the Conservation and Management of Sharks, Rays and Chimaeras in the Eastern Pacific Ocean (EPO)" as a member of the Permanent Commission of the South Pacific (CPPS).

Currently, Ecuadorian law (Executive Decree 486 of July 23, 2007) prohibits 
purposeful shark fishing in "continental" regions (i.e. not the Galapagos). In fact, Article 6 of the Decree provides that "Those who during the exercise of fishing, catch sharks, as unique and exclusive product of bycatch, can market and use their meat entirely." This means that fishermen are not allowed to remove the shark fins and to throw their bodies overboard after they have been caught. Fishermen are supposed to bring the whole shark body to the Ecuadorian ports, and once sharks have been recorded by fishing authorities, fishermen can cut off the shark fins to sell them. In addition to this decree, the use of fishing gear to carry out what is known as "longline shark fishing" is banned, as well as fishhooks numbers $1 / 0$ and / or 3/0. The steel or metal cable, known as "huaya" that is used for the capture of dolphinfish, tuna, and other species, is also banned.

These decisions, according to the current Ecuadorian government, allow greater transparency in the market of artisanal fisheries and ensure revenues for fishermen. This Decree is contrary to a previous one signed by former President Lucio Gutiérrez, who had declared a moratorium on shark fishing, prohibiting the sale and export of fins in 2004.

Shark fins are, per pound, the most lucrative portion of the shark fishery. The Food and Agriculture Organization (FAO) claims that shark finning is a $\$ 115$ million industry; however, careful estimates by Clarke (2004) - a leading researcher of the shark fin trade - indicate it is closer to a $\$ 450-\$ 500$ million industry. The shark fin is one of the most expensive fish products in the world, fetching upwards of $\$ 400$ per 
kilogram (Clarke, 2004; Vannuccini, 2002). Fins are primarily used for shark fin soup, a delicacy served at Chinese banquets and weddings, where the presence of such a luxury food indicates the wealth and generosity of the host. In addition, fins are used in medicinal tonics. Both uses date back to the Ming Dynasty (Clarke, 2004).

In Ecuador there are two sources of information relating to exports of shark fin. One source is provided by the Directorate General of Fisheries (DGP) and the other source is from the Central Bank of Ecuador (BCE). The information from these two institutions does not illustrate a clear understanding about the real situation of exports; however, they do not provide evidence of a sustained growth of shark fins exports.

\section{Methods}

\subsection{Study Area}

The fishing grounds of the Ecuadorian artisanal fishery for large pelagic species are located between $05^{\circ} 00^{\prime} \mathrm{N}$ and $15^{\circ} 00^{\prime} \mathrm{S}$, and as far west as the meridian of $100^{\circ} 00^{\prime} \mathrm{W}$ off the Galapagos Islands (Fig 1). According to the Undersecretary of Fishing Resources (Subsecretaria de Recursos Pesqueros), there are a total of 266 artisanal fishing communities located along the coastline of mainland Ecuador (SRP, 2014).

The landing sites used by these artisanal fishing communities vary from highlydeveloped ports such as Manta, to protected coastal embayments/coves (called "caletas"), to fishing settlements which can change in location on a yearly/seasonal basis (Herrera et al. 2013). 
Six fishing communities were identified for this study. Listed from north to south, with the province where they are located, are: Esmeraldas (Esmeraldas), Manta, San Mateo and Santa Marianita (Manabí), Santa Rosa (Santa Elena), and Puerto Bolivar (El Oro) (Fig. 3). These fishing towns were introduced to circle hooks through the promotional efforts of IATTC, WWF, and the Undersecretary of Fisheries (Subsecretaria de Recursos Pesqueros -SRP) due to their extensive use of surface longlines.

A comprehensive literature review was completed in order to account for all shark species, listings and / or registered species in continental coastal waters. The literature available from the National Fisheries Institute of Ecuador (INP) was used for the description of certain aspects of shark bycatch in the mainland, as well as for the description of the landing of pelagic fish species, including shark species. Among the most important information, there are: (i) annual reports on artisanal fisheries from 1991 to 2012, and (ii) the List of Ecuadorian Marine Fishes (Massay and Massay, 1999).

The INP recorded data through monthly fisheries control at the most important artisanal fishing ports. Of the six fishing landings, INP does not take into consideration Santa Marianita because the fishing boats of this community go to Manta for landing. The period of analysis is from 1991 to 2012. Existing data on landings are from between 1991 and 1996, a period during which information on the active fleet in each fishing port was collected, whereas from 1997 onward, data were 
collected by the fleet, according to the type of fishery in each port.

The surveys for the purposes of this study were carried out between February 20, 2011 and June 24, 2011. The sampling method was a combination of both random and snowball sampling. For the simple random method, we choose any fisher that we observed either on the beach, in the fishing port landing, or in the fishing market. Then, we proceeded to interview him, with his permission, and depending of the availability of fishers in the place of interview, we randomly picked up another fisher. In the case of lack of fishers in the place of interview, we use the snowballing sampling method by asking for his assistance to help identify other fishers with a similar trait of interest. We then observed the nominated fisher and continued in the same way until we obtained sufficient number of fishers.

Interviewers were screened and selected from university students from Ecuador. A pre-test exercise was undertaken to familiarize the interviewers with the questionnaires in order to improve their interviewing skills as well as the quality of the questionnaires. Fishers' participation involved their responses to several general questions and statements about diffusion and perception regarding circle hooks. The survey took 20 to 30 minutes minimum and up to about 45 minutes, depending on the fisher.

The questionnaire was composed of three main sections that included socioeconomic profiles, fishing experience and turtles, and perceptions and knowledge of turtle 
issues. The respondents were recruited in public places where people usually gather, such as fish landing sites and markets. In this research, the minimum age of the respondent was restricted to no less than 18 years old. Data was entered into SYSTAT software for analysis and tabulation.

Several key informant interviews were done to collect information for this study. Key informants were people who have firsthand knowledge about fisheries as well as the circle hook device in Ecuador. These interviews are qualitative, in-depth interviews, and in this case, interviewees ranged from fishing authorities, fishing leaders, scientists, to people who work in the agencies involved with the technology transfer.

Analysis of qualitative and quantitative data helps establish the size, prevalence, and presence of a shark fishery, providing a context in which to consider the promotion of circle hooks. This analysis also examines to what extent the use of circle hooks promote more concentrated efforts to capture sharks. Qualitative interviews were analyzed to gain insight into the shark fishery and its existence, the prevalence of circle hooks, and how interviewees perceive circle hooks are used.

Survey questions were selected for analysis along three lines of inquiry: use of circle hooks, catch rate of sharks, and the relationship between circle hooks and shark catch. Significance levels of p-value $<.05$ were used. Semi-structured interviews with key informants and survey data collected from the fishing villages that had participated in promotional efforts provided insight into the perceptions that fishers have regarding 
circle hooks.

\section{Results}

\subsection{Characteristics of users of circle hooks}

In order to learn from the characteristics of circle hooks users, we seek for any relationship between a fisher's education and shark captures, we first examined the distribution $(\%)$ of the use of circle hooks among fishers. The characteristics regarding levels of education in which individual differences among fishers emerge vary greatly. Most of the fishers $(60 \%)$ that were interviewed have attended either primary or elementary school. Only $7 \%$ of them said they had a higher level of education (university).

Then we sought to determine whether the level of education has an influence on whether or not fishers use the circle hooks to catch sharks. Twenty-six percent of fishers who have no education and $21 \%$ of those fishers who attended high school or college responded affirmatively that they would use circle hooks to catch sharks. The highest percentage of fishers who have no education $(74 \%)$ or who attended high school or college $(79 \%)$, said that the principle reason for using circle hooks was to catch other commercial species. However, $67 \%$ of the 9 key informant interviewees indicated that circle hooks were good for catching sharks.

Regarding fishers' first experience using a circle hook $(\mathrm{CH}), 59 \%$ of fishers reported having a positive or very positive first experience, while $42 \%$ of fishers who had not 
used the hook previously reported having a negative or very negative first experience. However, of those who had not used the hook previously, 23\% reported their first experience as being neutral and $35 \%$ reported their first experience as being positive or very positive. These results seem to indicate that having a positive first experience with the hook may not be the only determining factor in why fishers choose to use it.

\subsection{Characteristics of circle hooks regarding shark catches}

At most of the survey sites, fishers report that circle hooks are better for capturing sharks. Among only circle hook users, a larger percentage (78\%) of the Ecuadorian fishers fish for shark (Table 1). In the survey, several open-ended questions and one close-ended question produced some responses that support the perception that circle hooks are good for catching sharks. The survey included questions concerning comparisons between $\mathrm{j}$-hooks and circle hooks, first experience impressions with circle hooks, responses to a question asking for five good things about circle hooks, reasons for adopting circle hooks, and a multiple choice question for using a circle hook where "capturing (more) shark" sometimes appeared as one of the responses. Shark-related responses were more common among circle hook users. As can be seen in Table 4, most of these differences are statistically significant.

Reporting of shark catch differed among provinces (Chi square, $\mathrm{P}<.001$ ). Seventyfour percent of surveyed fishers in Manabí Province (Manta, Santa Marianita, San Mateo) and 73\% in Esmeraldas Province (Esmeraldas) reported shark as catch in the pelagic longline fishery. Fishers in the Santa Elena Province (Santa Rosa), however, 
only reported shark as catch $40 \%$ of the time. And only $13 \%$ of fishers in the El Oro Province (Puerto Bolivar) reported shark as a desired catch. El Oro's lower shark catch percentage may be due to its location within the Gulf of Guayaquil, which is brackish and, therefore, may not be ideal shark habitat. Because the longline artisanal sector is small in El Oro, the field team had difficulties finding informants. According to numerous local fishers, most boats there had switched to gillnetting.

\subsection{Reasons for using circle hooks}

Fishers' age and number of years fishing do not differ between circle hook users and non-users, but users tend to take longer fishing trips and use longer vessels. The main reason for users to take these long trips could be to catch large pelagic fishes (e.g. tuna). Variables such as age, years fishing, boat length, line length and number of hooks in fishing boats are statistically significant for the capture of sharks (Table 2).

As for the shark bycatch in fishing operations, fishers from all study areas have mentioned the presence of sharks as bycatch. However, the highest percentage of affirmative responses for the presence of shark bycatch corresponds to fishers from

San Mateo (95\%), followed by fishers from Esmeraldas (90\%), Manta (86\%), and Santa Marianita (80\%). The lowest percentages correspond to the towns of Santa Rosa (49\%) and Puerto Bolivar (11\%). $77 \%$ of captains, $69 \%$ of deckhands, and $66 \%$ of owners have mentioned the presence of sharks in their catch composition ( $\mathrm{p}$-Value $=.000)$ 
Twenty five percent of the interviewees who do not use circle hooks reported not capture sharks, while $75 \%$ reported capture sharks. This $75 \%$ of interviewees who do not use circle hooks to capture sharks is slightly lower compared to $79 \%$ of interviewees who do use circle hooks and report capturing sharks. Later on, interviewees that use circle hooks were asked why they use this device. Eight-six percent of them mentioned that the circle hook is good to protect sea turtles from dying and for the conservation of the species while $63 \%$ said that they catch more sharks with it.

In addition, interviewees were asked if the value of the bycatch increased, remained the same or decreased when they used circle hooks. Of the respondents who use circle hooks to conserve sea turtles, $48 \%$ reported that their bycatch value remained the same while another $48 \%$ indicated it had increased. For those respondents who used the circle hooks to capture more sharks, $52 \%$ reported the bycatch value remained the same while $30 \%$ indicated it had increased. Fishermen usually sell bycatch to middlemen because they need money to recover the money they spent on gasoline or other items regarding fishing.

\subsection{Shark landings}

The number of sharks that were landed in the fishing towns of this study in 2011 is in table 3. These shark landings were caught by the wooden and fiberglass boats that are part of the artisanal longline fishery. In this table we can see that the highest landing of sharks corresponds to the port of Manta (7227metric tons). This high number of 
sharks landing could be related to the sum of the local fishing boats from Manta plus those boats that come from San Mateo and Santa Marianita to disembark their product in Manta. It is important to mention that the largest landing of sharks, as is seen in this table, is associated with large pelagic fish species (tuna, billfishes, and swordfish) and with the coarse surface longlines. Catch rates of the target species in the tuna fishery are quite similar for circle hooks and $\mathrm{J}$ hooks. Based on target catch rates and reduced sea turtle interaction rates, fishers preferred the 16/0 circle hook.

\section{Discussion}

The circle hook was promoted in Ecuador as a conservation technology to protect sea turtles. The promotional efforts demonstrated the benefit of a circle hook as a conservation tool (Gaibor et al. 2016). In fact, a significant number of respondents in the study by Gaibor et al. (2016) indicated that circle hook use is important for the conservation of turtles. However, the results of this study confirm the hypothesis that the fishers were just as likely to value circle hooks to catch more sharks as they were to value circle hooks for the conservation of turtles. Indeed $78 \%$ of interviewees responded that they fish for sharks and $16 \%$ of them valued the circle hook for its ability to capture sharks. These same respondents were significantly more likely to use circle hooks rather than J-hooks to capture sharks (Table 4). This indicates that a subset of the population is motivated to use circle hooks to capture more sharks.

Despite the adoption rate of circle hooks being low, there still remains a prominent shark fishery in Ecuador. The highest percentage of affirmative responses for the presence of shark bycatch registered in this study indicates that the fishers from San 
Mateo catch more sharks (95\%) than the fishers from the other studied towns. Fishers from Santa Marianita, who received a more intense extension program regarding the promotion of circle hooks, also reported a high presence of shark bycatch $(80 \%)$ (Table 7). Notably, San Mateo and Santa Marianita land their catches in the port of Manta and not in their own towns. Therefore, Manta has a large fleet of boats, including fiberglass boats to catch large pelagic fish, and there are no records of sharks landing in the other two fishing towns.

The fact that sharks constitute a high percentage of the catch in the pelagic longline fishery, in addition to the high shark-catch numbers reported by survey informants, indicates that the catch is not strictly incidental, as officials suggest. Therefore, if sharks are not incidentally caught, it is possible that the shark catch is consumed in Ecuador. If we accept the premise that shark catch in Ecuador is meant for local food consumption, and if we consider that a total of 10,483 metric tons of marine fish were consumed in Ecuador in 2007 (FAOSTAT, Consumption of Fish and Fishery products), then $41 \%$ of marine fish consumed in Ecuador would have to have been shark in 2007 (4,301 metric tons of shark landings were reported in 2007 \{Diaz, $2008\})$.

Research suggests that such a high rate of local consumption of shark is unlikely. Francisco-Fabian (2001), and Revelo and Guzmán (1997), report that shark meat does not sell well on the coast because it is of poor quality and tends to spoil quickly. It is often mislabeled as marlin, sea bass, or flounder. One non-government key informant 
who is an expert on Ecuadorian fisheries noted that "Shark is consumed a lot here (in Ecuador) and it is sold as corvina (weakfish from Quito)" (key informant, personal communication, February 2011). In addition, we noticed that shark was apparently not consumed with any regularity on the coast despite high rates of capture, particularly in Manta. Furthermore, it seems unlikely that the amount consumed in Ecuador is the same as the amount of sharks landed. Therefore, much of the shark landings might be done for the object of shark finning for sale to the Asian market. The lucrative trade in shark fins and the established shark fishery in Ecuador provides an incentive to use the circle hook to target sharks. A non-government key informant who is an expert on Ecuadorian fisheries raises the simple question: "And why does [capture of sharks] happen? Because someone pays money for them." (key informant, personal communication, February 2011).

Shark fins bring in at minimum $\$ 20 / \mathrm{kg}$ (Francisco-Fabian, 2001). Numerous fishers told the field team that each set of fins could bring in $\$ 35-\$ 45$. Essentially, one set of fins is the equivalent of a fisher's salary on a good day. WildAid, a nonprofit organization intent on eradicating illegal marine fisheries, claims that shark fins from Ecuador are commonly smuggled into Peru labeled as plastic sheeting, then sold into the international markets (Watts, 2000).

The Ecuadorian law is clear that shark capture is only allowed to be incidental; therefore the existence of a targeted commercial fishery would be illegal. However, the existences of a shark fin industry, whether fins are separated from the shark at sea 
or at port, is a sensitive subject in Ecuador. On the one hand, government officials and fishers are reluctant to discuss the issue at all. On the other hand, some researchers claim "shark stocks can be harvested sustainably and, if carefully managed, can provide very stable fisheries" (Walker, 2005). The question in Ecuador is not whether a shark fishery can be sustainable but whether this fishery can be successfully managed.

Shark bycatch occurs in almost all activities of the Ecuadorian artisanal and industrial fleets, to a lesser or greater degree, depending upon the gear used in fishing operations. Solis and Mendívez (1999) reported that there are about 15,494 artisanal vessels in Ecuador which include canoes, wooden and fiberglass boats distributed throughout the provinces of Esmeraldas, Manabí, Santa Elena, Guayas, and El Oro. However, interviews with leaders of the National Federation Fishermen Cooperative (FENACOPEC) and observations at the main landing ports lead us to believe that the number of artisanal vessels has increased and that their quality has improved (e.g., use of fiberglass materials) during recent years.

Sharks are a significant enough portion of the longline pelagic fishery to constitute inclusion with tuna and billfish, two important species in Ecuador (Largacha, 2005; Mug, 2008). The artisanal landing records from 1991 to 2006 include sixteen shark species, as identified by the National Fisheries Institute. These species are grouped into seven families: Alopiidae, Pseudocarchariinidae, Carcharhinidae, Sphyrnidae, Laminidae, Triakidae and Squatinidae (Appendix 1). The quantitative data from the 
surveys confirm the INP data as well as key informants' observations. Captains, deckhands, and owners were each asked to identify target species with the open-ended question: What do you fish for? These groups recognized 50 different species as desired catch. Of those 50 species, 14 were sharks (28\%). For analysis, all species listed as desired catch were divided into two categories: shark catch and non-shark catch (See Appendix for a list of commonly caught sharks in Ecuadorian waters).

Of the nine key informants interviewed in Ecuador, two-thirds recognized the shark as an important and distinct portion of the Ecuadorian pelagic longline fishery catch. These six key informants considered the shark a significant enough segment of the longline fishery to nominate it as a catch. Two of the three key informants who did not recognize the shark as a part of the Ecuadorian longline fishery were technicians. The questions that they answered were primarily focused on promotional efforts regarding circle hooks. Although key informants consistently recognize shark as a catch, this recognition does not provide insight into the state of the fishery. One of our key informants, a government biologist from Ecuador, echoed this statement: "Fishers target bigger species like albacore, marlins, and different sharks like la rabona, tiger, and thresher from mid-March to December" (personal communication, February 2011). Another key informant - a nongovernmental expert in Ecuadorian fisheriesmade the following observation about the status of shark fisheries: "...shark fishing has increased over the years. I don't know about incidental catch. Some fishers bring in ten sharks and one dorado (common dolphinfish). If they are not catching dorado 
they will definitely catch something else. At some point there won't be any sharks and they will start fishing rays" (key informant, personal communication, February 2011).

Depending on the nine key informants, the capture of shark is described as either incidental or intentional. Key Ecuadorian government informants with ties to the agency responsible for regulation of fisheries characterized the shark bycatch as incidental and used primarily for sustenance: "These boats use lines with 300 to 400 hooks. So out of 300 hooks seven are shark. That doesn't seem to be a targeted species. Your answer is very clear. They are incidental." (January, 2011). The fact that sharks constitute such a high percentage of the catch in the pelagic longline fishery, in addition to the high shark-catch numbers reported by survey informants, indicate that the catch is not strictly incidental, as officials suggest.

As Gaibor et al. (2016) mentioned, circle hooks may provide some benefits in reducing sea turtle mortality in the artisanal longline fisheries of Ecuador. Assuming this reduced mortality also leads to increased post-release survival, the use of circle hooks could very well prove beneficial for shark conservation in well-regulated fisheries. However, despite the perceptions of some fishers as well as of key informants, it remains unclear whether circle hook use increases the bycatch of sharks overall, an outcome that would have the undesired effect of increasing shark mortality in the mostly unregulated (as far as shark bycatch is concerned) global pelagic longline fisheries (Kaplan et al. 2007). 


\section{Conclusions}

There is no easy solution to the current shark catch situation in Ecuador. Arguably, the shark issue has been politicized in Ecuador. President Correa has given much support to the requests of artisanal fishers, and they have benefited in several respects. His decisions have helped the artisanal fisheries sector to improve their living conditions. However, according to statistics from research (INP) and control (SRP) institutions, a considerable increase in the catch of shark species is reported under "incidental captures." Therefore, any ban on shark bycatch could cause the artisanal fishing sector to react against any regulations.

In this sense, the Ecuadorian government and the agencies that were involved in the promotion of circle hooks (and any future regulatory agencies) are in the unenviable position of trying to decide whether or not to continue promoting a hook that may save sea turtles but at the same time may put sharks at risk. Before any agency extends further promotional efforts for the circle hook program or any other bycatch reduction device, the cultural values of the fishers and their communities must be understood. Research on the human dimensions of sharks, the industries that exploit them and the human communities that depend on them are critical for the success of conservation management (Campbell and Cornwell, 2008).

While the survey results indicated that sharks were a target species, regardless of hook used, it does not reveal the quantity of sharks caught. It is possible that circle hook users target sharks and bring more sharks to shore than $\mathrm{j}$-hook users. Observers on 
board boats that use circle hooks and on board boats that use j-hooks would help managers understand whether the circle hook is leading to more sharks being caught.

The growing demand for shark products, coupled with their high profitability, creates an incentive for capture. First, promoting a hook that leads to increased shark catch can create unintended consequences for the marine ecosystem. It is therefore important to understand if hook exchanges are desirable before promoting them and distributing them. Second, organizations should investigate the effect of a shark fishery on the Ecuadorian ecosystem. More systematic studies on the status of shark populations and the role sharks play in the regional marine ecosystem could provide important information; currently few such studies exist. It is possible that an increased shark catch is an acceptable outcome of policies that reduce turtle bycatch. Third, organizations should develop policy alternatives that seek to conserve both sea turtles and the sharks. Such policy alternatives must consider whether there is, in fact, a targeted shark fishery. Depending on whether the shark fishery is incidental or targeted the types of effective policy for management change drastically.

If the shark fishery is primarily incidental, with a insignificant number of fishers targeting sharks, Ecuador could employ policies and activities similar to those to reduce the incidental capture of sea turtles in commercial fisheries. These shark bycatch reduction methods include a shift in setting depth, the use of weak hooks, eliminating lightsticks, and developing artificial bait. Setting lines deeper than 100 meters and switching to full fish bait has also been shown to reduce sea turtle bycatch 
by 55-90\% (Gilman, 2011). But switching to fish bait can increase operational costs, in comparison to using squid bait (Gilman et al. 2007), thereby discouraging fisher participation and in turn making it difficult to monitor policies that seek to implement changes in line depth. Fisher participation would be required for success in both initiatives (Gilman, 2011).

If, as the research suggests, Ecuador does have a targeted shark fishery, then the previously mentioned policy efforts would be ineffective. Such policy assumes that the shark is bycatch and, therefore, a reduction in this bycatch would be a desirable outcome of gear and fishing behavior modification (Gilman, 2012). In a targeted shark fishery, such measures are unlikely to interest fishers. In such a case, policy would be better directed at finding ways to create a sustainable shark fishery. Understanding the motivation for shark capture would allow for more direct management. For example, if fins are the primary motivation for shark capture, and finning is the predominant practice, then the establishment of ratio-based capture rates could be effective. Ratiobased rates of capture make it illegal to have more than a 5 percent fin-to-carcass ratio on board at all times (Clarke, 2006). Such a policy could limit the number of sharks that are finned and left to die at sea. Its effectiveness is dependent on fining being a prominent practice. If the occurrence of finning is not significant, other policy alternatives must be considered, even if the motivation for shark capture arises from the sale of fins.

More traditional management methods, such as the establishment of quotas or size 
limits, could be better suited to manage the stock in a sustainable manner. Quotas or size limits are easier to enforce than policy on gear modification for bycatch reduction (Gilman, 2011). However, this regulation could result in finning at sea.

Creating policy that permits a targeted shark fishery would allow circle hook promotional efforts to continue. Even though the circle hooks could promote an increase in shark capture, that increase could be mitigated by policy designed to create a sustainable catch. In any case, any policy in Ecuador that seeks to reduce shark capture must consider fisher participation, political feasibility, conservation goals, enforceability, and social equity. Without fisher participation, managers would experience difficulty monitoring and controlling fisheries and meaningful policy measures would likely fail (Gilman, 2011). The short-lived ban on shark fin exports in 2004 highlights the need for politically feasible solutions. Achieving conservation goals through policy requires the consideration of multiple species groups (at a minimum sharks and sea turtles) and Ecuador-specific solutions (Gilman, 2011).

Recent history in Ecuador can provide contextual clues to what portion of the shark fishery provides economic incentives for catching shark. The Decree discussed in the regulation section, which describes sharks as bycatch and which requires bringing whole shark bodies to fishing landings where fins can be removed and sold, is incongruent with conservation because it leaves a space for catching shark as bycatch. This is particularly interesting given the admission by fishermen that circle hooks catch more sharks. 
Part of the incentive for participation in a shark fin industry stems from the high profit on fins. A key informant IATTC biologist said: "The thing is, you have to understand this is an artisanal fishery and the average fisherman makes 30 or 40 dollars a day on a good trip. That's apart from the fish he takes home..." (December 2010).

The results provided by this study, as well as the statistics from research institutions, indicate a tendency toward the growth of shark landings from artisanal fisheries in the Ecuadorian mainland. The largest shark landings have been recorded in Manta and Esmeraldas. This is because of the types of fisheries catching dolphinfish in one season, and tuna, swordfish and weevil on the other, and also the size of the existing fleet in each of these fishing ports.

Statistics presented in this study showing an increase in shark landings since 2006 could be linked to the presidential decree. Additionally, a shortage of fishing resources, especially large pelagic fish such as tuna and weevil, suggests that the fishers may have redirected their efforts to shark species to cover costs generated by fishing operations, especially in regard to the fleets from Santa Marianita, San Mateo and Manta. This increase in shark landings could be linked to the use of circle hooks, which has been promoted for conservation purposes in Ecuador since 2003. Results from this study point out that fishers found that circle hooks are strong enough to capture sharks in the long line fisheries. Given the legal allowable amount of bycatch, 
the fact that circle hooks generate more shark bycatch and the high profitability of the shark market, a targeted shark fishery may have developed in Ecuador.

\section{Acknowledgements}

Financial support for this study was provided by the Intact project. Thanks are due to the National Fisheries Institute of Ecuador who provided technical and logistical support for the study, and to all surveyors (Michael Vina, Nancy Benitez-Vina, Monica Fabara, Lorena Monserrate, Omar Alvarado and Christina Jines) for field assistance.

\section{References}

Alverson, D.L., 1994. in Indiscriminate Slaughter at Sea. http://www.audubon.org/campaign/lo/ow/iss.html. (accessed 07.15.15)

Bonfil, R., 1994. Overview of the world elasmobranch fisheries. FAO Fisheries Technical Paper, No. 341, Rome.

Bonfil, R., 2000. The problem of incidental catches of sharks and rays, its likely consequences and some possible solutions, in: Watts, S (Ed.), The End of the Line? Global threats to sharks. Wild Aid. Brothers,

Campbell, L.M., Cornwell, M.L., 2008. Human dimensions of bycatch reduction technology: Current assumptions and directions for future research. Endang. Species Res. 5, 325-334.

Compagno, L., Dando, M., Fowler, S., 2005. Sharks of the World. Princeton Field Guides,Princeton University Press, New Jersey.

Cortés, E., 1995. Demographic analysis of the Atlantic sharpnose shark, Rhozoprionodon terraenovae in the Gulf of Mexico. Fish. Bull. 93, 57-66 p.

Diaz, M., 2008. Desembarques Artesenales De Tiburones Y Rayas En Los Principales Puertos Pesqueros Del Ecuador Durante 2007. Rep. Guayaquil, Ecuador: Instituto Nacional De Pesca.

FAO. 1995. Shark utilization, marketing and trade. FAO Fisheries Technical Paper.

FAOSTAT. http://faostat.fao.org/site/610/default.aspx\#ancor (accessed 13.06.12) 
Gaibor, N., R. Pollnac, M. Vina, K. Castro. 2016. Fishers' perception on concerning the adoption and promotion of circle hooks as a bycatch reduction device to protect sea turtles. Unpublished doctoral dissertation, University of Rhode Island. USA.

Gilman, E., Kobayashi, D., Swenarton, T., Brothers, N., Dalzell, P., Kinan-Kelly, I., 2007. Reducing sea turtle interactions in the Hawaii-based longline Swordfish Fishery. Biol. Conserv. 139, 19-28.

Gilman, E., Clarke, S., Brothers, N., Alfaro-Shigueto, J., Mandelman, J., Mangle, J., Peterson, S., Piovano, S., Thomson, N., Dalzell, P., Donoso, M., Goren, M., Werner, T., 2008. Shark interactions in pelagic longline fisheries. Mar. Policy. 32, 1-18.

Gilman, E.L., 2011.Bycatch governance and best practice mitigation technology in global tuna fisheries. Mar. Policy 35, 590-609.

Gilman, E., Chaloupka, M., Read, A., Dalzell, P., Holetschek, J., Curtice, C., 2012. Hawaii longline tuna fishery temporal trends in standardized catch rates and length distributions and effects on pelagic and seamount ecosystems. Aquat. Conserv. 22, 446-488.

Godin, A.C., Carlson, J.K., Burgener, V., 2012. The effect of circle hooks on shark catchability and at-vessel mortality rates in longlines fisheries. Bulletin of Marine Science. 88, 469-483.

Grove, J. S., Lavenberg, R. J., 1997. The Fishes of the Galápagos Islands. Stanford University Press, Stanford, California.

Hannah, L, Lohse, D., Hutchinson, C., Carr, J.L., Lankerani, A., 1994. A preliminary inventory of human disturbance of world ecosystems. AMBIO. 23, 246-50.

Hazin, F.H.V., Boeckman, C.E., Leal, R.P., Kihara, K., Otsuka, K., 1994. Distribution and relative abundance of the blue shark, Prionace glauca, in the southwestern equatorial Atlantic Ocean. Fish. Bull. 92, 474-480

Herdson, D., Rodríguez, T., Martinez, J., 1985. Las pesquerías artesanales de la costa del Ecuador y su captura en el año 1982. Boletín Científico y Técnico, vol. 8.

Herrera, M., Coello, D., Cajas J., 2011. Desembarques de Elasmobranquios en las Pesquerías Artesanales del Ecuador durante el 2011. Instituto Nacional de Pesca.

Holden, M.J., 1973. Are long-term sustainable fisheries for elasmobranches possible? Rapp. P. -V Cons. Int. Explor. Mer. 164, 360-367.

Holden, M.J., 1974. Problems with the rational exploitation of elasmobranches populations and some suggested solutions, in: Harden Jones, F.R. (Ed.), Sea Fisheries Research. Elek Science, London, pp. 117-137. 
Holden, M.J., 1977. Elasmobranches, in: Gulland, J.A. (Ed.), Fish population dynamics. John Wiley, London, pp. 187-215.

Kaplan, I.C., Cox, S.P., Kitchell, J.F., 2007. Circle hooks for Pacific longliners: Not a panacea for marlin and shark bycatch, but part of the solution. T. Am. Fish. Soc. 136, $392-401$.

Largacha, E., Parrales, M., Rendon, L., Velásquez, V., Orozco, M., Hall, M., 2005. Working with the Ecuadorian fishing community to reduce the mortality of Sea Turtles in longline fisheries: Year One, March 2004 to March 2005. Rep. Western Pacific Regional Fishery Management Council.

Martinez-Ortiz, J., Aires-da-Silva, A., Lennet-Cody, C., Maunder, M., 2015. The Ecuadorian artisanal fishery for large pelagics: Species composition and spatiotemporal dynamics. DOI: 10.1371/journal.pone.0135136. 27 agosto 205.

Massay, S., Massay, J., 1999. Revisión de la lista de peces marinos del Ecuador. Boletín Científico y Técnico. Instituto Nacional de Pesca. Guayaquil-Ecuador, vol. 17.

Mug, M., Hall, M., Vogel, N., 2008. Bycatch Initiative: Eastern Pacific Programme A vehicle towards sustainable fisheries progress report of fishing experiments with modified gear (2004-2007). Rep. World Wildlife Fund, Inter-American Tropical Tuna Commission, 2008.

NOAA. 2012. Partners with fishery organizations, academia, and private industry to develop new technologies that save sea turtles. NOAA Magazine Online (Story 144). NOAA. Web. (accessed 10.04.12)

Solís-Coello, P., Mendívez, W., 1999. Puertos pesqueros artesanales de la costa continental ecuatoriana. Programa de Cooperación Técnica para la Pesca Unión Europea-VECEP ALA92/43, Instituto Nacional de Pesca, Guayaquil.

Stevens, J.D., Bonfil, R., Dulvy, N.K., Walker, P.A., 2000. The effects of fishing on sharks, rays and chimaeras (chondrichthyans), and the implications for marine ecosystems. ICES J. Mar. Sci. 57, 476-494.

Peralta, M. 2009. Desembarques de la pesca artesanal de Peces Pelágicos Grandes y Tiburones en la costa ecuatoriana durante 2008. Informe Técnico. Instituto Nacional de Pesca, Guayaquil.

Presidencia de la República del Ecuador. 2007. Decreto № 486 Expedir las normas para la regulación de la pesca incidental del recurso tiburón. AC25 Doc. 17 Annex 2. Ecuador (Rev. 1) - p. 1 
Revelo, W., Guzmán, M.Z., 1997. La pesca artesanal en Santa Rosa de Salinas Provincia del Guayas. La Organización de las Naciones Unidas para la Agricultura y la Alimentación, Guayaquil.

Serafy, J.E., Cooke, S.J., Diaz, G.A., Graves, J.E., Hall, M., Shivji, M., Swimmer, Y., 2012. Circle hooks in commercial, recreational, and artisanal fisheries: Research status and needs for improved conservation and management. B. Mar. Sci. 88, 371-391.

Stevens, J.D., Bonfil, R., Dulvy, N.K., Walker, P.A. 2000. The effects of fishing on sharks, rays, and chimaeras (Chondrichthyans), and the implications for marine ecosystems. ICES J.Mar.Sci. 57:476-494 p.

Vannuccini, S., 2002. Shark utilization, marketing and trade. Rep. no. 389. Food and Agriculture Organization, Fisheries.

Walker, T.I., Hudson, R.J., Gason, A.S., 2005. Catch evaluation of target, by-product and by-catch species taken by gillnets and longlines in the shark fishery of Southeastern Australia. J. Northwest Atlantic Fish. Sci., 35, 505-530.

Watts, S., 2000. The End of the Line? Global threats to sharks. WildAid. pp 61.

Williams, M.J., 2002. Technology, knowledge systems, population dynamics, and coastal ecosystems. AMBIO. 31, 337-39.

Zimmerer, K.S., Young K.R., 1998. Nature's geography: New lessons for Conservation in developing countries. Madison, Wis.: University of Wisconsin.

Zimmerer, K.S., 2006. Cultural ecology: At the interface with political ecology - the new geographies of environmental conservation and globalization. Prog. Hum. Geog. $30,63-78$. 


\section{TABLES}

Table 2.1. Percent distribution of fishers' responses to questions among users of circle hooks regarding sharks.

\begin{tabular}{lcccccc}
\hline \multicolumn{1}{c}{ Variables } & $\%$ & $\chi^{2}$ & df & Phi & Total N & P \\
& & & & & & \\
\hline $\begin{array}{l}\text { Reason for Using } \\
\text { Circle Hook (Shark) }\end{array}$ & 77.778 & 10.933 & 1 & 0.20 & 281 & 0.001 \\
\hline $\begin{array}{l}\text { Better for Shark than } \\
\text { J-Hook }\end{array}$ & 15.873 & $17.489^{*}$ & 1 & 0.27 & 281 & $<0.001$ \\
$\begin{array}{l}\text { First Experience, } \\
\text { Catch More Shark }\end{array}$ & 1.587 & $0.008^{*}$ & 1 & 0.06 & 281 & $>0.05$ \\
\hline $\begin{array}{l}\text { Catch More Shark } \\
1 \text { of 5 Good Things }\end{array}$ & 6.349 & $4.546^{*}$ & 1 & 0.16 & 281 & 0.033 \\
\hline $\begin{array}{l}\text { Better for Shark so } \\
\text { Changed to Circle } \\
\text { Hook }\end{array}$ & 2.857 & $0.014^{*}$ & 1 & 0.08 & 162 & $>0.05$ \\
\hline
\end{tabular}


Table 2.2.Pooled Variance among variables (e.g. age, years fishing, boat length, line length, and number of hooks) and Capture of sharks

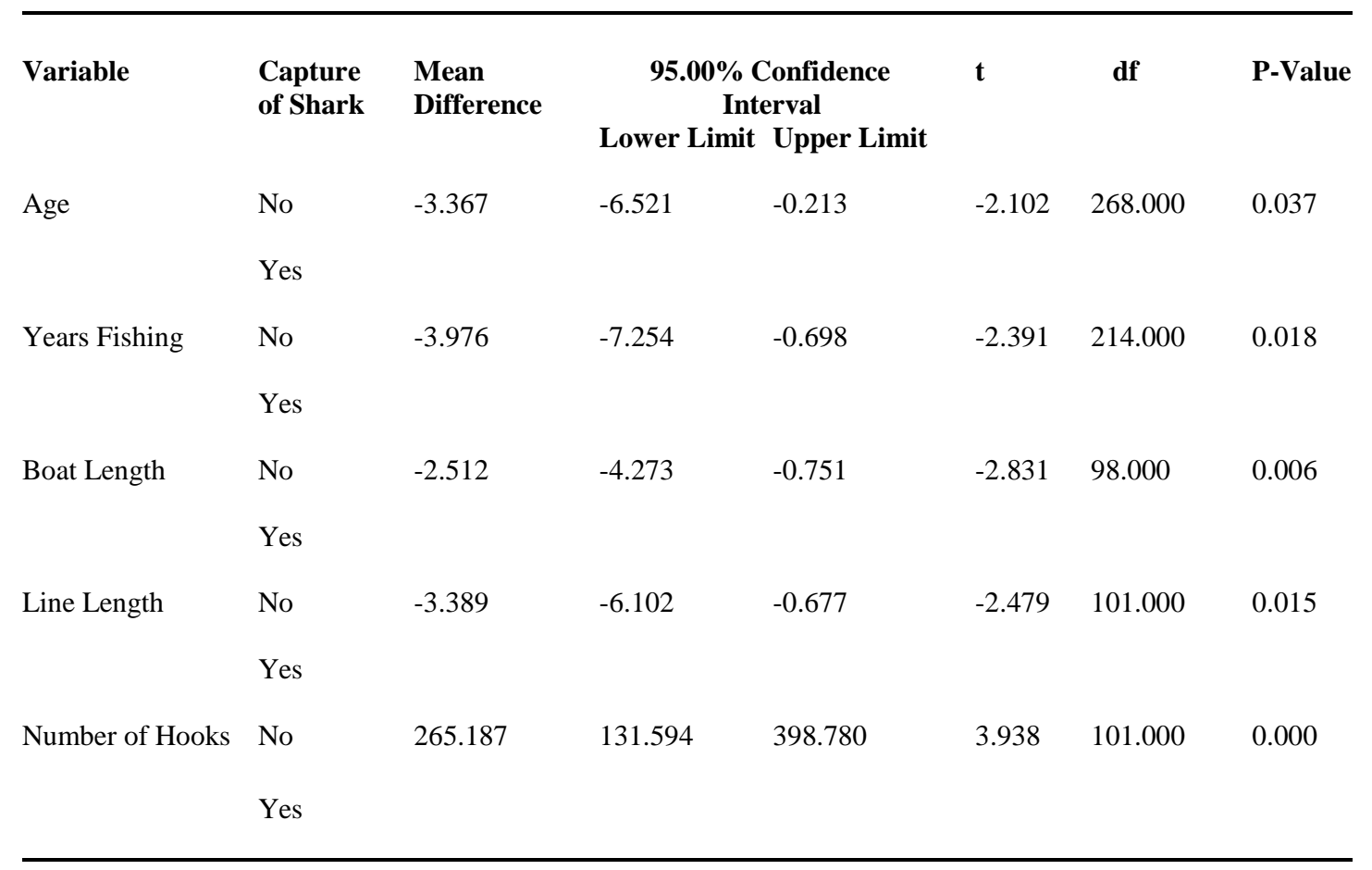


Table 2.3. Annual disembark (t) of sharks per fishing port, per fishing target, per type of boat and fishing gear during 2011.

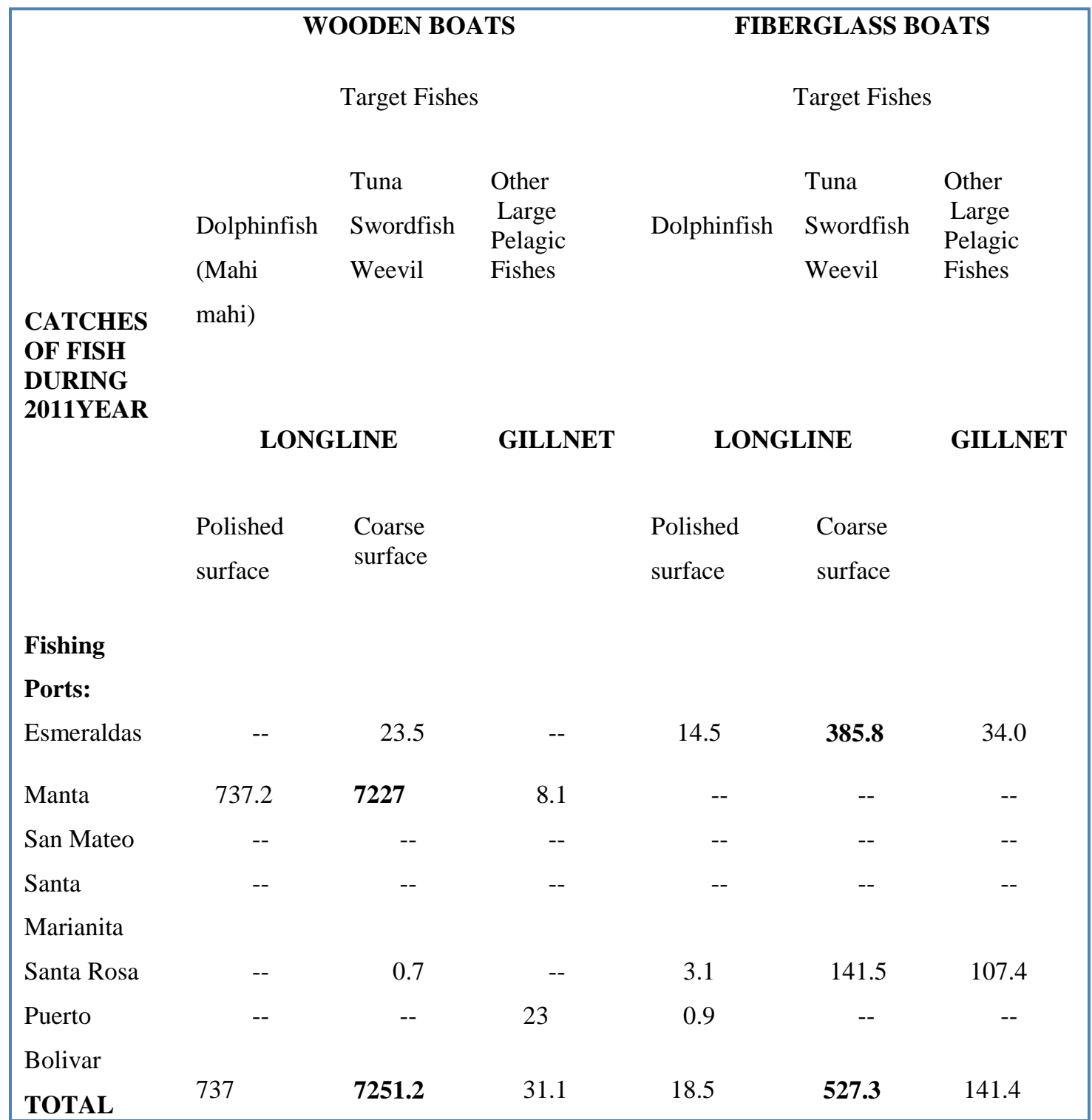

-- No catches were recorded

Note: Data collected by the National Fisheries Institute was used to analyze the number of shark landing and its association in the artisanal longline fishery. 


\section{FIGURE LEGENDS}

Figure 1. Shark fishing's areas by the target fishing resource of the artisanal fishing fleet. Figure 1a shows the distribution area of the fishery fleet that capture tuna-weevil and swordfish species, while figure $1 \mathrm{~b}$ shows the distribution area of the fishery fleet that capture dolphinfish.

Figure. 2. Total annual landings ( $\mathrm{t}$ ) of pelagic fishes and shark species

Figure. 3. Fishing Site Areas where this study was conducted: Esmeraldas is economically important for the northern part of Ecuador; Manta is the main fishing port along the coastal Ecuador; San Mateo is a fishing village located on a cliff overlooking the sea 7.5 miles from Manta; Santa Marianita, a small artisanal fishing village about $20 \mathrm{~km}$ south of Manta, and; Santa Rosa, located in the Peninsula Santa Elena (Province of Santa Elena) is one of the most important artisanal fishing ports of Ecuador 


\section{FIGURES}
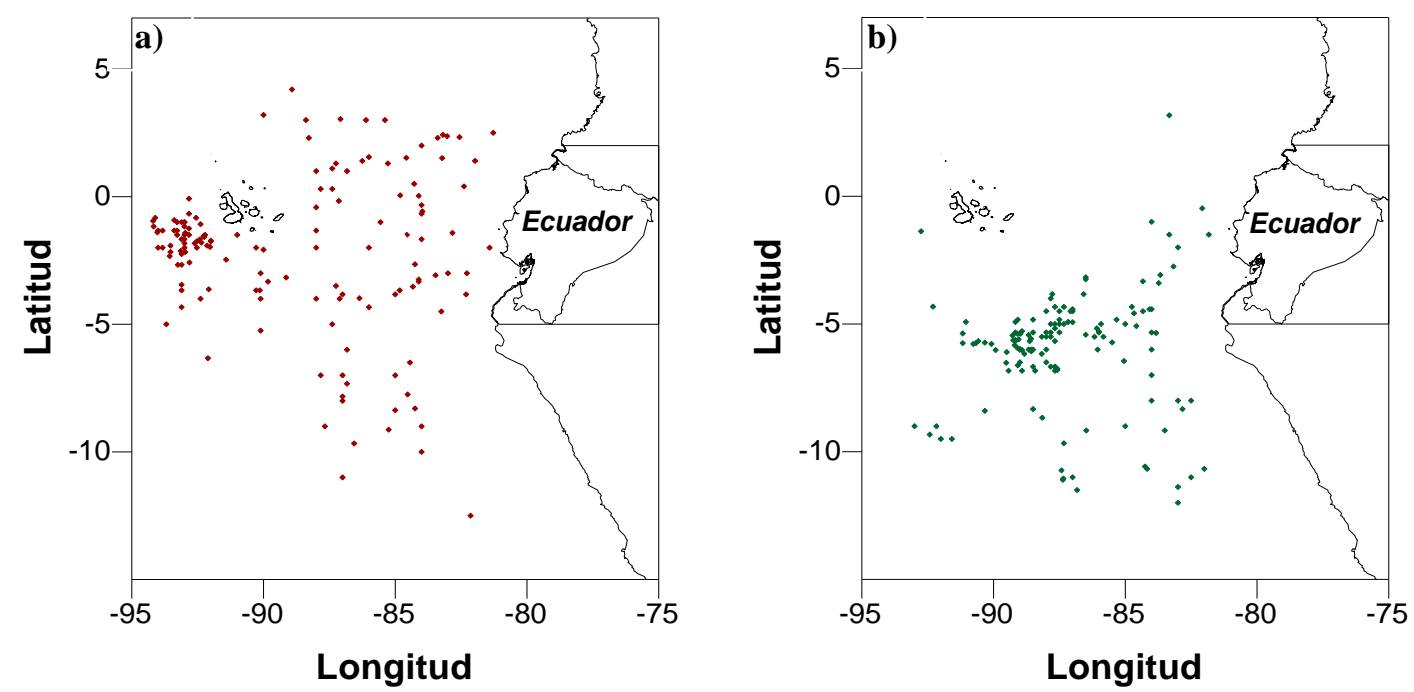

Figure 9: 1-II Shark fishing's areas by the target fishing resource of the artisanal fishing fleet. Figure 1a shows the distribution area of the fishery fleet that capture tuna-weevil, and swordfish species, while figure $1 \mathrm{~b}$ shows the distribution area of the fishery fleet that capture dolphinfish. 


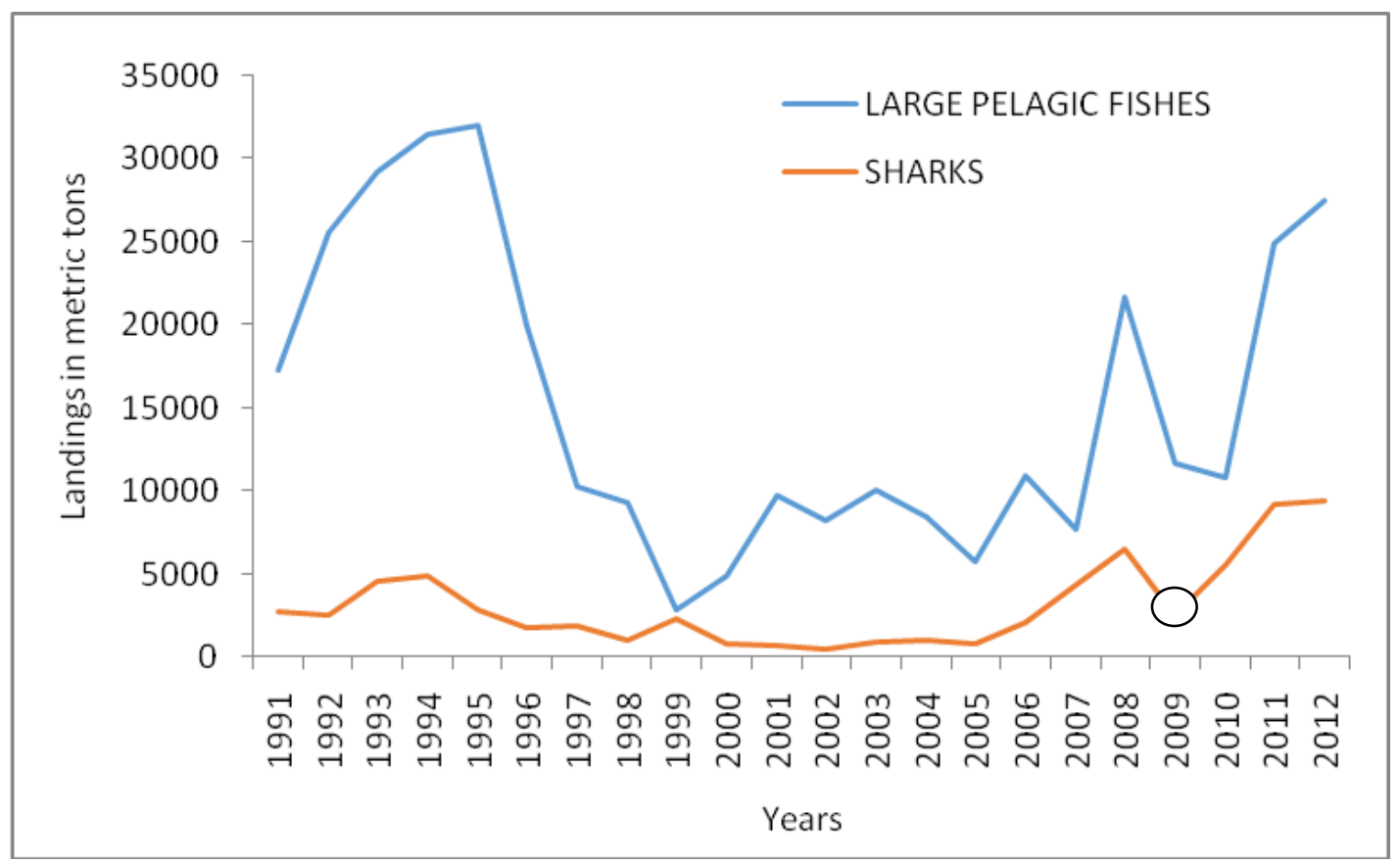

Figure 10: 2-II. Total annual landings (t) of pelagic fishes and shark species. The catch of sharks tends to trend with catch of large pelagic which suggests bycatch. Large pelagic catches increased at higher rate than sharks in last two decades. The blank circle means lack of data by the National Fisheries Institute due to lack of budget.

Lack of data

Source: INP, 2012 


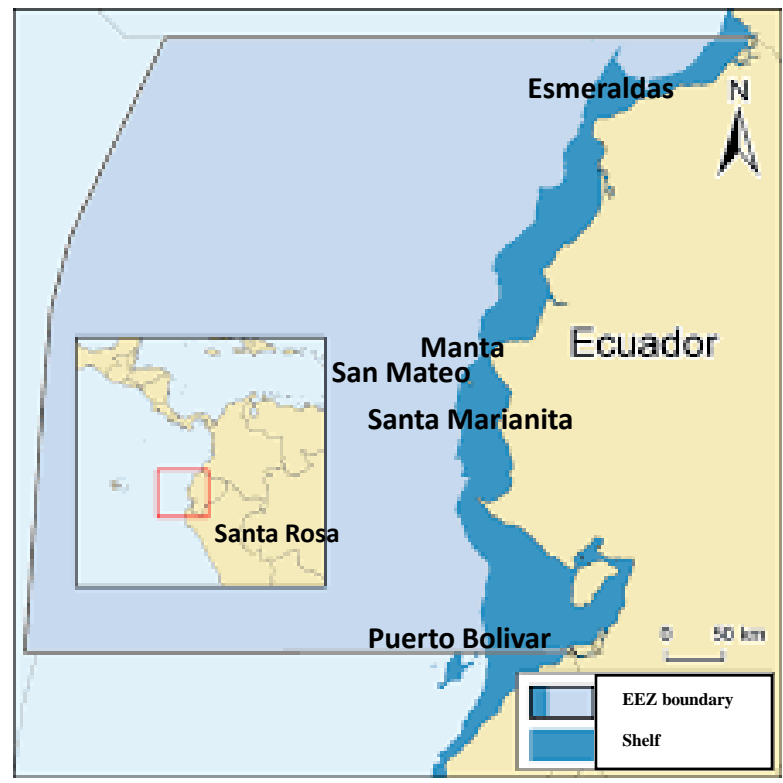

Source: INP 2007. Adapted by Gaibor 2015

Figure 11: 3-II. Fishing Site Areas where this study was conducted: Esmeraldas located in the Esmeraldas province is economically important for the northern part of Ecuador. Manta is the main fishing port along the coastal Ecuador; San Mateo is a fishing village located on a cliff overlooking the sea 7.5 miles from Manta, and Santa Marianita, a small artisanal fishing village about $20 \mathrm{~km}$ south of Manta belong to the province of Manabí. Santa Rosa, located in the Peninsula Santa Elena (Province of Santa Elena) is one of the most important artisanal fishing ports of Ecuador, and Puerto Bolívar is located in the El Oro province, southern coast of Ecuador. 


\section{APPENDIX I}

List of recorded shark species in inland waters of Ecuador, family, scientific name, common name and fleet catch type: (A) associated fleet, (B) trawler fleet, (C) artisanal fleet, and (D) cruise research.

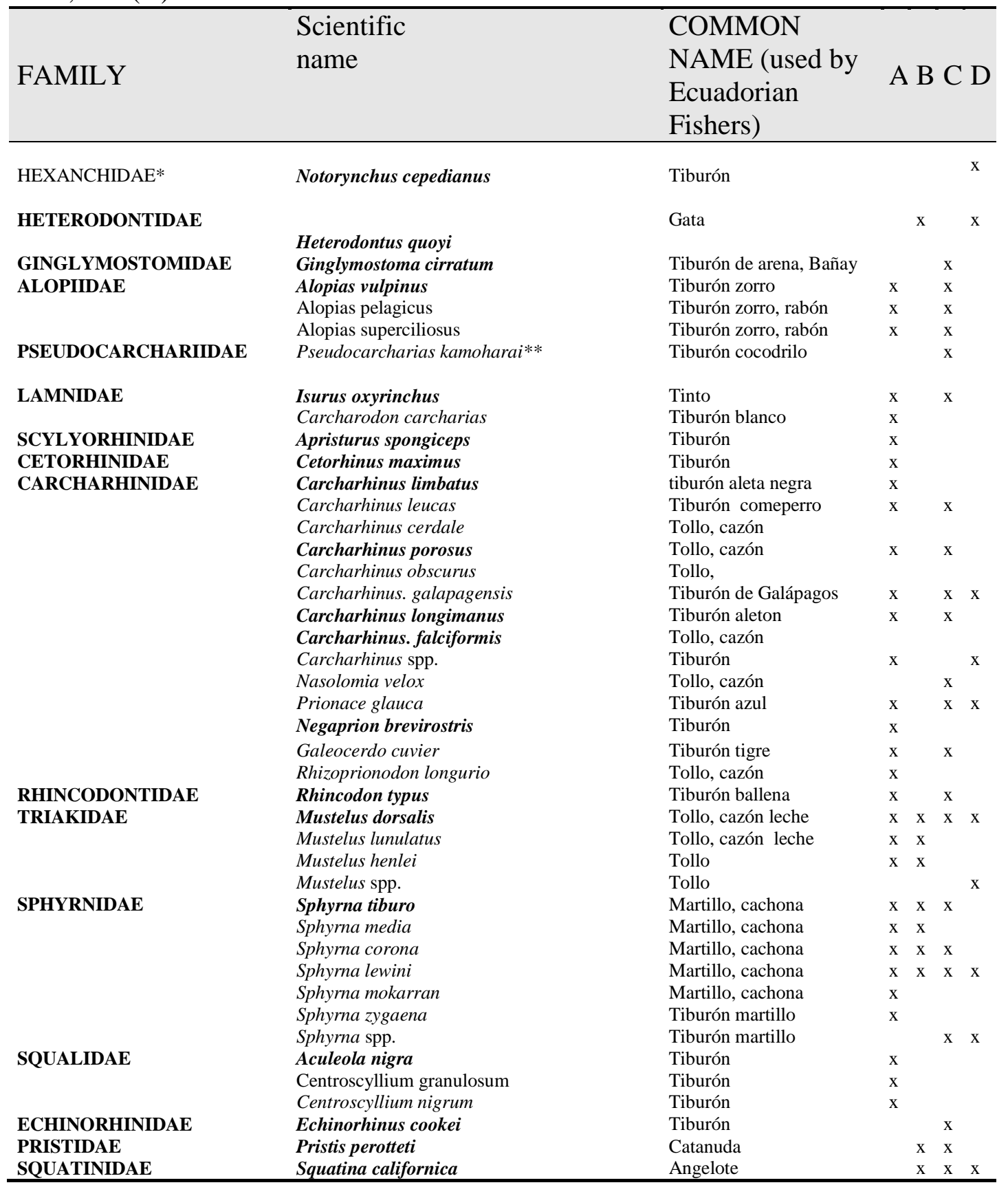




\title{
MANUSCRIPT 3
}

\section{A Case Study of the Effects of Turtle Excluder Devices on Conservation and the Shrimp Fishery in Ecuador}

\author{
Nikita Gaibor ${ }^{1}$, Richard Pollnac ${ }^{2}$
}

To be submitted to the Journal of Marine Policy 2016

${ }^{1} \mathrm{PhD}$ Candidate, Department of Marine Affairs, University of Rhode Island, Kingston, RI, 02881, USA, Email: nikita_gaibor@my.uri.edu

${ }^{2}$ Professor. Department of Marine Affairs, University of Rhode Island, 1 Greenhouse Rd., Kingston, RI 02881, US.A, Email: pollnacrb@uri.edu 


\section{CHAPTER III}

\section{Abstract}

This paper analyzes the causes of regulatory compliance of Turtle Excluder Devices (TEDs) in the shrimp trawl fishery. This study indicated that $82 \%$ of shrimp vessels use TEDs. This high percentage could be related to the mandatory use of TEDs and the significant penalties and repercussions for non-compliance. Although, initially, many of the fishers resisted using TEDs and fished without them, their behavior changed because they realized the importance of obeying the law and it avoided an embargo on their activities. Fishers' perceptions of this study assumed that the likelihood of sea turtles being caught while using TEDs would be low. However, this study also assumed that the likelihood of fishers reporting turtle capture would be low. Hence, the estimate of shrimp vessels accidentally catching turtles in their own nets served as a lower-bound estimate. This study concluded that the use of TEDs in Ecuador, although it was imposed in a top-down management manner driven by the interests of government agencies in export markets, its use over the years may have helped sea turtles survive and may have reduced the bycatch of other species. However, the most important aspect of this study was revealed when viewed retrospectively with regard to the mandatory measures for TEDs. From a shrimp boat captain's perception, it did not significantly reduce the volume of catch and it was effective in turtle and marine conservation.

Keywords: TEDs, compliance, sea turtle, bycatch, shrimp fishery. 


\section{Introduction}

Turtle Excluder Devices (TEDs) have been the focus of attention and controversy in fisheries [1] for some time and have been cited as a "success story" of fisheries bycatch reduction (e.g. [2]). A TED (Fig.1) is a specialized fishing device composed of a grid of bars with an opening either at the top or the bottom of the trawl net that allows a captured sea turtle to escape when it is caught. In particular, when sea turtles are caught in the trawl, they strike the grid bars and are ejected through the opening. Although TEDs were designed to allow sea turtles to escape from shrimp nets, they also have the potential to be a finfish conservation tool because they allow the escape of valuable bycatch fishes from shrimp nets.

The highest rates of bycatch-over 11 million metric tons per year-are associated with shrimp trawling [3]. It has been estimated that shrimp trawl fisheries produce more than one-third of the total bycatch, although they catch only two percent of the world total catch of all fish by weight [4]. Shrimp trawling consists of dragging a large net behind a boat to catch shrimp at a specified depth, capturing everything in their path. Shrimp trawling operations have been identified to have the greatest impact on sea turtle species that inhabit environments that attract shrimp trawlers. Sea turtles breathe at the surface, but when they are trapped underwater they can die because they can only hold their breath for up to 45 minutes. Indeed, shrimp trawlers often wait up to four hours before hauling in their nets.

Driven by the situation of sea turtle populations and in order to minimize fisheries bycatch in shrimp trawlers, in the late 1980s, former President George H. W. Bush signed Public Law 101-162, requiring the State Department, in consultation with the Department of Commerce, to initiate negotiations with foreign nations to develop agreements for sea turtle conservation. Since 1996 all producer countries that export shrimp to the United States are required to use TEDs in their shrimp trawler vessels, to prevent the inadvertent capture of turtles, according to provisions written by the Court of Commerce [5]. A certification must be completed annually in order to export shrimp to the United States. In addition, governments and non-governmental 
organizations along the Eastern Pacific Ocean (EPO) have been working to reduce the mortality of sea turtles as bycatch in their fisheries.

TEDs have been voluntarily used by some commercial fishers but in certain Exclusive Economic Zones (EEZs) and in waters of the Eastern Pacific States, such as Ecuador, their use is mandatory. Despite regulatory efforts to impose mandatory use of TEDs to protect endangered sea turtles, TED use has been controversial and has been met with resistance within some segments of the commercial fishing industry.

As part of the EPO and having taken part in bilateral agreements with the United States, the Ecuadorian shrimp industry was forced to implement the use of this Bycatch Reduction Device (BRD). Shrimp boats began to implement the TED in late 1996. However, in 1997 exports were paralyzed for one month when the Ecuadorian shrimp vessels did not pass the US inspection for use of TEDs [6]. This ban was considered a unilateral trade measure by the US Government and was in clear contradiction of World Trade Organization principles where production and processing methods are not valid reasons for product differentiation. In addition, the ban was based on the application of the US domestic law outside a country's jurisdiction.

In spite of these obvious violations of international trade rules in 1997, Ecuador presented a request to the US Department of State for a new inspection of its shrimp trawler fleet. Indeed, Ecuadorian fisheries officials agreed that this was the best course of action considering that if the embargo would have persisted, the State Department could have banned all Ecuadorian shrimp imports for the rest of the year (1997), and thus paralyze shrimp operations until a new inspection could be carried out in 1998. By that time the Ecuadorian shrimp ban would have affected no less than 10 percent of Ecuador's total shrimp exports, calculated at US \$ 700 million per year [6]. The Ecuadorian shrimp trawlers blamed their TED noncompliance on inexperience in using the device, as well as the short time given to comply with the new requirement [6]. Since then, the Ecuadorian fishing authorities and the National Marine Fisheries 
Service of the US have conducted unannounced inspections annually, in order to verify the correct use of the TEDs.

The shrimp fishery in Ecuador successfully began its operation in the 1950s and played an important role in the Ecuadorian economy during the 1970s and the 1980s. Two major fishing fleets have been dedicated to harvesting shrimp in Ecuador. These fleets included the shrimp "langostino" trawl vessels and the shrimp "pomada" trawl vessels. The first one captured Pacific white shrimp (Litopenaeus vannamei), Western white shrimp (L. occidentalis), Pacific blue shrimp (L. stylirrostris), followed by brown shrimp (Farfantepenaeus californiensis) and pink shrimp (F. brevirostris). For its part, the pomada-trawl vessels harvested exclusively the "titi" shrimp (Protrachypene precipua) and deep-sea shrimp (Solenocera agassizi).

These shrimp species are important to the economy of Ecuador. Currently about 6,000 tons of pomada shrimp is exported to the United States, the European Union, and Chile. Each pound of these shrimp species is marketed at approximately US $\$ 0.80$ (key informant 2011, personal communication). These species were even more important during the 1970s and 1980s. However, catches decreased due to overfishing as well as the influence of adverse climatic conditions (e.g. La Niña). In addition, a decline of commercial shrimp and fish species was attributed to bycatch in the artisanal post-larval shrimp nets that were deployed along the intertidal zone of Ecuador [7, 8]. Further, shrimp and post-larval shrimp stocks declined due to this type of fishing activity in the 1980s and 90s [7,8,9,10]. Serious over-exploitation of stocks and the lack of appropriate regulations for their management to ensure their sustainability have been the negative factors that have caused the decrease in the size of the shrimp populations.

A solution to this complex problem arose with the great increase in shrimp cultivation in the estuaries of the Ecuadorian coast. In less than 20 years of activity, the shrimp sector generated in foreign exchange US \$874.4 and \$853.8 million in 1997 and 1998, respectively [11]. However, during the 2000s, the lack of application of sustainable 
management concepts to shrimp mariculture caused the appearance of a series of pathogens that diminished shrimp production by $70 \%$ [12]. Only the business sector that used high technology methods survived this crisis. In 2011, the Ecuadorian shrimp exports to the United States were US \$493.5 million [11].

Fisheries bycatch is common in the Ecuadorian shrimp fisheries and it is believed that a large portion of incidental catches is thrown overboard. Unfortunately, this portion of the catch is rarely, if ever, reported. One of the few studies to determine shrimp bycatch was done by Little and Herrera in 1991 [13]. Their estimated finding was 261 species, of which $38 \%$ was shrimp, $5 \%$ retained fish, $36 \%$ discarded fish and $21 \%$ other species that were generally invertebrates. Of the total catch, rays and catfish represented the highest species percentages with $33 \%$ and $15 \%$, respectively $[13,14]$. The relationship of fish to shrimp fluctuated from 4.4: 1 to 11.7: 1, with fish consisting mainly of ground fish species [13]. Late in 2015, a catch reconstruction study of the Ecuadorian fisheries reported that shrimp trawlers harvested $25.4 \%$ of the total catch, with an average of 5,500 tons of shrimp per year [14]. The same authors indicated that discards represented $17.2 \%$ and that the bycatch was $57.4 \%$. Unfortunately, in both studies, sea turtles were unreported. Therefore, up to now, it has not been possible to quantify the incidence of sea turtle captures during fisheries operation, although it is believed that some turtle species such as L. olivacea, C. mydas, D. coriacea and E. imbricate have declined in population because of shrimp fishing activity and longline fisheries.

In contrast, a study conducted by Diamond [15], 23 years after the 1991 study, the overall ratio of bycatch to shrimp of 0.26 (3 times more shrimp than discarded bycatch) was very low compared to other shrimp fisheries, with shrimp making up about $75 \%$ of every tow. This finding is clearly different from that of the previous 1991 study. An interesting factor that Diamond points out in her study is that the differences in the catch between these two studies - the increase of pomada shrimp and the decrease of bycatch species - could be due to changes in fishing practices, effort, or fishing gear. Regarding the latter, the use of TEDs, which is now standard in 
the fishery, would have helped reduce the 1991-bycatch results had they been available. TEDs were just beginning to be used in Ecuador in 1998. It is likely that pomada shrimp increased and bycatch species decreased concurrently compared to 1991 numbers due to positive environmental conditions, such as: (i) El Niñomoderate and strong-events, during the years 1992-1993, 1997-1998, 2002-2003, that positively affected the increase of shrimp species [16]; (ii) the recovery of the mangrove ecosystem in the Gulf of Guayaquil due to an extensive governmental program; and, (iii) the behavior change in the use of TEDs due to law enforcement.

There was no doubt that the use of TEDs in shrimp trawler nets was beneficial, not only for the conservation and management of sea turtles, but also there were socioeconomic benefits in the shrimp export industry. However, there were no studies on the implementation of this BRD and the effect of regulations on the mortality reduction of sea turtles and other species.

There was also a need for social studies in Ecuador regarding fishers' perceptions about marine conservation devices, such as TEDs. To better understand the utility of this BRD as well as other types of technology, one needed to particularly study fishers, who had used, were using, or were going to use the device, in order to learn from their experiences to determine if a BRD would or would not work. Because no one had considered the effects of the use of TEDs on fishers' perception, this study became relevant.

This study hypothesized that compliance with regulations requiring TEDs was a significant factor in accounting for bycatch reduction in the shrimp fisheries, in conjunction with other protective measures. Because of regulations, Ecuadorian shrimpers used TEDs and did so because the risks of legal penalties outweighed the minimal financial losses and inconveniences.

The purpose of this study was to evaluate fishers' perceptions regarding the mandatory use and compliance of TEDs, and in retrospect, was to determine if fishermen believed 
that this BRD ensured the conservation of sea turtles and assured improved fisheries management.

\subsection{Features of the Shrimp Fisheries 1.1.1. The Shrimp "Pomada" Fishery}

The pomada shrimp fleet operates mainly in Posorja; in 1956, it began fishing with five vessels and by the 1980s, it had reached a maximum number of 74 boats [17]. Today, the fleet vessel number has decreased $48.64 \%$ from its maximum to only 38 vessels [17] (Fig. 3). The pomada shrimp vessels work 18 days per month with an average of 9 hours per day $[17,18]$. The pomada shrimp catch, which is processed primarily for export, is estimated to be around 10,000 tons a year [19]. In the last decade, the contribution of this sector to GDP shows significant growth figures showing an average growth of GDP fisheries sector for the period 2000-2010 of $7.49 \%$ compared to $4.37 \%$ showing the economy whole, with cumulative growth for the decade 2001-2010 of $41.61 \%$ [20]. It also employs many members of the local Posorja community on the fishing boats and in the processing plants (key informants 2011, personal communication) [15].

The pomada shrimp fleet is concentrated mainly in two fishing areas: the Gulf of Guayaquil and Esmeraldas Province. These two areas were established by regulations in a Ministerial Agreement (426-A, October 2012). The pomada shrimp catch is reported to be seasonal, with a 'high' season from March to June and a 'low' season during the rest of the year $[15,17]$. Time spent in active fishing per trip is estimated at around 500 minutes, although fishing activity may vary by vessel and by month [15].

Shrimp species are prevalent and more available in the Gulf of Guayaquil $\left(3^{\circ} \mathrm{S}, 80^{\circ} \mathrm{W}\right)$, which is the largest $\left(12,000 \mathrm{~km}^{2}\right)$ estuarine ecosystem in the Southeastern Pacific Ocean [21, 22, 23, 24, 25]. The fleet of boats that catch pomada shrimp (Protrachypene precipua) conduct their fishing outside the first mile boundary from 
the coast, which form three fishing areas: the first region is 10 miles long and extends from Punta Pelados to Casa Practicos (Fig. 2); the second region is 13 miles long from Punta Norte of Puná $\left(02^{\circ} 50.000^{\prime} \mathrm{S}-80^{\circ} 16.417^{\prime} \mathrm{O}\right)$ to Cierre de Las Prácticas $\left(03^{\circ} 2.894^{\prime} \mathrm{S}-80^{\circ} 12.922^{\prime} \mathrm{O}\right)$ and Las Elices $\left(02^{\circ} 56.458^{\prime} \mathrm{S}-80^{\circ} 16.263^{\prime} \mathrm{O}\right)$ (Fig. 2$)$; the third area $\left(56.910 ' \mathrm{~S}^{\circ} 02^{\circ}-80^{\circ} 24.667^{\prime} \mathrm{O}\right)$ forms a crescent to the East.

The boats are made of wood with lengths varying from 10 to $25 \mathrm{~m}$, and the ship's hold has a capacity of 4-ton. Ice is required to preserve the catch. The boats have engines with 150 to $200 \mathrm{HP}$ [26]. The pomada vessels have an average of 13.69 Net Register Tons (TNR) and an average length of 18 meters [27].

The gear used by the pomada fleet is a trawl, which is conical in shape and comprises several sections (wings, body and face bag). The trawl is tied to two ropes: a top rope including buoys and a bottom rope made with leads. For optimum operation, the gear net is also coupled to two rectangular wooden doors and in turn, these doors are tied with ropes to the boat. The shrimp pomada nets are 50 to 75 feet long with an eye mesh size $1 \frac{1 / 2}{2}$ to $1 \frac{1}{4}$ in the body and 1 inch in the cod end. This net operates at depths of 4 to $12 \mathrm{~m}$. [28]. All shrimp nets have to use TEDs to operate and all boats must be equipped with TEDs as well as with GPS and two-way radios.

The pomada fleet underwent a major change when the fishery law classified its fleet as an industrial fleet in 2007. Therefore, under this regulation, it ceased to be considered as part of the artisanal fleet.

\subsubsection{The Shrimp "Langostino" Trawl Fishery}

According to Cobo and Loesch [29], the langostino shrimp fishery started to operate in the Ecuadorian waters in 1952. By 1954, there were 28 shrimp boats that caught 660 tons of shrimp, which made the first marine shrimp exports to the US [17]. The fleet grew to 156 boats catching 200 pounds of shrimp tails daily by 1963 [29]. By 1968, the fleet had 200 vessels. In 1987, there were 297 shrimp vessels that caught 7,171 
tons of shrimp [30] and by 1996, 266 boats remained with an annual catch of 4,800 6,600 tons [31]. However, by 2009, of the 155 registered shrimp boats, only 122 boats were operating [32]. Most of the shrimp catches from this fishery throughout these years has been exported to the US.

More than $85 \%$ of the shrimp boats were built between 1950 and the late 1970 s. The first boats were brought from the Gulf of Mexico, but in the 1960s, the Ecuadorians began to build their own vessels by hand in the shipyards along the Ecuadorian coast. Although, most of these vessels have a wooden hull, in 2006 two boats were made of steel. These vessels used fixed engines with 200 to $450 \mathrm{HP}$. The duration of each trip was between 15 and 22 days [32, 33].

The fishing areas where the langostino fleet operated were in the Gulf of Guayaquil (Puná, Santa Clara, Jambelí, and in border waters with Peru). These areas were the most important for the development of the fishery. Fishing operations were also carried out outside the coastal zone of Santa Elena Province, between the area of Palmar and Bajo de Ballenita, and in Esmeraldas, where there was a large fleet whose work was concentrated between Punta Sua and the border with Colombia. These sites were economically important for the northern part of Ecuador, where there are landings not only for shrimp species but also for diverse fish species. It has been estimated that there were 3,000 fishers and 1,042 boats [34].

The langostino shrimp boats generally operated within a mile of the protection zone, which is not permitted by Ecuadorian industrial fishery law. Because of this, major conflicts occurred within the artisanal fishery sector.

\subsection{Regulations}

Management of shrimp includes different measures in Ecuador. These include regulations on fishing gear to achieve the overall goal of a sustainable yield in their fisheries. For example, there are regulations on mesh size to improve the selective 
properties of fishing gear to reduce bycatch of juvenile fish and to safeguard the recruitment of groups of larger fish in a population.

In recent years there has been growing interest in the ecosystem effects of fisheries and addressing the impact of fishing operations on the target species of fishing as well as bycatch or non-commercial species and their habitats. Better capture quality is also an important aspect of fishing gear and fishing operations [35]. In the past the development of gear and fishing methods only focused on the fishing target species. Now researchers, fishing managers and fisheries personnel face the challenge of developing gear, methods and regulations to meet the different considerations mentioned above. This is part of the ecosystem approach that is emerging for fisheries management.

Among regulatory standards, the following regulations are related to the shrimp fleet and protecting shrimp resources in Ecuador. On August 16, 2002, Ministerial Agreement No. 047 ratified the mandatory use of TEDs for industrial shrimp boats, although the devices had been in use since 1996. In addition, since April 15, 2014, Article 6 of Agreement No. 242 issued by the Ecuadorian government established the mandatory use of TEDs for the artisanal fishing fleet that catches pomada shrimp (Protrachypene precipua) with a fishing gear named "changa." Ministerial Agreement No. 2305 (August 6, 1984) established an exclusive fishing zone for artisanal fishers within eight miles of the coastline. This agreement excluded the industrial shrimp trawler fleet from this zone. Ministerial Agreement No. 080 (19 March 1988), however, referenced Agreements No. 2303 of 1984 and No. 345 of 1988 that repealed Agreement No. 2305 and thereby allowed the shrimp trawl fleet to conduct fishing within 8 miles of the coastline. The July 2003 Agreement No. 03/316" mentioned that the shrimp catch must be outside of the coastal nautical mile reserve. In addition, to protect marine resources, closed seasons have been established. Since 1985, most closure seasons have operated from November to December (a duration of 45-60 days). The closure dates have been supported by the National Fisheries Institute of Ecuador (INP) technical reports. Through Ministerial Agreement 106 (October 2002), 
shrimp larval capture was prohibited at the national level. These types of regulations were developed and implemented to protect breeding stocks of shrimp and other bioaquatic species during the main spawning periods. This legislation was created due to shortages of post-larvae shrimp and the decline in catch quantities (1994-1985).

Regarding the pomada shrimp fishery, the policies that are executed are: (i) temporary closed seasons, which usually apply for two or three months per year during the months of January, February, March and/or April; (ii) fishing gear restrictions including a maximum towing length of 50 meters with a minimum mesh size of $1 \frac{1 / 4}{4}$ inch and the use of TEDs to reduce bycatch; (iii) a closure area that protects spawning grounds of marine species where fishing boats are not allowed to fish within one mile of the coast and shrimp trawlers are forbidden to fish in the coastal zone between "Punta El Pelado" and "Chanduy"; and (iv) a catch limit that does not allow the landing of more than 2,267 kilograms per boat per day (i.e., 2.27 metric tons or 5,000 pounds per day).

\section{Materials and Methods}

\subsection{Study Areas}

The fishing grounds of the Ecuadorian artisanal fishery targeting shrimp species are located between $05^{\circ} 00^{\prime} \mathrm{N}$ and $15^{\circ} 00^{\prime} \mathrm{S}$. Fishing by the shrimp fleet is concentrated mainly in two fishing areas: the Gulf of Guayaquil and Esmeraldas Province (Fig. 3). Therefore, the selected study area included Posorja in Guayas Province (Gulf of Guayaquil) and Esmeraldas in Esmeraldas Province. These two fishing communities were chosen because most of the shrimp-langostino fleets and the pomada fleets land their products in these two towns and they are home to a majority of the interviewees.

\subsection{Sampling and Survey Implementation}

The data for this study was collected using a questionnaire during January-June 2011. The questionnaire was administered in face-to-face interviews with shrimp fishers, 
captain and owners with an assurance of individual anonymity and confidentiality.

In total, 171 fishers (captains, owners, as well as deckhands) were interviewed at each site area. They answered questions in several categories regarding TEDs: attributes of the technology, prevalence of use, enforcement and legality, process and quality of promotion and workshops, and governance. In addition, at each location, surveyors interviewed key informants (e.g. fishing leaders, President of the association of shrimpers, researchers, and fishing authorities) to determine their depth of knowledge of the shrimp fisheries.

The respondents were recruited in public places where fishers usually gather, such as at fish landing sites and in the markets. For this research, the minimum age of the respondent was restricted to no less than 18 years old.

The team received support from the National Fisheries Institute of Ecuador, which was critical in the implementation of the surveys. The project also gained valuable insights from consultations with key informants associated with the fisheries industry or who worked in it.

Data was coded and entered into the SYSTAT software for analysis and tabulation.

\section{Results}

\subsection{Socioeconomic Characteristics}

The survey respondents from Posorja turned out to be younger than those from Esmeraldas. The youngest interviewee in Posorja was 18 years old and the oldest respondent was 65 years old, while in Esmeraldas the youngest interviewee was 22 years old and the oldest one was 76 years old (Fig.4). There were no women interviewed. 
Regarding the level of education of the fishers that use TEDs, 52\% of interviewees had attended elementary school; 34\% had gone to high school; $10 \%$ had attended college; and $4 \%$ had no formal education. For both towns, the largest percentage value represented the group of fishers who listed elementary school as their highest level of education. The relationship of fishers using TED and their education did not differ between the two towns (Chi-Square $=2.575 ; \mathrm{p}=0.109$ ) (Figure 5). Therefore, academic education level does not affect fishers' participation in the use of TEDs.

\subsection{Dependent Variable}

Interviewees in both fishing communities were asked about the use of TEDs. Of the 143 interviewed, $82 \%$ responded that "All" shrimp trawlers use TEDs, 17\% said that "Most" of them use this device, and only 0.7\% said that "Less than half" use TEDs. The differences between the towns are not statistically significant. Of the responses, $86 \%$ of shrimp trawlers in Posorja and $78 \%$ of them in Esmeraldas use TEDs. Among their motivations for using TEDs, interviewees explained, "once they were correctly placed the capture rate is identical to the one before the introduction of TED." In addition, another key informant, the former president of the shrimp pomaderos association said that using a TED helped to keep the net clean and let wood pieces and trash exit. However, among those who responded_- "most" and "less than half" — they indicated the main problems in TED use occur during the winter season (December May) due to the increase in river levels that bring sticks, tree trunks and branches, as well as garbage. The garbage clogs the TED and nothing passes through it. To untangle the net out at sea and take the garbage out becomes a difficult operation. However, according to this key informant, "this happens only when there is a lot of rain and the ocean currents are strong." To rectify the use of TEDs by the shrimp fleet, this key informant suggested that shrimp trawler boats should have two to three TEDs on board in case one of them is damaged. This would allow them to continue fishing.

Regarding the interviewees' first experiences with TEDs, 53\% of the fishers responded negatively and $18 \%$ responded positively. Therefore, most of the fishers 
had trouble managing and operating the device when they started to use it on their shrimp vessels. One of the key informants, a deckhand said, "When TEDs first arrived, we did not understand why we needed to use them. We thought that the pomada shrimp would escape. But, after we learned how to properly place and use it, we realized the TED has various advantages." Another key informant indicated, "If we use the correct angle, the opening is the right size and we should be able to fish without problems. At first, when we had little experience and because of our eagerness to follow the rules, we had the flaps wide open and we lost a lot of shrimp. However, when the Americans came for an inspection, they taught us to shut the flap more and to stow the sides of the nets (not the top lid, but the sides)."

Fishers were also asked if there was an increase or decrease of vessels using TEDs over time. $71 \%$ of respondents said there was no change. This implies the amount of vessels using TEDs have not changed. Between sites, the higher percentage value for responses indicating no change or "same" corresponds to Posorja. The two towns, however, are statistically significantly different with regard to the differences in the distribution of their responses $(p-$ Value $=0.019)$.

When interviewees were asked whether TED should be voluntary or mandatory, 94\% of them said "mandatory" while only $6 \%$ thought it should be voluntary. Very similar percentage values for mandatory use were registered for both towns; Posorja reported 94\% and Esmeraldas had 93\%. This could mean that shrimp fishers agree with the use of a conservation device, but do not necessarily believe that fellow fishers will apply it if its use is voluntary.

The following results relate compliance with TED regulations in these two fishing communities. $74 \%$ of interviewees responded that they "all obey" the regulations for correct TED installation and use of TEDs, while $20 \%$ of fishermen said that most of them "obey" and only 6\% responded that either "some disobey" (1\%) or "all disobey" $(5 \%)$ 
Interviewees from both towns were asked if they know the regulations regarding the use of TEDs; $77 \%$ of them responded affirmatively and $23 \%$ said "no". This confirms that the majority of fishers from both communities are aware of TED regulations. Fishers said that they knew that each shrimp vessel needed to be equipped with three TEDs of which two should be in nets, and one on reserve. Regulations indicate that TEDs must be set/installed at the correct angle (45 degree), must be well graduated, and should have adequate floats, among other things.

Captains were asked if they break the rules concerning the use of TEDs. Sixty six percent of them responded that they do not break the rules. However, 34\% mentioned that they do break them sometimes. Differences between the two communities (Esmeraldas and Posorja) are not statistically significant (Chi-Square $=0.646$; p-Value $=0.422$ ). The majority of respondents state that they do not want to be associated with a fleet known for not using TEDs. Indeed, one of the key informants, an officer from the Undersecretary of Fishing Resources, commented that perhaps, there will never be $100 \%$ of fishers that use TEDs, but overall progress has been made.

When captains were asked about the regularity with which the authorities inspect the use of TEDs, $90 \%$ of them reported that it is regular, meaning that they need to have TEDs on board. In addition to the inspection of TEDs by fishing authorities, captains were asked if these inspections are fair. $72 \%$ responded that they are fair, but the Posorja captains were more likely to report that the inspections were fair when compared to the Esmeraldas captains. Among their responses, interviewees said that inspections should exist to ensure compliance. They also commented that it is important to ensure that they are not prohibited from exportation. Also, the key informants pointed out that the inspectors from the Undersecretary of Fishing Resources (SRP) do make fishing inspections at sea. If the inspectors find a shrimp vessel without TEDs, the inspectors impose fines on the vessel operation. In the case that a shrimp vessel does not get certified as a TED user by an inspector, it is not permitted to fish for shrimp. It cannot even leave the dock. The SRP provides a permit if the shrimp vessel uses TEDs. Without this permit, no activity is allowed. This 
permit is known as "papel de trafico" (traffic paper). A shrimp vessel without this permit cannot buy gasoline. It is simply shut down. It is also probable that $72 \%$ of the captains believe that the inspections are fair, because when there is something wrong with the use of the TEDs, the inspectors are able to explain how to repair them.

Captains were also asked if they would continue using TEDs if their use were voluntary and not mandatory. Sixty six percent of respondents said that they would continue to use TEDs. More than twice as many fishers from Posorja than those from Esmeraldas gave a favorable response, a result that is statistically significant (ChiSquare $=13.881 ; \mathrm{p}$-Value $=0.000)$. The difference in the response of these two towns could be that shrimp fishers from Posorja are members of a formal fisher association that may have helped them to become more aware of the use of TEDs and their purposes.

Regarding the promotion of TEDs through workshops, $78 \%$ of interviewees said that they attended at least one workshop, while $22 \%$ responded that they did not participate in any workshop. The percentage of those from Posorja (93\%) was much higher than those who attended workshop in Esmeraldas (63\%). In general, interviewees mentioned that the workshops that they had attended were good and beneficial, especially because the technicians who participated were very effective at communicating issues concerning TEDs.

Turning to conservation of sea turtles, $84 \%$ of all respondents believe that TEDs ensure conservation of sea turtle species. $89 \%$ of Posorja respondents and $79 \%$ of Esmeraldas respondents indicated that TEDs save sea turtles when they are incidentally caught in a shrimp trawl. In other words, this technology works well for sea turtles. They escape easily, without any problems, because the flap is always open.

When interviewees were asked if they eat sea turtles (i.e. meat or eggs), $95 \%$ from Posorja and 85\% from Esmeraldas responded "No." Only 5\% from Posorja said that they eat sea turtle, in contrast to $15 \%$ from Esmeraldas. Although the percentages of 
respondents that do eat sea turtles are relatively low, they confirm that there is still consumption of sea turtles in Ecuador.

Fishers were queried concerning their perception of sea turtle populations when they first started to fish compared to present-day conditions in the study area. Most fishers indicated an overall decline in all turtle population species found in the study area. The majority of the fishers (44\%) agreed that sea turtles had higher populations when they started fishing. Their perception regarding turtle populations indicated a sharp decline from 10-20 years ago when compared to the present. About $34 \%$ of the fishers said that the present sea turtle populations have remained the same while $20 \%$ indicated that there has been an increase (more) in sea turtles in the study area. A few shrimpers insisted that trawling was not harmful to turtles because turtles do not exist in their area. One captain claimed that he had never seen a sea turtle over a period of 20 years except on the wall of an environmentalist group's office; some other captains claimed that they had not heard of anyone encountering turtles at sea. Shrimpers also claimed that TEDs, which are basically heavy metal grates, are dangerous to have on board ships. However, not a single fisher has ever reported an injury involving a TED. Fishers from Posorja, in contrast, to those from Esmeraldas, were more likely to report that the amount of turtle present today is the same (43\%) or greater (33\%), than it was when they began fishing $($ Chi-Square $=28.571 ; \mathrm{p}$-Value $=0.000)$.

Interviewees were also asked about the importance that sea turtles play in the marine environment. The majority ( $81 \%$ ) said that sea turtle plays an important role in the marine environment. Many captains and boat owners did not think turtles were endangered because as they said, “The scientists don't even know how many turtles are out there." Some shrimpers claimed that beachfront development, which destroys turtle nesting habitat, had a much greater effect compared to trawling (key informant 2011, personal communication).

Interviewees were also asked if sea turtles are important in terms of consumption or decorative value. Regarding this question, $66 \%$ of respondents said that sea turtles are 
important to them in this respect. Fishers from Posorja were more likely to say the sea turtle is very important compared to those fishers from Esmeraldas (67\%). The percentage of total respondents who said that chelonian species are not important is very low $(3 \%)($ Chi-Square $=13.952 ; \mathrm{p}$-Value $=0.000)$.

Captains were asked if they were to catch a sea turtle, would they do all that they could to help the sea turtle to survive before their crew returned it to the water. $77 \%$ of the interviewees responded affirmatively and $28 \%$ said they would do nothing. Of the affirmative responses, interviewees said that if they caught a sea turtle, they would untangle it from the shrimp net, bring it onboard, put some water on it to get its reaction, and finally, return it to the sea.

Captains were asked whether TEDs decrease or increase the amount of valuable bycatch. Of all interviewees, $72 \%$ responded that bycatch has decreased, while $9 \%$ said that TEDs increased bycatch. In fact, a key informant said, "The TED also helps fish to escape, as well as sea turtles." Therefore, it can be assumed that bycatch reduction is largely a result of the use of TEDs. This result supports what Diamond had found in her study on bycatch.

Captains were also asked if they would like to be involved in fisheries management decisions. $58 \%$ of all interviewees stated that they would like to participate in these decisions, but $42 \%$ said "No." The slight majority of positive responses indicate that there is a need for captain involvement; fisheries co-management could be one of the tools to apply to the shrimp fishery. However, the results showed that not everyone necessarily wants the decision making power of co-management. Perhaps, this $42 \%$ do not want to be bothered with co-management.

\section{Discussion}

Bycatch reduction has been largely due to the use of selective fishing gears such as trawl nets equipped with TEDs. Although the implementation of TEDs was imposed 
by US government agencies, results of this study indicated that $82 \%$ of shrimp vessels use these devices. This high percentage could be related to the fact that TED use is mandatory, and there are significant penalties and repercussions for non-compliance. Although at the beginning of the implementation, many of the interviewees (owners, captains and deckhands) resisted using TEDs and fished without them, their behaviors changed because they realized the importance of obeying the law and it avoided an embargo on their activities.

It is clear, therefore, that most of the Ecuadorian shrimp trawlers use TEDs. Indeed, some shrimp boats have two-to-three TEDs on board to replace one if it gets damaged. There is no doubt that people involved in the shrimp fishery want to avoid the risk of legal penalties that outweigh the minimum financial losses and inconveniences. However, there are boats with the "papel tráfico" (traffic paper) that do not use the TEDs and take the risk of being boarded, inspected and penalized. For those who follow the rule, their reasons may be related either to avoid the disapproval of their group or community, or to see themselves as a moral being who wants to do the right thing [36].

A third factor is legitimacy, which means that the individual feels that the authority enforcing the law is entitled to dictate behavior. This in turn depends on whether individuals think that the law is fair and applied in a fair manner. Whether legitimacy is maintained or undermined is dependent on people's experiences with legal authorities (Tyler 1990).

Because TEDs were enforced, shrimp fishers did not like to use them at the beginning. However, with time, they realized that TEDs did not significantly affect the volume of the shrimp caught. Some shrimp vessels $(0.7 \%)$ did not use TEDs and this could be related to the loss of bycatch such as "corvinas" when they use TEDs. Fishers usually take the bycatch either to sell or to use at home, which represents extra revenue. 
According to the results of this study, $74 \%$ of interviewees obeyed the use of TEDs because they $(84 \%)$ believed that TEDs protected sea turtles when caught in shrimp trawler nets. There was no doubt that TEDs are necessary for the protection of endangered sea turtles. Further, fishers had a good understanding of sea turtle population trends over the last 15-20 years, as evidenced by the high percentages of interviewees citing a sharp decline over this period. The findings indicated that fishers were aware of the importance of sea turtles. However, according to one key informant who was a captain, he said "fear of being associated with sea turtle bycatch also discouraged captains and fishers from resuscitating injured turtles." Therefore, the chance for the survival of sea turtles was slim. Fishers did not report cases that involved the mortality of sea turtles for fear of being sanctioned by the fishing authority and because of the amount of time and effort required to report them.

Fishers' perceptions assumed that the likelihood of sea turtles being caught while using TEDs would be low. Similarly, this study assumed that the likelihood of fishers reporting turtle capture would be low. Hence, the estimate of shrimp vessels accidentally catching turtles in their nets served as a lower-bound estimate.

Study observations highlighted the need for better understanding of legislation among fishers, despite their awareness that not using TEDs would result in a fine, denial of permission to capture shrimp, and a shrimp exportation embargo.

Regarding bycatch, $72 \%$ of interviewees responded it had decreased during last few years while another key informant, an official from the Undersecretary of Fishing Resources, he said, "It does not really affect how much they catch if they use TEDs correctly." In his opinion, he believed shrimp vessels only lose about $3 \%$ or $5 \%$, maybe even $10 \%$ of their catch, which was not much." In other words, TEDs did not affect the quantity of the product.

Although this study does not include the shrimp catches from the artisanal shrimp fleet, there is an overlap in the fishing area as well as in the target species between the 
industrial shrimp pomada fleet and the artisanal shrimp pomada fleet. In 2014, Diamond [15] estimated that 500 artisanal fishers were involved in shrimping activity and their catches were estimated at 5,000 tons of shrimp annually-fully one-half that of the industrial fleet. According to Diamond [15] and this study, more work is required to understand the overlap between these two shrimp fleets, especially if the artisanal shrimp fishery does not use TEDs in their trawl net called "Changa"

\section{Conclusions}

The high adoption rate of TED is related to the ban on exports of shrimp to the United States. However, over time and with the incentive to continue exporting shrimp, TED has resulted to be a conservation tool, if used correctly, without loss of profit.

This study concluded that the use of TEDs in Ecuador, although it was imposed in a top-down management manner driven by the interests of government agencies in export markets, its use over the years may have helped sea turtles survive and may have reduced the bycatch of other species. However, the most important aspect of this study is revealed when viewed retrospectively with regard to the mandatory measures for TEDs. Fishers, currently, do not see this bycatch reduction device, as a negative tool. As in the shrimp boat captain's perception, it does not significantly reduce the volume of catch and it is effective in turtle and marine conservation.

\section{References}

[1] M. A. Donnelly, The history and politics of turtle excluder devices regulations, Endangered Species Update 6 (1989) 1-5.

[2] E.F. Melvin, J. K. Parrish, L. L. Conquest, Novel tools to reduce seabird bycatch in coastal gillnet fisheries, Conserv. Biol. 13 (1999) 1386-1397.

[3] D.L. Alverson, M.H. Freeberg, J.G. Pope, S.A. Murawski, A global assessment of fisheries bycatch and discards. FAO Fisheries Technical Paper. No. 339. Rome, 1994. 
[4] Clucas, I, 1997. A Study of the Options for Utilization of Bycatch and Discards from Marine Capture Fisheries. FAO Fisheries Circular No. 928 FIIU/C928

[5] United States Department of State. 1999. Shrimp Import Legislation for Sea Turtle Conservation [Public Notice 3086]. The Guidelines for the Implementation of Section 609 of P.L. 101-162 Relating to the Protection of Sea Turtles in Shrimp Trawl Fishing Operations. Revised in 1999 (64 FR 36946).

[6] M. A. Albán, Trading Sovereignty: Ecuador's Strategic Silence on the Shrimp Ban, Bridges 2 (1998). 12pp.

[7] N. Gaibor, R. García-Sáenz, M. Luzuriaga de Cruz, S. Massay, D. Ortega, F. Villamar, E. Mora, A. Basantes, H. Vicuña. 1992. Evaluación de la pesquería de Postlarvas de Camarón Peneido y su Fauna Acompañante. Informe Interno INP/PMRC/10/92 Preparado para la Subsecretaría de Recursos Pesqueros del Ecuador.

[8] N. Gaibor, 1997, Socio-Economic, Cultural and Political Aspects of the Shrimp Aquaculture Industry in Ecuador: The Shrimp Post-Larvae Fishery Case. University of Rhode Island, Kingston, RI.

[9] D. Southgate, M. Whitaker, Economic Progress and the Environment: One Developing Country's Policy Crisis, Oxford University Press, Oxford, 1994.

[10] B. Epler, 1992, Social Ramifications of Mariculture on Coastal Ecuadorian Communities. In Coastal Aquaculture in Developing Countries: Problems and Prospects. R. Pollnac and P.Weeks (eds.). Kingston, RI: ICMRD. 24-43 pp.

[11] PROECUADOR. 2012. Perfil de Camarón en Estados Unidos. Oficina Comercial de Ecuador en Chicago, Estados Unidos. Dirección de Inteligencia Comercial e Inversiones. Octubre.

[12] M. Cruz, N. Gaibor, E. Mora, R. Jiménez, J. Mair, The Known and Unknown about the Marine Biodiversity in Ecuador (Continental and Insular), Gayana 67 (2003) 232-260. ISSN 0717-652X.

[13] M. Little, M. Hererra. 1992. The by-catch of the Ecuadorian shrimp fleet. 1991. Internal Report. Instituto Nacional de Pesca - Overseas Development Administration of the United Kingdom Government. 90 p.

[14] J.J. Alava, A. Lindop, J. Jacquet, 2015, Marine Fisheries Catch Reconstructions for Continental Ecuador: 1950-2010. The Fisheries Centre, University of British Columbia. Vancouver, Canada. Working Paper \#2015-34.

[15] S. Diamond, 2014. Characterization and Estimation of Discarded Bycatch in the Pomada Shrimp Fleet of Ecuador. 
[16] J. Lopez-Martinez, F. Arreguín-Sánchez, S. Hernandez-Vásquez, E. HerreraValdivia, M.O. Nevárez-Martinez, R. Morales-Azpeita, S. Lluch-Cota, D.B. and Lluch-Cota, Effects of the El Niño Events on the Brown Shrimp Fishery in the Gulf of California, Mexico, Invest. Mari., 30 (2002).

[17] W. Mendívez, R. García, D. Chicaiza. 2013. La pesca Industrial y Artesanal de Camarón en Ecuador. Informe Ejecutivo. Instituto nacional de Pesca. 16pp.

[18] D. Chicaíza, 2013. Crecimiento, Mortalidad y Aspectos Reproductivos del camarón pomada Protrachypene precipua (Burkenroad 1934) en el Golfo de Guayaquil - Ecuador. Tesis. Facultad de Ciencias del Mar. Universidad Católica del Norte. Coquimbo, Chile. 69 pp.

[19] M. Agüero,y L.Guaman, 2011. Identificación, Analisis y Evaluacion de alternativas de ordenación de la pesca de arrastre de Ecuador. Prepared for the Centro Inter-Americano para el Desarrollo de Ecosistemas Sustentables (ICSED-CENIDES), the Instituto Nacional de Pesca (INP) de Ecuador, and Conservation InternationalEcuador.

[20] Banco Central del Ecuador, 2010. "ECUADOR: Producto Interno Bruto por clase de actividad económica".

[21] M. Stevenson. 1981. Variaciones estacionales del Golfo de Guayaquil, un estuario tropical. Boletín Científico y técnico. Instituto Nacional de Pesca. Guayaquil - Ecuador. Vol. IV N 1 . En: Capacidad de pesca y manejo pesquero en América Latina y el Caribe. Edit. por M. Agüero. FAO Documento Técnico de Pesca. No. 461. Roma, FAO. 2007. 205-256 pp.

[22] V. Osorio. 1984. Características de la variación de la salinidad del estuario interior del Río Guayas en relación a la descarga de los ríos Daule y Babahoyo a la acción de las mareas. Tesis de grado. Escuela Politécnica del Litoral (ESPOL), Guayaquil - Ecuador. 150 pp.

[23] L. Arriaga. 1989. The Daule Peripa dam project, urban development of Guayaquil and their impact on shrimp mariculture. In: Establishing a sustainable shrimp mariculture industry in Ecuador. Edit. by S. Olsen and L. Arriaga. Technical Report E6, URI - AID - DIGEMA. 147 - 162.

[24] F. Ormaza - González. 2007. Factores sinérgicos y ambientales determinantes de la excesiva capacidad de Pesca e Ineficiencias de la gestión: La pesquería del camarón de Ecuador. En: Agüero M (ed). Capacidad de pesca y manejo pesquero en América 65. Latina y el Caribe. pp. 205-255. Roma. FAO Documento Técnico de Pesca. No. 461. p. 403.

[25] N. Gaibor, L. Arriaga, F. Ormaza-González. 1999. Características oceanográficas y pesqueras en el Ecuador durante 1994-1995. Boletín Especial. Instituto Nacional de Pesca. Guayaquil-Ecuador 156 pp. 
[26] D. Chicaiza, R. García-Sáenz, W. Mendivez, J. Correa. 2007. La pesquería de Arrastre del Camarón Pomada (Protrachipene precipua) en la zona de Posorja Durante marzo a Diciembre 2007. Informe Técnico. Instituto nacional de Pesca. 12 p.

[27] Subsecretaría de Recursos Pesqueros (SRP). 2011. Embarcaciones de Arrastre Operativas a Diciembre del 2011.

[28] ADAPP. 2009. Mar, Pesca, Desarrollo para un Futuro Mejor: Planteamiento de Pesca de Camarón Pomada, Sector Posorja. Asociación de Armadores Pesqueros Pomaderos "Primero de Mayo" ADAPP.

[29] M. Cobo, H. Loesch. 1966. Estudio Estadístico de la Pesca del Camarón en el Ecuador y de algunas características biológicas de las especies explotadas. Bol. Cient. Tec. INP, Ecuador 1 (6).

[30] J. Correa, R. García-Sáenz, W. Mendívez, J. González, D. Chicaiza, W. Ruiz, C. Villón. 2007. Diagnóstico Pesquero y Acuícola del Recurso Camarón Marino en Ecuador. Informe Técnico Instituto Nacional de Pesca. 43 p.

[31] W. Revelo and J. Guzman, 1997. La pesca artesanal en Santa Rosa de Salinas, provincia del Guayas. Ecuador. Informe de consultoría FAO. 1997.

[32] ASEARBAPESCA. 2009. Capacidad y Sobrecapacidad de la Pesquería en el Ecuador - Flota Camaronera de Arrastre. Reporte Técnico. 16 p.

[33] C. Villón, 2007. Análisis del Sector Pesquero del Ecuador Continental. Documento Técnico. Subsecretaría de Recursos Pesqueros - Conservación Internacional. 114p.

[34] N.Herrera, R. Castro, D. Coello, I. Saa y E. Elias, 2013. Puertos, Caletas y Asentamientos Pesqueros Artesanales del Ecuador.(Tomo 1.- Provincias de Esmeraldas, Manabí y Santa Elena Tomo 2.- Guayas y El Oro).

[35] FAO. 1995. Code of Conduct for Responsible Fisheries. Fisheries and Aquaculture Department. The Food and Agriculture Organization of the United Nations, Rome, Italy.

[36] Robinson, P.H. and J.M. Darley (1997), 'The Utility of Desert,' Northwestern University Law Review 91:453-99 


\section{FIGURE LEGENDS}

Figure 1. Turtle Excluder Devices (TEDs) are Shrimp Trawler net modifications, consisting of grates that are sewn into nets adjacent to open flaps that function as escape hatches.

Figure 2. Fishing areas (Gulf of Guayaquil) of the Pomada Shrimp Fleet that captures the specie Protrachypene. Precipua, which is best known as shrimp pomada.

Figure 3. Site Areas (Posorja and Esmeraldas) where this research was conducted. Both sites are the fishing area activities for the shrimp trawler fleet, while the Gulf of Guayaquil is the main fishing area for the pomada fleet.

Figure 4. Distribution of Interviewed Fishers' Ages by Fishing Town.

Figure 5. Distribution of Interviewed Fishers' Education Levels by Fishing Town. 


\section{FIGURES}

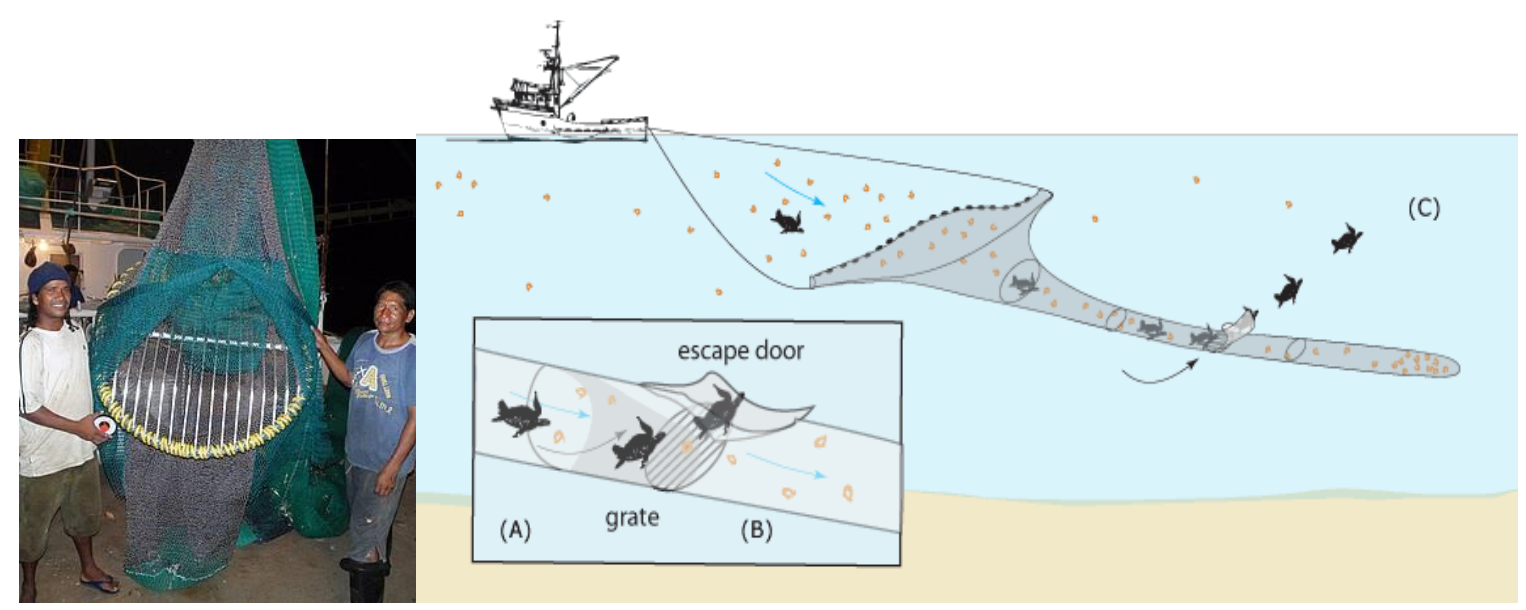

Source: Monterrey Fish Market http://www.montereyfish.com/pages/methods/teds.html

Figure 12: 1-III. Turtle Excluder Devices (TEDs) is a grid of bars with an opening either at the top or the bottom of the shrimp trawl net. TEDs are sewn into nets. Small animals such as shrimp pass through the bars and are caught in the bag end of the trawl. When larger animals, such as sea turtles (A) or sharks, are captured in the trawl, they strike the grid bars (B) and are ejected through the opening (C). 


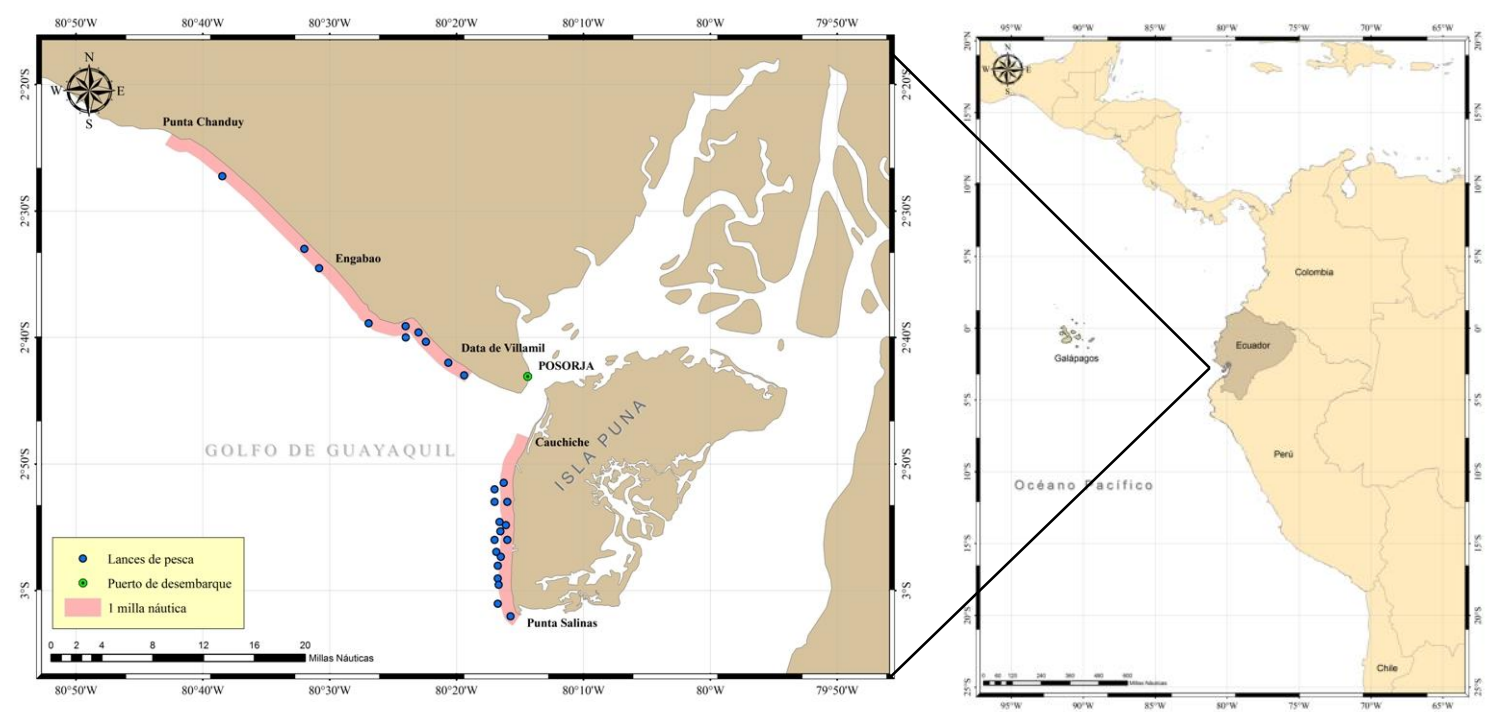

Source: Chicaiza 2013

Figure 13: 2-III. Fishing areas (Gulf of Guayaquil) of the Pomada Shrimp Fleet that captures the specie Protrachypene. Precipua, which is best known as shrimp pomada. 


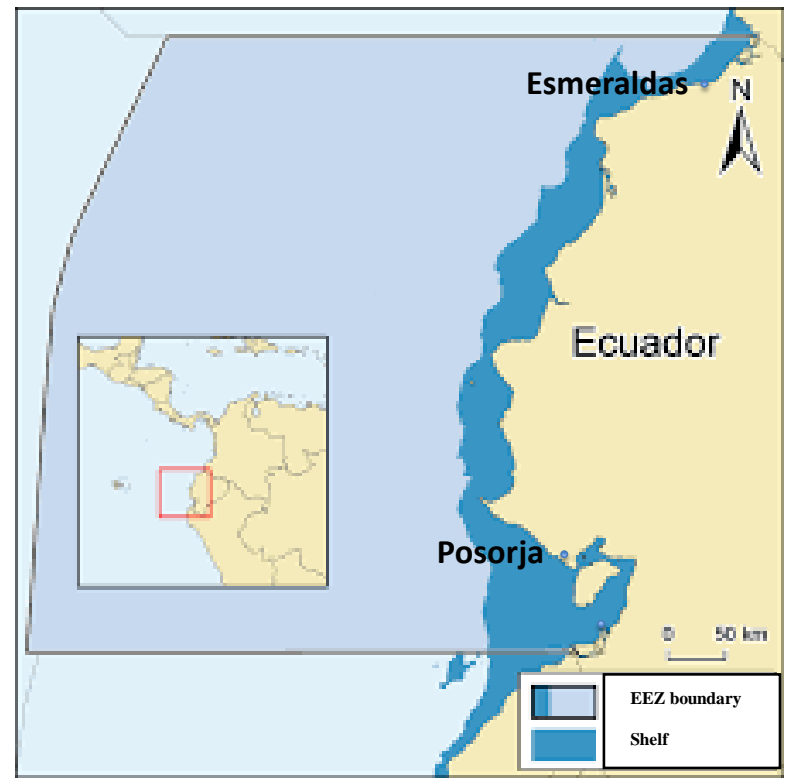

Source: INP 2007. Adapted by Gaibor 2015

Figure 14: 3-III. Site Areas (Posorja and Esmeraldas) where this research was conducted. Both sites are the fishing area activities for the shrimp trawler fleet, while the Gulf of Guayaquil is the main fishing area for the pomada fleet.. 


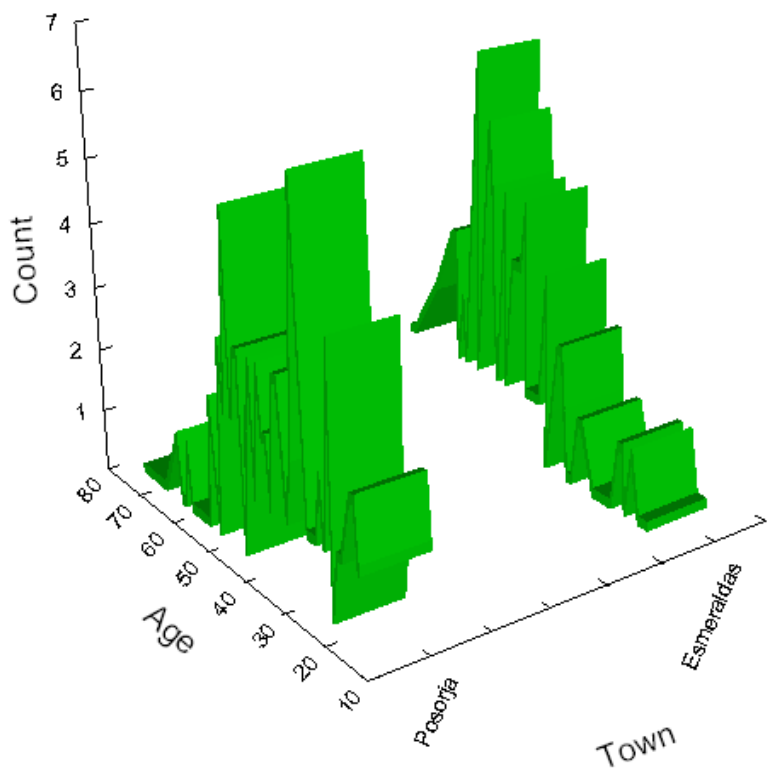

Figure 15: 4-III. Distribution of Interviewed Fishers' Ages by Fishing Town. 


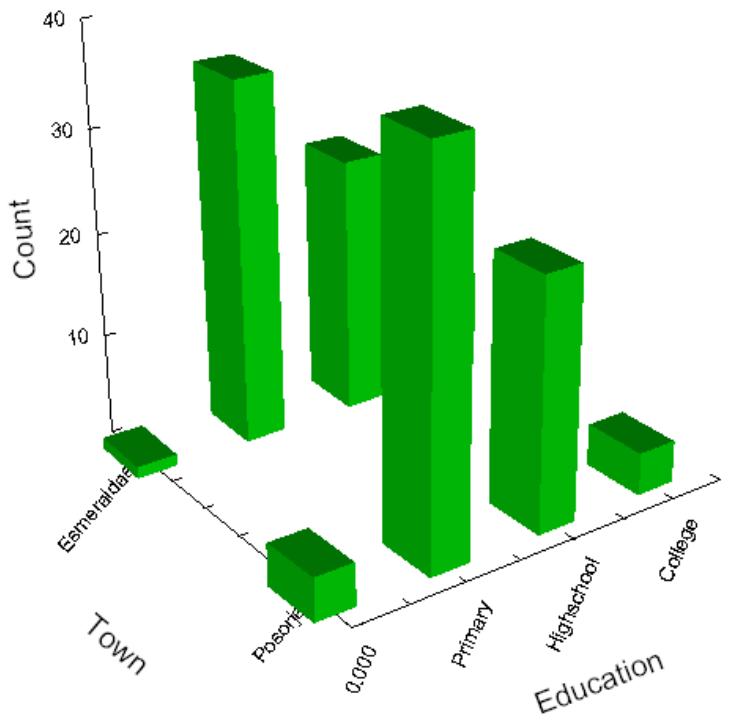

Figure 16: 5-III. Distribution of Interviewed Fishers' Education Levels by Fishing Town. 
APPENDIX 


\section{APPENDICES}

\section{APPENDIX 1: CIRCLE HOOK SURVEY}

\section{Interviewer}

Entrevistador (intvr)

Time

Hora(time)

Town

Ciudad o Pueblo (town)
Date

Fecha(date)

Location of interview

Ubicación de la entrevista

Province

Provincia (province)

\section{SCREENING QUESTIONS}

1. $F, O, C, D$ What is your position (boat owner, captain, crew, etc.)

Cuál es su posicion (propietario bote, capitan, tripulacion, etc.)

2. $F, O, C, D$ Are you a shrimp trawler or a longliner?

Es usted un pescador camaronero o palangrero?

shrimp trawler [1] longliner [2]both[3] neither [98]

\section{DEMOGRAPHICS}

3. $F, O, C, D, M, L$ How old are you?

Que edad tiene?

4. $F, O, C, D, M, L$ Sex: $\mathrm{M}[1] \mathrm{F}[0]$

5. $F, O, C, D, M, L$ Level of Education?

Nivel de studios?

\section{DESCRIPTION OF THE FISHERY}

6. $F, O, C, D$ What do you fish for?

Que pesca?

7. C Where do you go fishing?

Donde pesca? 


\section{ATTRIBUTES OF TECHNOLOGY: CIRCLE HOOKS}

\section{DEPENDENT VARIABLE}

\section{8. (CH- F, $O, C, D, L, M)$ What type of hook is this? (show Circle hook and if necessary a J-hook}

for comparison)? DK [99](If don't know skip to \#82)

Qué tipo de anzuelo es este? (mostrar anzuelo circular y anzuelo J para comparar si se necesita) NS [99] (si no sabe vaya a la\#82) (hooktype)

9. $F, O, C, D, L, M$ What portion of boats use circle hooks?

None [5] Some [4] half [3] most [2] all [1] DK [99]

Cuántas embarcaciones usan los anzuelos circulares? (chbtuse)

Ninguna [5] Algunas [4] Mitad [3] la mayoría [2] Todas [1] NS [99]

10. $F, O, C, D, L, M I s$ Is the number of boats using circle hooks decreasing? Is it staying the same, or increasing?

decreasing [3] $\quad$ same [2] $\quad$ increasing [1] $\quad$ DK [99]

El número de embarcaciones usando anzuelos circulares está disminuyendo, se mantiene igual, o está aumentando? (chbtchng)

Disminuyendo [3] $\quad$ Igual [2] $\quad$ Aumentando [1] NS [99]

11. $O, C, D$. Do you use circle hooks? Yes [1] No [0] (If NO skip to \#54)

Usa usted anzuelos circulares? (usech) $\quad \mathrm{Si}[1] \quad \mathrm{No}[0]$ (Si es NO, vaya a \#54)

12. $O, C$. Why do you use circle hooks?

Por que usa Anzuelos circulares? (whych)

13. $O, C$. Have your reasons for continuing to use circle hooks changed from the reasons why you started using them?

Yes [1] No [0] (if no skip to \#59)

Sus razones para continuar usando los Anzuelos circulares son diferentes a aquellas por las que comenzó a usar losanzuelos circulares? (rsnch)

Si [1] No[0](si es NO vaya a \#59)

14. $O, C, D$. Did you ever use them?Yes [1] No [0] (if no, skip to \#61)

Alguna vez los ha usado? (evrusech) SI [1] No [0] (si es NO, vaya a la \#61) 


\section{ATTRIBUTES OF TECHNOLOGY}

15. $O, C, D$. How positive was your first experience using circle hooks?

very negative [5] negative [4] neutral [3] positive [2] very positive [1]

Qué tan positiva fue su primera experiencia usando los anzuelos circulares?(frstxprch)

Muy negativa [5] Negativa [4] Normal [3] Positiva [2]Muy Positiva [1]

16. $O, C, D$. Please explain

Por favor explique (expchxpr)

17. $F, O, C, D$. What are five good things about circle hooks?

Dígame cinco cosas buenas acerca de los anzuelos circulares?(fvgdch)

18. $F, O, C, D$. What are five bad things about circle hooks?

Dígame cinco cosas malas acerca de los anzuelos circulares? (fvbdch)

19. Does the species you fish for influence the size of the circle hook you are willing to use?

Yes [1] No [0] (if no skip to \#67)

Las species que usted pesca influyen en el tamaño de los anzuelos circulars que usted usaría? (sizespec)

Si [1] No [0] (si es no, vaya a \#67)

20. Please explain

Por favor, explique (expsize)

21. $F, O, C$ Who benefits from the use of circle hooks? If given name, find out occupation) Quienes se benefician del uso de los anzuelos circulares? (Si se nombra alguien averiguar la ocupacion)(chben) 
22. $F, O, C$. Who bears the cost and burden from the use of circle hooks (If given name, find out occupation/role)?

$F, O, C$ Quien tiene que asumir el costo y la responsabilidad de el uso de los Anzuelos circulares? (Si se nombra alguien averiguar la ocupación)

(chcost)

23. $F, O, C, D$. Do you think that circle hooks keep sea turtles from dying?

Yes [1] No [0] Dk [99]

Cree que el uso de los anzuelos circulares evita que las tortugas mueran? (chtrtdie)

$\mathrm{Si}[1] \quad \mathrm{No}[0] \quad \mathrm{NS}[99]$

24. $F, O, C$. Does using circle hooks decrease or increase valuable bycatch?

decrease [3] same [2] increase [1] DK [99]

Cuando usted usa anzuelos circulares, la cantidad de pesca incidental valiosa disminuye o aumenta? (chbycch)

disminuye [3] igual [2] aumenta [1] NS [99]

\section{Please explain}

Por favor explique (chbcexp)

26. $O, C$. Which of these reasons for using circle hooks is most important to you

Catch more sharks [1] Conserve Turtles [0] Neither [98]

Cuál de estas razones es la más importante para usar anzuelos circulares? (chimprsn)

Captura más tiburones [1] Conservar tortugas [0] Ningún [98]

\section{ENFORCEMENT / LEGALITY}

27. $F, O, C, D, L, M$. Is use of circle hooks voluntary or mandatory?

Voluntary [1] Mandatory [0] DK [99]

El uso de los anzuelos circulares es voluntario u obligatorio? (chvolman)

Voluntario [1] Obligatorio [0] NS [99] 
28. $F, O, C, D, L, M \quad$ Do you think the circle hook should be mandatory? Yes [1] No [0]

Piensa que los anzuelos circulares deberían ser obligatorios? (chbeman) Si [1] No[0]

29. $F, O, C$ Do you feel that making circle hooks mandatory would be:

Difficult [3] Possible [2] Easy [1]

Considera que hacer los anzuelos circulares obligatorios seria: (chmandif)

Difícil [3] Posible [2] Fácil [1]

30. $F, O, C$. Please explain

Por favor explique?(expchman)

\title{
PROCESS AND NATURE OF PROMOTION
}

31. $F, O, C$. How do you know about circle hooks? check all that apply

written materials

video

free circle hooks

Other (specify) workshop __

conversation outside of workshop/training

hook exchange

DK

Como se ha informado de los anzuelos circulares? marque todas las que apliquen (knowch)

Materiales escritos (chwrtnmt) (chvideo)

Video

anzuelos circulares gratis__(freech) (other)

Otro(especifique)
Talleres (chwrkshp)

Conversacion fuera de taller/entrenamiento (chconv) Intercambio de anzuelos (chexch)

(1)


SI [1] (si es SI vaya a \#87) No [0] (si es no y si esta familiarizado con los anzuelos circulares vaya a \#92; si es no y si no esta familiarizado con los anzuelos circulares vaya a \#103).

33. $F, O, C$. What did you like about the workshop?

Que le gustó del capacitador?(chwrklke)

34. $F, O, C$ What did you not like about the workshop?

Qué no le gustó del capacitador?(chnwrlke)

35. $F, O, C$. Has anyone shared with you research results showing that circle hooks are helping sea turtles in your area?

Yes [1] $\quad \mathrm{No}[0]$

Ha compartido alguien con usted información de los resultados de los anzuelos circulares que indiquen que este dispositivo esta protegiendo a las tortugas? (chshrres)

Si [1] No [0] NS [99]

36. $F, O, C$. Were the promotion activities good enough to convince you to use circle hooks?

Yes [1] No [0]

Fueron las actividades de promoción suficiente para motivarlo a usar anzuelos circulares? (chprmact)

Si [1] No [0]

\section{VALUES \& MOTIVATIONS}

37. $O, C, D$. Are there more or less turtles now than when you started fishing?

A lot less [5] $\quad$ less [4] same [3] more [2] $\quad$ a lot more [1]

Hay mas o menos tortugas ahora que cuando empezó a pescar? (chtrtlmr)

Muchas menos [5] menos [4] igual [3] mas [2] muchas mas [1]

38. $O, C, D$. Why do you think this is?

A que se debe esto?(ychtrtmr) 
39. $F, O, C, D, M, L$ How important are the sea turtles to you?

Not important [4] neither [3] $\quad$ important [2] $\quad$ very important [1]

Que tan importante son las tortugas para usted. (chtrtyou)

No me importan [4] me da igual[3] importantes[2] muy importantes[1]

40. $F, O, C, L$ Why?

Por que?(ychtrt)

41. $F, O, C, D, M, L$ How important are sea turtles to the environment?

Not important [4] neither [3] $\quad$ important [2] very important [1]

Qué tan importante son las tortugas para el ambiente marino? (chtrtenv)

No son importantes [4] da igual [3] Son Importantes [2] Son muy importantes [1]

42. $C, D$ When you catch a sea turtle what do you do with it?

En caso de que usted capture una tortuga, que hace con ella? (chctchdo)

43. $C, D, M$. Do you eat sea turtles? Yes [1] No [0] (if no skip to \#116)

Usted consume tortugas marinas?(cheattrt) $\quad \mathrm{Si}[1] \quad \mathrm{No}[0]$ (si es no, vaya a la \#116)

44. Do you eat less, the same, or more sea turtles now than you did ten years ago?

Less[3] Same[2] More [1]

Usted consume menos, igual, o más tortugas marinas ahora que hace diez años?(chtrttme)

Menos [3] Igual [2] Mas [1]

45. $C, D, M, L$. What other uses do you have for sea turtles?

Que otros usos le da usted a lastortugas?(chtrtuse)

\section{CLOSER:}

46. $O, C$. Who is a leader in the fishery who can be interviewed for this survey?

Quien es un líder en la pesquería que además pueda ser entrevistado para esta encuesta ? (chfshldr) 


\section{APPENDIX 2: TEDs SURVEY}

DEMOGRAPHIC SURVEY:

\#1.How old are you?

\#2. Sex:

\#3. Level of Education?

\section{DEPENDENT VARIABLE}

\#4. What portion of boats use TEDs?

\#5. Is the number of boats using TEDs decreasing, is it staying the same, or increasing? F, O, C, \#20.

\#6. Do fishermen obey the regulations for correct TED installation and use?

\#7. How many years ago did you first learn about TEDs? _ years

\#8. Do you use TEDs? Yes No (If NO skip to \#27)

\#9. How many years have you been using TEDs? years

\#10. Why do you use TEDs?

\#11. Have your reasons for continuing to use TEDs changed from the reasons why you started using them? Yes [1] No [0] (if no skip to \#31)

\section{ATTRIBUTES OF TECHNOLOGY}

\#12. On a scale of 1 to 5, how positive was your first experience using TEDs?

\#13. Please explain

\#14. What are five good things about TEDs?

\#15. What are five bad things about TEDs?

\#16. Who benefits from the use of TEDs? If given name, find out occupation)

\#17. Do you think that TEDs keep sea turtles from dying? Yes [1] No [0] Dk [99]

\section{ENFORCEMENT / LEGALITY}

\#18. Is use of TEDs voluntary or mandatory? Voluntary [1] Mandatory [2] DK [99]

\#19. Do you know the regulations about TED use? Yes [1] No [0] (If no skip to \#41)

\#20. Do people break the rules about how to use TEDs?

\#21. How often are the TEDs inspected by authorities:

\#22. If a person is caught violating TED regulations, is he penalized?:

Never [4] (if never skip to \#50) Rarely [3] Usually [2] Always [1]

Si una persona es encontrada incumpliendo las regulaciones o leyes acerca de los TEDs, es sancionada?

Nunca [4] (Si es nunca vaya a \#50) Rara vez [3] Usualmente [2] Siempre [1]

\#23. How? circle all that apply

Fine [1] seizure of catch [2] seizure of boat [3]

removal of fishing license [4] prison [5] other(specify):

\#24. Would you describe the penalty as:

Too strict [5] strict [4] appropriate [3] lenient [2] very lenient [1]

Cómo describiría esta sanción? :

Muy estricta [5] estricta [4] apropiada [3] flexible [2] muy flexible [1]

\#25. Do you think inspections by the U.S. are necessary? Y [1] N [0]

\#26. Please explain 


\section{PROCESS AND NATURE OF PROMOTION}

\#27.How do you know about TEDs? circle all that apply written materials [1]

workshop [2]

video [3]

conversation outside of workshop/training [4] free

TED [5]

Other (specify)

DK [99]

\section{VALUES \& MOTIVATIONS (PERCEPTION)}

\#28. Do you think TEDs should be voluntary? Yes [1] No [0]

\#29. Would you continue to use TEDs if use was voluntary? Yes [1] No[0] DK [99]

\#30. Why?

\#31. Are there more or less turtles now than when you started fishing?
A lot less [5]
less [4] same [3]
more [2]
a lot more [1]

\#32. How important are sea turtles to you?

Not important [4] neither [3] $\quad$ important [2] $\quad$ very important [1]

\#33. Why?

\#34. How important are sea turtles to the environment?

Not important [4] neither [3] important [2] very

important [1]

\#35. Does using TEDs decrease or increase valuable bycatch?

decrease [3] $\quad$ same [2] Increase [1] DK [99] (If don't know skip to \#90)

\#36. Please explain

\#37. When you catch a sea turtle what do you do with it?

\#38. Do you eat sea turtles? Yes [1]No [0] (if no skip to \#95)

GOVERNANCE

\#39. Have fishermen been integrated into fisheries management/regulations decisions? (fshmntds)

Yes [1] No [98]

\section{CONFLICT/EQUITY}

\#40. Is there conflict between artisanal and industrial fisheries?

Yes [1] No [0] DK [3] (if no or don't know skip to \#114) 